NBER WORKING PAPER SERIES

THE EFFECTS OF RENT CONTROL EXPANSION ON TENANTS, LANDLORDS, AND INEQUALITY: EVIDENCE FROM SAN FRANCISCO

\author{
Rebecca Diamond \\ Timothy McQuade \\ Franklin Qian \\ Working Paper 24181 \\ http://www.nber.org/papers/w24181
}

\author{
NATIONAL BUREAU OF ECONOMIC RESEARCH \\ 1050 Massachusetts Avenue \\ Cambridge, MA 02138 \\ January 2018
}

We are grateful for comments from Ed Glaeser, Christopher Palmer, Paul Scott, and seminar participants at The Conference on Urban and Regional Economics, the Fall HULM Conference, NTA Annual Meeting, NBER Real Estate Summer Institute, NBER Fall Public and Labor Studies Meetings, NYU Stern, the Stanford Finance Faculty Lunch, UC Berkeley, and the University of Illinois. The views expressed herein are those of the authors and do not necessarily reflect the views of the National Bureau of Economic Research.

NBER working papers are circulated for discussion and comment purposes. They have not been peer-reviewed or been subject to the review by the NBER Board of Directors that accompanies official NBER publications.

(C) 2018 by Rebecca Diamond, Timothy McQuade, and Franklin Qian. All rights reserved. Short sections of text, not to exceed two paragraphs, may be quoted without explicit permission provided that full credit, including $(\odot$ notice, is given to the source. 
The Effects of Rent Control Expansion on Tenants, Landlords, and Inequality: Evidence from San Francisco

Rebecca Diamond, Timothy McQuade, and Franklin Qian

NBER Working Paper No. 24181

January 2018

JEL No. H0,R0

\begin{abstract}
We exploit quasi-experimental variation in assignment of rent control to study its impacts on tenants, landlords, and the overall rental market. Leveraging new data tracking individuals' migration, we find rent control increased renters' probabilities of staying at their addresses by nearly $20 \%$. Landlords treated by rent control reduced rental housing supply by $15 \%$, causing a $5.1 \%$ city-wide rent increase. Using a dynamic, neighborhood choice model, we find rent control offered large benefits to covered tenants. Welfare losses from decreased housing supply could be mitigated if insurance against rent increases were provided as government social insurance, instead of a regulated landlord mandate.

Rebecca Diamond

Graduate School of Business

Stanford University

655 Knight Way

Stanford, CA 94305

and NBER

diamondr@stanford.edu

Timothy McQuade

Stanford Graduate School of Business School

655 Knight Way

Stanford, CA 94305

tmcquade@stanford.edu

Franklin Qian

Landau Economics Building

579 Serra Mall

Stanford, CA 94305

zqian1@stanford.edu
\end{abstract}




\title{
The Effects of Rent Control Expansion on Tenants, Landlords, and Inequality: Evidence from San Francisco*
}

\author{
Rebecca Diamond ${ }^{\dagger}$, Tim McQuade ${ }^{\ddagger}, \&$ Franklin Qian ${ }^{\S}$
}

December 27, 2017

\begin{abstract}
We exploit quasi-experimental variation in assignment of rent control to study its impacts on tenants, landlords, and the overall rental market. Leveraging new data tracking individuals' migration, we find rent control increased renters' probabilities of staying at their addresses by nearly $20 \%$. Landlords treated by rent control reduced rental housing supply by $15 \%$, causing a $5.1 \%$ city-wide rent increase. Using a dynamic, neighborhood choice model, we find rent control offered large benefits to covered tenants. Welfare losses from decreased housing supply could be mitigated if insurance against rent increases were provided as government social insurance, instead of a regulated landlord mandate.
\end{abstract}

\section{Introduction}

Steadily rising housing rents in many of the US's large, productive cities has brought the issue of affordable housing to the forefront of the policy debate and reignited the discussion over expanding or enacting rent control provisions. State lawmakers in Illinois, Oregon, and California are considering repealing laws that limit cities' ability to pass or expand rent control. Already extremely popular around the San Francisco Bay Area, with seven cities having imposed rent control regulations, five additional Bay Area cities placed rent control measures on the November 2016 ballot, with two passing. Rent control in the Bay Area consists of regulated price increases within the duration of a tenancy, but no price restrictions between tenants. Rent control also places restrictions on evictions.

${ }^{*}$ We are grateful for comments from Ed Glaeser, Christopher Palmer, Paul Scott, and seminar participants at The Conference on Urban and Regional Economics, the Fall HULM Conference, NTA Annual Meeting, NBER Real Estate Summer Institute, NBER Fall Public and Labor Studies Meetings, NYU Stern, the Stanford Finance Faculty Lunch, UC Berkeley, and the University of Illinois.

†Stanford University \& NBER. Email: diamondr@stanford.edu.

${ }^{\ddagger}$ Stanford University. Email: tmcquade@stanford.edu .

${ }^{\S}$ Stanford University. Email: zqian1@stanford.edu . 
A substantial body of economic research has warned about potential negative efficiency consequences to limiting rent increases below market rates, including over-consumption of housing by tenants of rent controlled apartments (Olsen (1972), Gyourko and Linneman (1989)), misallocation of heterogeneous housing to heterogeneous tenants (Glaeser and Luttmer (2003), Sims (2011)), negative spillovers onto neighboring housing (Sims (2007), Autor et al. (2014)) and neglect of required maintenance (Downs (1988)). Yet, due to incomplete markets, in the absence of rent control many tenants are unable to insure themselves against rent increases. A variety of affordable housing advocates have argued that tenants greatly value these insurance benefits, allowing them to stay in neighborhoods in which they have spent many years and feel invested in.

Due to a lack of detailed data and natural experiments, we have little well-identified empirical evidence evaluating the relative importance of these competing effects. ${ }^{1}$ In this paper, we bring to bear new micro data, exploit quasi-experimental variation in the assignment of rent control provided by unique 1994 local San Francisco ballot initiative, and employ structural modeling to fill this gap. We find tenants covered by rent control do place a substantial value on the benefit, as revealed by their migration patterns. However, landlords of properties impacted by the law change respond over the long term by substituting to other types of real estate, in particular by converting to condos and redeveloping buildings so as to exempt them from rent control. This substitution toward owner occupied and high-end new construction rental housing likely fueled the gentrification of San Francisco, as these types of properties cater to higher income individuals. Indeed, the combination of more gentrification and helping rent controlled tenants remain in San Francisco has led to a higher level of income inequality in the city overall.

The 1994 San Francisco ballot initiative created rent control protections for small multifamily housing built prior to 1980. This led to quasi-experimental rent control expansion in 1994 based on whether the multifamily housing was built prior to or post 1980. To examine rent control's effects on tenant migration and neighborhood choices, we make use of new panel data which provides address-level migration decisions and housing characteristics for close to the universe of adults living in San Francisco in the early 1990s. This allows us to define our treatment group as renters who lived in small apartment buildings built prior to 1980 and our control group as renters living in small multifamily housing built between 1980 and 1990. Using our data, we can follow each of these groups over time up until the present, regardless of where they migrate to.

On average, we find that in the medium to long term, the beneficiaries of rent control are between 10 and $20 \%$ more likely to remain at their 1994 address relative to the control group. These effects are significantly stronger among older households and among households that have already spent a number of years at their treated address. This is consistent with the fact that both of these populations are less mobile in general, allowing them to accrue greater insurance benefits.

\footnotetext{
${ }^{1}$ A notable exception to this is Sims (2007) and Autor et al. (2014) which use the repeal of rent control in Cambridge, MA to study it's spillover effects onto nearby property values and building maintenance.
} 
On the other hand, for households with only a few years at their treated address, the impact of rent control can be negative. Perhaps even more surprisingly, the impact is only negative in census tracts which had the highest rate of ex-post rent appreciation. This evidence suggests that landlords actively try to remove their tenants in those areas where the reward for resetting to market rents is greatest. In practice, landlords have a few possible ways of removing tenants. First, landlords could move into the property themselves, known as move-in eviction. The Ellis Act also allow landlords to evict tenants if they intend to remove the property from the rental market - for instance, in order to convert the units to condos. Finally, landlords are legally allowed to offer their tenants monetary compensation for leaving. In practice, these transfer payments from landlords are quite common and can be quite large. Moreover, consistent with the empirical evidence, it seems likely that landlords would be most successful at removing tenants with the least built-up neighborhood capital, i.e. those tenants who have not lived in the neighborhood for long.

To understand the reduced form impact of rent control on rental supply, we merge in historical parcel history data from the SF Assessor's Office, which allows us to observe parcel splits and condo conversions. We find that rent-controlled buildings were almost $10 \%$ more likely to convert to a condo or a Tenancy in Common (TIC) than buildings in the control group, representing a substantial reduction in the supply of rental housing. Consistent with these findings, we moreover find that, compared to the control group, there is a $15 \%$ decline in the number of renters living in these buildings and a $25 \%$ reduction in the number of renters living in rent-controlled units, relative to 1994 levels. This gap is driven by landlords demolishing their old housing and building new rental housing. New construction is exempt from rent control.

In order to evaluate the welfare impacts of these reduced form effects, we construct and estimate a dynamic discrete choice model of neighborhood choice. Motivated by our reduced form evidence, we allow for household preferences to depend on neighborhood tenure and age, and allow for monetary "buyouts" where landlords of rent-controlled properties can pay their tenants to move out. The model features fixed moving costs and moving costs variable with distance. A key contribution of the paper, relative to the existing dynamic discrete choice literature, is that we develop methods which harness the quasi-experimental setting such that no assumptions about how agents form beliefs about expected future states of the world are required. ${ }^{2}$ To our knowledge, all previous dynamic discrete choice models required either explicit modeling of how beliefs are formed or assuming that beliefs are on average rational. Dropping this assumption is very useful as one might expect households to have bias in their beliefs about future housing costs. We also show how to do general equilibrium welfare analysis in a dynamic model without making any assumptions about how agents form beliefs using a first-order approximation to welfare. Specifically, we show how changes in the value function can be solved for using a system of linear equations and no information on how beliefs are formed. These welfare methods could be used in other settings,

\footnotetext{
${ }^{2}$ The only assumption is that average treatment and control households do not use different methods to form beliefs, an assumption one would expect to hold if treatment is indeed randomly assigned.
} 
even if one does not have a quasi-experiment available.

We find that rent control offered large benefits to impacted tenants during the 1995-2012 period, averaging between $\$ 2300$ and $\$ 6600$ per person each year, with aggregate benefits totaling over $\$ 214$ million annually and $\$ 2.9$ billion present discounted value terms. These effects are counterbalanced by landlords reducing supply in response to the introduction of the law. We conclude that this led to a city-wide rent increase of $5.1 \%$. This has a present discounted cost of $\$ 2.9$ billion dollars to tenants. Further, we find $42 \%$ of these losses are paid by future residents of San Francisco, while incumbent SF residents at the time of the law change bear the other 58\%. On net, incumbent SF residents appear to come out ahead, but this is at the great expense of welfare losses from future inhabitants. We discuss how the substantial welfare losses due to decreased housing supply could be mitigated if insurance against large rent increases was provided as a form of government social insurance, instead of a regulated mandate on landlords.

Our paper is most related to the literature on rent control. Recent work by Autor et al. (2014) and Sims (2007) leverages policy variation in rent control laws in Cambridge, Massachusetts to study the property and neighborhood effects of removing rent control regulations. Our paper studies the effects of enacting rent control laws, which could have very different effects than decontrol. De-control studies the effects of removing rent control on buildings which remain covered. Indeed, we find a large share of landlords substitute away from supply of rent controlled housing, making those properties which remain subject to rent-control a selected set. Further, we are able to quantify how tenants use and benefit from rent control, a previously unstudied topic due to the lack of the combination of appropriate data, natural experiments and estimation methods.

There also exists an older literature on rent control combining applied theory with crosssectional empirical methods. These papers test whether the data are consistent with the theory being studied, but usually cannot quantify causal effects of rent control. (Early (2000), Glaeser and Luttmer (2003), Gyourko and Linneman (1989), Gyourko and Linneman (1990), Moon and Stotsky (1993), Olsen (1972)).

Our estimation methods build on the dynamic discrete choice literature. Previous work using dynamic demand for housing and neighborhoods has required strong assumptions about how agents form expectations and how all neighborhood characteristics evolve over time (Bishop and Murphy (2011), Kennan and Walker (2011), Bayer et al. (2016), Davis et al. (2017), Murphy (2017)). We relax these assumptions by building on Scott (2013). His key insight is to use realized values of agents' future expected utility as a noisy measure of agents' expectations. This method, extended to a quasi-experimental setting, allows us to avoid making explicit assumptions about how agents form expectations. Further, we do not need to assume how all state variables transition over time. Both of these assumptions are typically needed to estimate dynamic discrete choice models. Scott leverages "renewal" actions in tenants' choice sets, whereby the estimation focuses on specific actions in agents' choice sets which exhibit finite dynamic dependence, greatly simplifying 
the dynamic problem (Arcidiacono and Miller (2011), Arcidiacono and Ellickson (2011)). Our contribution is to show how Scott's method can be extended to a set of difference-in-difference style linear and instrumental variable regressions that can be used in combination with a natural experiment to identify the model parameters.

Finally, our paper is related to a separate strand of literature on community attachment in sociology. Kasarda and Janowitz (1974) provide survey evidence that length of residence is correlated with various self-reported indicators of neighborhood attachment. We estimate households' attachments to their neighborhoods, as revealed by their migration decisions. Consistent with survey evidence, we find community attachment grows with years living in one's neighborhood, but it accumulates quite slowly over time. One additional year of residence increases one's community attachment by the equivalent of $\$ 300$.

The remainder of the paper proceeds as follows. Section 2 discusses the history of rent control in San Francisco. Section 3 discusses the data used for the analysis. Section 4 presents our reduced form results. Section 5 develops and estimates a dynamic discrete choice structural model. Section 6 discusses the welfare impacts of rent control. Section 7 concludes.

\section{A History of Rent Control in San Francisco}

Rent Control in San Francisco began in 1979, when acting Mayor Dianne Feinstein signed San Francisco's first rent-control law. Pressure to pass rent control measures was mounting due to high inflation rates nationwide, strong housing demand in San Francisco, and recently passed Proposition 13. ${ }^{3}$ This law capped annual nominal rent increases to $7 \%$ and covered all rental units built before June 13th, 1979 with one key exemption: owner occupied buildings containing 4 units or less. ${ }^{4}$ These "mom and pop" landlords were cast as less profit driven than the large scale, corporate landlords, and more similar to the tenants being protected. These small multi-family structures made up about $44 \%$ of the rental housing stock in 1990, making this a large exemption to the rent control law.

While this exemption was intended to target "mom and pop" landlords, in practice small multifamilies were increasingly purchased by larger businesses who would then sell a small share of the building to a live-in owner so as to satisfy the rent control law exemption. This became fuel for a new ballot initiative in 1994 to remove the small multi-family rent control exemption. This ballot initiative barely passed in November 1994. Beginning in 1995, all multi-family structures with four units or less built in 1979 or earlier were now subject to rent control. These small multi-family structures built prior to 1980 remain rent controlled today, while all of those built from 1980 or

\footnotetext{
${ }^{3}$ Proposition 13, passed in 1978, limited annual property tax increases for owners. Tenants felt they were entitled to similar benefits in the form of capped annual rent increases.

${ }^{4}$ The annual allowable rent increase was cut to $4 \%$ in 1984 and later to $60 \%$ of the CPI in 1992, where it remains today.
} 
later are still not subject to rent control.

\section{Data}

We bring together data from multiple sources to enable us to observe property characteristics, determine treatment and control groups, track migration decisions of tenants, and observe the property decisions of landlords. Our first dataset is from Infutor, which provides the entire address history of individuals who resided in San Francisco at some point between the years of 1990 and 2016. ${ }^{5}$ The data include not only individuals' San Francisco addresses, but any other address within the United States at which that individual lived during the period of 1990-2016. The dataset provides the exact street address, the month and year at which the individual lived at that particular location, the name of the individual, and some demographic information including age and gender. We link these data to property records provided by DataQuick, which allow us to distinguish owners from renters by comparing last names in Infutor to the listed owners of the property in DataQuick. We also link in renovation permits, condo conversions data from San Francisco.

To examine the representativeness of the Infutor data, we collapse the Infutor data to the census tract level in 1990 and 2000. We then compare census tract variation in data provided by Infutor to similar data reported by the census in 1990 and 2000. Our data closely match in terms of population counts, the age of the occupied housing stock, and the homeownership rates. Indeed, the Infutor data cover close to the universe of the San Francisco population. See Appendix A for more details. We use an imputation procedure to construct annual rents at the zipcode level, combining house price transaction data, census and ACS reported median rents, and the Fischer aggregate time series detailed in Appendix A.1. ${ }^{6}$

Summary statistics are provided in Table 1. As shown in this table, without any controls, our covariates are quite balanced between treatment and control tenants and parcels.

\section{Reduced Form Effects}

Studying the effects of rent control is challenged by the usual endogeneity issues. The tenants who choose to live in rent-controlled housing, for example, are likely a selected sample. To overcome these issues, we exploit the particular institutional history of the expansion of rent control in San Francisco. Specifically, we exploit the successful 1994 ballot initiative which removed the original 1979 exemption for small multifamily housing of four units or less, as discussed in Section 2.

\footnotetext{
${ }^{5}$ Infutor is a data aggregator of address data using many sources including phonebooks, magazine subscriptions, and credit header files.

${ }^{6}$ Historical data on annual San Francisco wide market rents are from a dataset produced by Eric Fischer, who collected historical apartment advertisements dating back to the 1950s.
} 
In 1994, as a result of the ballot initiative, tenants who happened to live in small multifamily housing built prior to 1980 were, all of a sudden, protected by statute against rent increases. Tenants who lived in small multifamily housing built 1980 and later continued to not receive rent control protections. We therefore use as our treatment group those renters who, as of December 31, 1993, lived in multifamily buildings of less than or equal to 4 units, built between years 1900 and 1979. We use as our control group those renters who, as of December 31, 1993, lived in multifamily buildings of less than or equal to 4 units, built between the years of 1980 and 1990 . We exclude those renters who lived in small multifamily buildings constructed post 1990 since individuals who choose to live in new construction may constitute a selected sample and exhibit differential trends. We also exclude tenants who moved into their property prior to 1980, as none of the control group buildings would have been constructed at the time.

When examining the impact of rent control on the parcels themselves, we use small multifamily buildings built between the years of 1900 and 1979 as our treatment group and buildings built between the years of 1980 and 1990 as our control group. We again exclude buildings constructed

in the early 1990s to remove any differential effects of new construction. Figure E.1 shows the geographic distribution of treated buildings and control buildings in San Francisco.

\subsection{Tenant Effects}

We begin our analysis by studying the impact of rent control provisions on its tenant beneficiaries. We use a differences-in-differences design described above, with the following exact specification:

$$
Y_{i t}=\delta_{z t}+\alpha_{i}+\beta_{t} T_{i}+\gamma_{s t}+\epsilon_{i t}
$$

Here, $Y_{i t}$ are outcome variables equal to one if, in year $t$, the tenant $i$ is still living at either the same address, in the same zipcode $z$, or in San Francisco as they were at the end of 1993. The variables $\alpha_{i}$ denote individual tenant fixed effects. The variable $T_{i}$ denotes treatment, equal to one if, on December 31, 1993, the tenant is living in a multifamily building with less than or equal to four units built between the years 1900 and 1979.

We include fixed effects $\gamma_{s t}$ denoting the interaction of dummies for the year $s$ the tenant moved into the apartment with calendar year $t$ time dummies. These additional controls are needed since older buildings are mechanically more likely to have long-term, low turnover tenants; not all of the control group buildings were built when some tenants in older buildings moved in. Finally, note we have included a full set of zipcode by year fixed effects, $\delta_{z t}$. In this way, we control for any differences in the geographic distribution of treated buildings vs. control buildings, ensuring that our identification is based off of individuals who live in the same neighborhood, as measured by zipcode. Our coefficient of interest, quantifying the effect of rent control on future residency, is denoted by $\beta_{t}$.

Our estimated effects are shown in Figure 1, along with $90 \%$ confidence intervals. We can see 
that tenants who receive rent control protections are persistently more likely to remain at their 1993 address relative to the control group. Not only that, but they are also more likely to be living in San Francisco. This result indicates that the assignment of rent control not only impacts the type of property a tenant chooses to live in, but also their choice of location and neighborhood type.

These figures also illustrate how the time pattern of our effects correlates with rental rates in San Francisco. We would expect that our results would be particularly strong in those years when the outside option is worse due to quickly rising rents. Along with our yearly estimated effect of rent control, we plot the yearly deviation from the log trend in rental rates against our estimated effect of rent control in that given year. We indeed see that our effects grew quite strongly in the mid to late 1990s in conjunction with quickly rising rents, relative to trend. Our effects then stabilize and slightly decline in the early 2000s in the wake of the Dot-com bubble crash, which led to falling rental rates relative to trend. Overall, we measure a correlation of $49.4 \%$ between our estimated same address effects and median rents, and a correlation of $78.4 \%$ between out estimated SF effects and median rents.

In Table 2, we collapse our estimated effects into a short-term 1994-1999 effect, a mediumterm 2000-2004 effect, and a long-term post-2005 effect. We find that in the short-run, tenants in rent-controlled housing are 2.18 percentage points more likely to remain at the same address. This estimate reflects a 4.03\% increase relative to the 1994-1999 control group mean of $54.10 \%$. In the medium term, rent-controlled tenants are 3.54 percentage points more likely to remain at the same address, reflecting a 19.38\% increase over the 2000-2004 control group mean of $18.27 \%$. Finally, in the long-term, rent-controlled tenants are 1.47 percentage points more likely to remain at the same address. This is a $12.95 \%$ increase over the control group mean of $11.35 \%$. These effects are intuitive since we expect the utility benefits of staying in a rent controlled apartment to grow over time as the wedge between controlled and market rents widen.

Tenants who benefit from rent control are 2.00 percentage points more likely to remain in San Francisco in the short-term, 4.51 percentage points more likely in the medium-term, and 3.66 percentage points more likely in the long-term. Relative to the control group means, these estimates reflect increases of $2.62 \%, 8.78 \%$, and $8.42 \%$ respectively. Since these numbers are of the same magnitude as the treatment effects of stay at one's exact 1994 apartment, we find that absent rent control essentially all of those incentivized to stay in their apartments would have otherwise moved out of San Francisco.

While there may be some sorting into older buildings based on personal characteristics, it seems likely that once neighborhood characteristics have been controlled for, as well as the number of years lived in the apartment as of December 31, 1993, these characteristics would not lead to differential trends in migration decisions which could contaminate our estimates. As a robustness test, in Table E.1, we have restricted our treatment group to individuals who lived in structures built between 1960 and 1979, thereby comparing tenants in buildings built slightly before 1979 to 
tenants in buildings built slightly after 1979 . We find very similar results. ${ }^{7}$

These estimated overall effects mask interesting heterogeneity. We begin by cutting the data on three dimensions. First, we cut the data by age, sorting individuals into two groups, a young group who were aged 20-39 in 1993 and an old group who were aged 40-65 in 1993. We also sort the data based on the number of years the individual has been living at their 1993 address. We create a "high turnover" group of individuals who had been living at their address for less than four years and a "low turnover" group of individuals who had been living at their address for between four and fourteen years. Finally, we cut the sample of zipcodes based on whether their rent change from 1990 to 2000 was above or below the median. We form eight subsamples by taking the $2 \times 2 \times 2$ cross across each of these three dimensions and re-estimate our effects for each subsample.

The results are reported in Figures 2 and 3. We summarize the key implications. First, we find that the effects are weaker for younger individuals. We believe this is intuitive. Younger households are more likely to face larger idiosyncratic shocks to their neighborhood and housing preferences (such as changes in family structure and employment opportunities) which make staying in their current location particularly costly, relative to the types of shocks older households receive. Thus, younger households may feel more inclined to give up the benefits afforded by rent control to secure housing more appropriate for their circumstances.

Moreover, among older individuals, there is a large gap between the estimated effects based on turnover. Older, low turnover households have a strong, positive response to rent control. That is, they are more likely to remain at their 1993 address relative to the control group. In contrast, older, high turnover individuals are estimated to have a weaker response to rent control. They are less likely to remain at their 1993 address relative to the control group.

To further explore the mechanism behind this result, we now investigate these effects based on the 1990-2000 rent appreciation of their 1993 zipcodes. Among older, lower turnover individuals, we find that the effects are always positive and strongest in those areas which experienced the most rent appreciation between 1990 and 2000, as one might expect. For older, high turnover households, however, the results are quite different. For this subgroup, the effects are actually negative in the areas which experienced the highest rent appreciation. They are positive in the areas which experienced below median rent appreciation. ${ }^{8}$

This result suggests that landlords are likely actively trying to remove tenants in those areas where rent control is affording the most benefits, i.e. high rent appreciation areas. There are a few ways a landlord could accomplish this. First, landlords could try to legally evict their tenants by, for example, moving into the properties themselves, known as owner move-in eviction. Alternatively, landlords could evict tenants according to the provisions of the Ellis Act, which

\footnotetext{
${ }^{7}$ In Table E.1, we have also ran our regressions with census tract by year fixed effects and our results are robust to this even finer neighborhood classification. Dropping the zip-year fixed effects also produces similar results.

${ }^{8} \mathrm{~A}$ similar pattern holds for younger individuals as well, although the results are weaker.
} 
allows evictions when an owner wants to remove units from the rental market - for instance, in order to convert the units into condos or a tenancy in common. Finally, landlords are legally allowed to negotiate with tenants over a monetary transfer convincing them to leave. Such transfers are, in fact, quite prevalent in San Francisco. Moreover, it is likely that those individuals who have not lived in the neighborhood long, and thus not developed an attachment to the area, could be more readily convinced to accept such payments. Since the tenants who are most likely to leave rent control are those who likely value it the least (those who have not lived in the neighborhood for a long time), it appears that landlords are paying people to move out instead of evicting them. If landlords were mostly using evictions, we'd expect them to evict those whose evictions are most profitable to the landlord: those who likely will stay a long time. Indeed, since landlord can pay

tenants to move out, rent control need not inefficiently distort renters' decisions to remain in their rent controlled apartments. Tenants may "bring their rent control with them" in the form of a lump sum tenant buyout. Of course, if landlords predominantly use evictions, tenants are not compensated for their loss of rent protection, weakening the insurance value of rent control.

These considerations help to rationalize some additional, final findings. In Figure 4a, we examine the impact that rent control has on the types of neighborhoods tenants live in in a given year. We find that treated individuals, i.e. those who received rent control, ultimately live in census tracts with lower house prices, lower median incomes, lower college shares, and higher unemployment rates than the control group. As Figure $4 \mathrm{~b}$ shows, this is not a function of the areas in which treated individuals lived in 1993. In this figure, we fix the location of those treated by rent control at their 1993 locations, but allow the control group to migrate as seen in the data. If rent-controlled renters were equally likely to remain in their 1993 apartments across all locations in San Francisco, we would see the sign of the treatment effects on each neighborhood characteristic to be the same as in the previous regression. Instead, we find strong evidence that the out-migration of rent-controlled tenants came from very selected neighborhoods. Had treated individuals remained in their 1993 addresses, they would have lived in census tracts which had significantly higher college shares, higher house prices, lower unemployment rates, and no effect on household median income than the control group. This evidence is consistent with the idea that landlords undertake efforts to remove their tenants or convince them to leave in improving, gentrifying areas.

\subsection{Parcel and Landlord Effects}

We continue our analysis by studying the impact of rent control on the structures themselves. In particular, we examine how rent control impacts the nature of the tenants who live in the buildings, as well as its impact on investments that landlords choose to make in the properties. 
We run a similar specification to that above:

$$
Y_{k t}=\delta_{z t}+\lambda_{k}+\beta_{t} T_{k}+\epsilon_{k t},
$$

where $k$ now denotes the individual parcel and $\lambda_{k}$ represent parcel fixed effects. The variable $T_{k}$ denotes treatment, equal to one if, on December 31, 1993, the parcel is a multifamily building with less than or equal to four units built between the years 1900 and 1979 . The $\delta_{z t}$ variables once again reflect zipcode by year fixed effects. Our outcome variables $Y_{k t}$ now include the number of renters and owners living in the building, whether the building sits vacant, the number of renovation permits associated with the building, and whether the building is ever converted to a condo or TIC. The permits we look at specifically are addition/alteration permits, taken out when major work is done to a property.

We begin by plotting in Figure 5a the effects of rent control on the number of individuals living at a given parcel, calculated as percentage of the average number of individuals living at that parcel between the years 1990-1994. We estimate a decline of approximately $10 \%$ over the long-run, although this effect is not statistically significant.

We next decompose this effect into the impact on the number of renters and the number of owners living at the treated buildings. As shown in Figure 5b, we find that there is a significant decline in the number of renters living at a parcel, approximately equal to $20 \%$ in the late 2000 s, relative to the 1990-1994 level. Figure 5c shows that the decline in renters was counterbalanced by an increase of approximately $10 \%$ in the number of owners in the late 2000 s. This is our first evidence suggestive of the idea that landlords redeveloped or converted their properties so as to exempt them from the new rent control regulations.

We now look more closely at the decline in renters. In Figure 6b, we see that there is an eventual decline of almost 30\% in the number of renters living in rent-controlled apartments, relative to the 1990-1994 average. ${ }^{9}$ This decline is significantly larger than the overall decline in renters. This is because a number of buildings which were subject to rent control status in 1994 were redeveloped in such way so as to no longer be subject to it. These redevelopment activities include tearing down the existing structure and putting up new single family, condominium, or multifamily housing or simply converting the existing structure to condos. These redeveloped buildings replaced about $10 \%$ of the initial rental housing stock treated by rent control, as shown in Figure 6a.

A natural question is whether this redevelopment activity was a response of landlords to the imposition of rent control or, instead, if such activity was also taking place within the control group and thus reflected other trends. Since we have the entire parcel history for a property, we can check directly whether a multifamily property which fell under the rent control regulations in

\footnotetext{
${ }^{9}$ Note here that we mean relative to the number of individuals who lived at parcels which received rent control status due to the 1994 law change.
} 
1994 is more likely to have converted to condominium housing or a tenancy in common, relative to a multifamily property which did become subject to rent control. In Figure 6c, we show that treated buildings are 8 percentage points likely to convert to condo or TIC in response to the rent control law. This represents a significant loss in the supply of rent controlled housing.

As a final test of whether landlords actively respond to the imposition of rent control, we examine whether the landlords of rent-controlled properties disproportionately take out addition/alteration (i.e. renovation) permits. We find this to strongly be the case, as shown in Figure 6d. Of course, conversions of multifamily housing to condos undoubtedly require significant alteration to the structural properties of the building and thus would require such a permit to be taken out. These results are thus consistent with our results regarding condo conversion.

Taken together, we see rent control increased property investment, spurred the demolition and reconstruction of new buildings, generated conversion of rental units to owner occupied housing, and caused a decline of the number of renters per building. All of these responses lead to a housing stock which caters to higher income individuals. Rent control has actually fueled the gentrification of San Francisco, the exact opposite of the policy's intended goal.

\section{$5 \quad$ A Structural Spatial Equilibrium Model}

The reduced form shows that rent control can either increase or decreases tenancy durations depending on whether the tenant receives a buyout or eviction or instead remains at their residence at below market rents. To quantify how tenants trade off these decisions and to quantify the welfare impact of rent control to covered tenants, we estimate a dynamic discrete choice model of neighborhood choice.

\subsection{Model Setup}

Each year $t$, a household decides whether to remain in its current home, a choice which we denote as $\mathcal{S}$, or to move, in which case the household chooses a neighborhood $j \in \mathcal{J}$ to live in. We denote the household's choice as $x \in\{\mathcal{S}\} \cup \mathcal{J}$. The relevant state variables for the household's decision problem are the current neighborhood $j_{t-1} \in \mathcal{J}$, the number of years lived in the current neighborhood $\tau_{n, t-1} \in \mathbb{N} \cup\{0\}$, the number of years lived in the current house $\tau_{h, t-1} \in \mathbb{N} \cup\{0\}$, and whether the residence is rent-controlled $d_{t-1} \in\{0,1\}$. We also have a state variable $a_{t-1} \in\{Y, M\}$ denoting whether the household is in a young $(Y)$ or mature $(M)$ state of life. We let $\theta_{t-1}=\left(j_{t-1}, \tau_{n, t-1}, \tau_{h, t-1}, d_{t-1}, a_{t-1}\right)$ denote the household's current state variable. The transition dynamics of the state variable are straightforward. We have $j_{t}=j\left(x_{t}\right)$, where:

$$
\begin{aligned}
& j\left(x_{t}\right)=j_{t-1} \text { if } x_{t}=\mathcal{S} \\
& j\left(x_{t}\right)=x_{t} \text { otherwise. }
\end{aligned}
$$


This equation simply says that the neighborhood remains the same if the household decides to remain in its current home. Otherwise, the new neighborhood is given by the household's choice. The implications for years in the current neighborhood and years in the current house are clearly similar, with:

$$
\begin{aligned}
& \tau_{n}\left(x_{t}\right)=\tau_{n, t-1}+1 \text { if } x_{t} \in\left\{\mathcal{S}, j_{t-1}\right\} \\
& \tau_{n}\left(x_{t}\right)=0 \text { otherwise. }
\end{aligned}
$$

and

$$
\begin{aligned}
\tau_{h}\left(x_{t}\right) & =\tau_{h, t-1}+1 \text { if } x_{t}=\mathcal{S} \\
\tau_{n}\left(x_{t}\right) & =0 \text { otherwise. }
\end{aligned}
$$

Finally, we assume that each period young households transition to mature households with exogenous probability $\kappa_{t}$. This is clearly a simplification, made due to limitations of the data, but captures the idea that households experience certain life events such as marriage and having children at different ages. ${ }^{10}$ Mature households do not transition back into young households. We denote the (probabilistic) transition function as $\theta_{t}=\Theta\left(x_{t}, \theta_{t-1}\right)$. We identify the set of neighborhood locations $\mathcal{J}$ as the San Francisco zipcodes, the combined counties (other than San Francisco County) in the Bay Area, and an outside option denoting any location outside of the Bay Area.

We assume that a household $i$ has the following per-period utility from their housing decision:

$$
\begin{gathered}
u\left(x, \omega_{t}, \varepsilon_{i t}, \theta_{t-1}\right)=\gamma_{a} \exp R_{t}\left(j, d, \tau_{h}\right)+\alpha_{a} \tau_{n}+\varphi_{a}\left(x, j_{t-1}, \tau_{n, t-1}\right) \\
+\Lambda_{a}\left(x, \theta_{t-1}\right)+\omega_{j t}+\varepsilon_{i x t},
\end{gathered}
$$

where $R_{t}\left(j, d, \tau_{h}\right)$ denotes the rent paid at the chosen location, $\varphi_{a}\left(x, j_{t-1}, \tau_{n, t-1}\right)$ are moving costs, $\Lambda_{a}\left(x, \theta_{t-1}\right)$ are possible monetary transfers from landlords to tenants, $\omega_{j t}$ is an unobservable neighborhood taste shock, and $\varepsilon_{i x t}$ is an idiosyncratic logit error taste shock over the possible choices which is specific to household $i .{ }^{11}$ Note that we are suppressing the dependence of $(j, \tau, d)$ on $x$. If a tenant does not live in a rent-controlled property, she pays market rents, given by $R_{t}(j, 0)$. Thus, there is no dependence on $\tau_{h}$. In contrast, the rent paid by tenants in rent-controlled properties $R_{t}\left(j, 1, \tau_{h}\right)$ is a function of the number of years lived in the property. Crucially, note that the household has utility over exponential rents, with coefficient $\gamma_{a}$. We, of course, expect this coefficient to be negative. This assumption ensures, due to the effects of Jensen's inequality, that rent control offers real insurance value to tenants. We moreover allow for utility to depend on how long a household has lived in the current neighborhood, as measured by parameter $\alpha_{a}$.

\footnotetext{
${ }^{10}$ In principle, we could track the exact age as a stable variable, but this makes the state space very large.

${ }^{11}$ We measure rents as monthly rents divided by 3000, measured in 2010 dollars. We divide by 3000 for computational convenience.
} 
Intuitively, households may build up neighborhood capital over time which makes that location more attractive. For instance, over time people form meaningful friendships with their neighbors and acquire valuable local knowledge, such as that regarding local amenities. We allow both the rent utility parameter and neighborhood capital parameter to depend on whether the household is in the young or mature stage of life.

Households incur moving costs when they switch homes. We assume that there is a fixed moving cost $\varphi_{0, a}>0$, as well as a cost $\varphi_{d, a}>0$ that is variable with distance. We allow the variable moving cost parameter to depend on current neighborhood capital $\tau_{n, t-1}$, with the interaction effect measured by $\varphi_{\tau, a}$. This allows for the possibility that the desirability of nearby neighborhoods changes as one accrues neighborhood capital. In particular,

$$
\begin{aligned}
& \varphi_{a}\left(x, j_{t-1}\right)=0 \text { if } x_{t}=\mathcal{S} \\
& \varphi_{a}\left(x, j_{t-1}\right)=\varphi_{0, a}+\varphi_{d, a} d\left(j(x), j_{t-1}\right)+\varphi_{\tau, a}\left(d\left(j(x), j_{t-1}\right) \times \tau_{n, t-1}\right) \text { otherwise, }
\end{aligned}
$$

where $d\left(j(x), j_{t-1}\right)$ denotes the distance between the old and new neighborhoods. We allow the moving costs to vary with age. For example, it seems likely that households with children will find moving more costly than households without children, since changing schools could prove disruptive.

We also allow for possible monetary transfers from landlords of rent-controlled properties to tenants incentivizing them to move. These may represent true tenant buyouts or the amount of buyout that would have been required to rationalize the tenant out-migration, even if in reality the migration was due to eviction. In practice, the city of San Francisco allows for such negotiations and these payments are, in practice, quite prevalent. We do not explicitly model the bargaining game between landlords and tenants. Instead, we proceed in more reduced form fashion and parameterize the transfers as:

$$
\begin{aligned}
& \Lambda_{a}\left(x, \theta_{t-1}\right)=0 \text { if } x=\mathcal{S} \text { or } d_{t-1}=0 \\
& \Lambda_{a}\left(x, \theta_{t-1}\right)=\lambda_{1}\left[\ln R_{t}\left(j_{t=1}, 0\right)-\ln R_{t}\left(j_{5-1}, 1, \tau_{h, t-1}\right)\right]+\lambda_{2} \tau_{n, t-1}+\lambda_{Y} 1\left[a_{t-1}=Y\right] \text { otherwise. }
\end{aligned}
$$

The first equation simply says that, if the tenant does not move or does not live in rent-controlled housing, he receives no transfers. The first term in the second equation denotes the difference between market rents and rent-controlled rents. We would expect the coefficient on this term, $\lambda_{1}$, to be weakly positive. Intuitively, the greater the current difference between market rents and rent-controlled rents, the greater the incentive for landlords to remove tenants and thus the more landlords should be willing to pay to convince tenants to leave. We also allow for the outcome of the bargaining to depend on neighborhood tenure $\tau_{n}$, with the impact measured by the coefficient $\lambda_{2}$. This allows for more invested tenants to receive a larger payment, since their outside option, i.e. choosing to stay, is likely better than that of a short term tenant who has not built up a large 
stock of neighborhood capital. Finally, we allow the level difference in transfers to differ between young and mature households, measured by $\lambda_{Y}$.

We decompose the unobservable neighborhood amenity value $\omega_{j t}$ into

$$
\omega_{j t}=\omega_{j}+\tilde{\omega}_{j t},
$$

where $\omega_{j}$ is a time-invariant fixed effect and $\tilde{\omega}_{j t}$ is a per-period neighborhood specific shock. We impose no structure on the distribution of $\tilde{\omega}_{j t}$ beyond requiring that $F\left(\tilde{\omega}_{j, t+1} \mid \tilde{\omega}_{j t}, x_{i t}\right)=F\left(\tilde{\omega}_{j, t+1} \mid \tilde{\omega}_{j t}\right)$. That is, the decision of any individual agent has no impact on the distribution of the neighborhood amenity value next period.

Letting $\beta$ denote the common discount factor, the household's dynamic optimization problem at time $t$ is given by:

$$
V\left(\theta_{i, t-1}, \omega_{t}, \varepsilon_{i t}\right)=\max _{x^{*}} E\left(\sum_{s \geq t}^{\infty} \beta^{s-t} u\left(x^{*}, \omega_{t}, \varepsilon_{i t}, \theta_{i, t-1}\right) \mid \theta_{i, t-1}, \omega_{t}, \varepsilon_{i t}\right) .
$$

We next define the ex-ante value function $\bar{V}\left(\theta_{i t}, \omega_{t}\right)$ by integrating over the idiosyncratic errors:

$$
\bar{V}_{t}\left(\theta_{t-1}\right)=\int \ldots \int V\left(\theta_{t-1}, \omega_{t},\left(\varepsilon_{1}, \ldots, \varepsilon_{J+1}\right)\right) d F\left(\varepsilon_{1}\right) \ldots d F\left(\varepsilon_{J+1}\right)
$$

where $J$ is the number of neighborhoods and $\varepsilon_{J+1}$ it the logit error associated with staying in the current home. From this we can define the value function conditional on actions:

$$
v_{t}\left(x, \theta_{t-1}\right)=\bar{u}_{t}\left(x, \theta_{t-1}\right)+\beta E_{t}\left[\bar{V}_{t+1}\left(\Theta\left(x, \theta_{t-1}\right)\right)\right],
$$

where $\bar{u}_{t}\left(x, \theta_{t-1}\right)=u\left(x, \omega_{t}, 0, \theta_{t-1}\right), \Theta\left(x, \theta_{t-1}\right)$ denotes the state transition function, and $E_{t}[\cdot]$ denotes expectations conditional on time $t$ information.

Since the idiosyncratic taste shocks follow a logit specification, we get the standard results (see e.g. Hotz and Miller (1993)) relating conditional value functions to conditional choice probabilities $p_{t}\left(x \mid \theta_{t-1}\right)$ :

$$
p_{t}\left(x \mid \theta_{t-1}\right)=\frac{\exp \left(v_{t}\left(x, \theta_{t-1}\right)\right)}{\sum_{x^{\prime}} \exp \left(v_{t}\left(x^{\prime}, \theta_{t-1}\right)\right)} .
$$

In what follows, we denote the log of the denominator of this expression as:

$$
I_{t}\left(\theta_{t-1}\right)=\ln \left(\sum_{x^{\prime}} \exp \left(v_{t}\left(x^{\prime}, \theta_{t-1}\right)\right)\right)
$$

We also have that the ex-ante value function is given by:

$$
\bar{V}_{t}\left(\theta_{t-1}, \omega_{t}\right)=I_{t}\left(\theta_{t-1}\right)+\Gamma
$$

where $\Gamma$ is Euler's gamma. 


\subsection{Renewal Actions}

The key challenge in identifying dynamic discrete choice models is dealing with the expected continuation values in the Bellman equation. To be able to calculate the expected continuation values, one generally must make assumptions about exactly how agents form expectations, including exactly what information is known to the agent and how they expect market-level state variables to evolve. This normally requires assuming all market state variables (e.g. rents and amenities) are observed and follow assumed transition dynamics. We build on Scott (2013) and make no assumptions about how amenities evolve. We also make no assumptions on how agents form expectations about future market states. Unlike previous work, we do not need to assume agents have rational expectations. Since we are comparing differences between treatment and control groups, we only need to assume that differences in expectations between treatment and control households in the same neighborhood in the same year are on average zero. This allows all agents to have arbitrarily biased beliefs about the future and we do not need to specify the biases. We view this is an important advance over previous methods, as rational expectations can be a very strong assumption. Following work by Arcidiacono and Ellickson (2011) and Arcidiacono and Miller (2011), we make extensive use of renewal actions, or action(s) which, given current states $\theta_{t-1}$ and $\theta_{t-1}^{\prime}$, lead to the same state in the next period. This will allow us to difference out much of the long-term continuation values in the Bellman equation, which are impossible to estimate without strong assumptions.

\subsubsection{Immediate Renewals}

In what follows, we focus only on mature renters. A very similar analysis is conducted for young renters in Appendix B. Suppose we have two mature households in states $\theta_{t-1}$ and $\theta_{t-1}^{\prime}$. In period $t$, these two households take the actions $x$ and $x^{\prime}$ respectively. Using equation (4) and differencing we find that:

$$
v_{t}\left(x, \theta_{t-1}\right)-v_{t}\left(x^{\prime}, \theta_{t-1}^{\prime}\right)=\ln \left(\frac{p_{t}\left(x \mid \theta_{t-1}\right)}{p_{t}\left(x^{\prime} \mid \theta_{t-1}^{\prime}\right)}\right)+I_{t}\left(\theta_{t-1}\right)-I_{t}\left(\theta_{t-1}^{\prime}\right)
$$

Substituting in for the conditional value functions, we get:

$$
\begin{aligned}
& \bar{u}_{t}\left(x, \theta_{t-1}\right)-\bar{u}_{t}\left(x^{\prime}, \theta_{t-1}^{\prime}\right)+\beta E_{t}\left[\bar{V}_{t+1}\left(\Theta\left(x, \theta_{t-1}\right)\right)\right]-\beta E_{t}\left[\bar{V}_{t+1}\left(\Theta\left(x^{\prime}, \theta_{t-1}^{\prime}\right)\right)\right] \\
= & \ln \left(\frac{p_{t}\left(x \mid \theta_{t-1}\right)}{p_{t}\left(x^{\prime} \mid \theta_{t-1}^{\prime}\right)}\right)+I_{t}\left(\theta_{t-1}\right)-I_{t}\left(\theta_{t-1}^{\prime}\right) .
\end{aligned}
$$

Now assume $x$ and $x^{\prime}$ are renewal actions in the sense that $\Theta\left(x, \theta_{t-1}\right)=\Theta\left(x^{\prime}, \theta_{t-1}^{\prime}\right)$. Note that we do not require $x=x^{\prime}$, although this will often be the case. For example, if two households in non-rent controlled housing are living in the same neighborhood $j$ and have the same level of 
neighborhood tenure, then $x=\mathcal{S}$ and $x^{\prime}=j$, i.e. one household choosing to stay in the current home and the other moving to another house in the same neighborhood, constitute renewal actions. The key implication is that the future continuation values difference out, leaving:

$$
\bar{u}_{t}\left(x, \theta_{t-1}\right)-\bar{u}_{t}\left(x^{\prime}, \theta_{t-1}^{\prime}\right)=\ln \left(\frac{p_{t}\left(x \mid \theta_{t-1}\right)}{p_{t}\left(x^{\prime} \mid \theta_{t-1}^{\prime}\right)}\right)+I_{t}\left(\theta_{t-1}\right)-I_{t}\left(\theta_{t-1}^{\prime}\right) .
$$

If $\theta_{t-1} \neq \theta_{t-1}^{\prime}$, we also need to remove the difference of log sums, which implicitly involves future continuation values as well.

To do so, suppose the households move to some neighborhood $j^{*} \in \mathcal{J}$, with $j^{*} \neq x$ and $j^{*} \neq x^{\prime}$. This always constitutes a renewal action, so we get equation (7) again with $x$ and $x^{\prime}$ replaced with $j^{*}:$

$$
\bar{u}_{t}\left(j^{*}, \theta_{t-1}\right)-\bar{u}_{t}\left(j^{*}, \theta_{t-1}^{\prime}\right)=\ln \left(\frac{p_{t}\left(j^{*} \mid \theta_{t-1}\right)}{p_{t}\left(j^{*} \mid \theta_{t-1}^{\prime}\right)}\right)+I_{t}\left(\theta_{t-1}\right)-I_{t}\left(\theta_{t-1}^{\prime}\right) .
$$

Differencing equations (7) and (8) yields:

$$
\begin{aligned}
\ln \left(\frac{p_{t}\left(x \mid \theta_{t-1}\right)}{p_{t}\left(x^{\prime} \mid \theta_{t-1}^{\prime}\right)}\right)-\ln \left(\frac{p_{t}\left(j^{*} \mid \theta_{t-1}\right)}{p_{t}\left(j^{*} \mid \theta_{t-1}^{\prime}\right)}\right)= & {\left[\bar{u}_{t}\left(x, \theta_{t-1}\right)-\bar{u}_{t}\left(x^{\prime}, \theta_{t-1}^{\prime}\right)\right] } \\
& -\left[\bar{u}_{t}\left(j^{*}, \theta_{t-1}\right)-\bar{u}_{t}\left(j^{*}, \theta_{t-1}^{\prime}\right)\right]
\end{aligned}
$$

which removes the log sums. Intuitively, equation (9) compares the difference in utility between two different actions a household in state $\theta_{t-1}$ could take versus a household in state $\theta_{t-1}^{\prime}$. This "differences-in-differences" approach removes all long-term utility differences since actions are selected to create renewals.

\subsubsection{One Period Ahead Renewals}

Now suppose that $x$ and $x^{\prime}$ are not renewal actions in period $t$. Following Scott (2013), we substitute the expected difference in continuation values in equation (6) with its realization and expectational errors:

$$
\begin{aligned}
& \bar{u}_{t}\left(x, \theta_{t-1}\right)-\bar{u}_{t}\left(x^{\prime}, \theta_{t-1}^{\prime}\right)-\ln \left(\frac{p_{t}\left(j \mid \theta_{t-1}\right)}{p_{t}\left(j^{\prime} \mid \theta_{t-1}^{\prime}\right)}\right)-\left[I_{t}\left(\theta_{t-1}\right)-I_{t}\left(\theta_{t-1}^{\prime}\right)\right] \\
= & \beta\left(\bar{V}_{t+1}\left(\Theta\left(x^{\prime}, \theta_{t-1}^{\prime}\right)\right)-\bar{V}_{t+1}\left(\Theta\left(x, \theta_{t-1}\right)\right)\right)+\xi_{t}^{V}\left(x^{\prime}, \theta_{t-1}^{\prime}\right)-\xi_{t}^{V}\left(x, \theta_{t-1}\right)
\end{aligned}
$$

where

$$
\xi_{t}^{V}\left(x, \theta_{t-1}\right)=\beta\left(E_{t}\left[\bar{V}_{t+1}\left(\Theta\left(x, \theta_{t-1}\right)\right)\right]-\bar{V}_{t+1}\left(\Theta\left(x, \theta_{t-1}\right)\right)\right)
$$

is the expectational error.

We now again make use of renewals. Suppose that at time $t+1$, both households move to the same neighborhood, that is $x_{t+1}=x_{t+1}^{\prime}=j^{*} \in \mathcal{J}$. To see the effects of this, first substitute out 
the realized ex-ante value functions using equations (4) and (5). We have:

$$
\begin{aligned}
& \bar{u}_{t}\left(x, \theta_{t-1}\right)-\bar{u}_{t}\left(x^{\prime}, \theta_{t-1}^{\prime}\right)-\ln \left(\frac{p_{t}\left(j \mid \theta_{t-1}\right)}{p_{t}\left(j^{\prime} \mid \theta_{t-1}^{\prime}\right)}\right)-\left[I_{t}\left(\theta_{t-1}\right)-I_{t}\left(\theta_{t-1}^{\prime}\right)\right] \\
= & \beta\left(v_{t+1}\left(j^{*}, \Theta\left(x^{\prime}, \theta_{t-1}^{\prime}\right)\right)-v_{t+1}\left(j^{*}, \Theta\left(x, \theta_{t-1}\right)\right)\right) \\
& -\beta \ln \left(\frac{p_{t+1}\left(j^{*}, \Theta\left(x^{\prime} \mid \theta_{t-1}^{\prime}\right)\right)}{p_{t+1}\left(j^{*}, \Theta\left(x \mid \theta_{t-1}\right)\right)}\right)+\Delta \xi_{t}^{V},
\end{aligned}
$$

where:

$$
\Delta \xi_{t}^{V}=\xi_{t}^{V}\left(x^{\prime}, \theta_{t-1}^{\prime}\right)-\xi_{t}^{V}\left(x, \theta_{t-1}\right)
$$

Since $j^{*}$ is a renewal action, the time $t+2$ expected value functions difference out and this equation becomes:

$$
\begin{aligned}
& \bar{u}_{t}\left(x, \theta_{t-1}\right)-\bar{u}_{t}\left(x^{\prime}, \theta_{t-1}^{\prime}\right)-\ln \left(\frac{p_{t}\left(j \mid \theta_{t-1}\right)}{p_{t}\left(j^{\prime} \mid \theta_{t-1}^{\prime}\right)}\right)-\left[I_{t}\left(\theta_{t-1}\right)-I_{t}\left(\theta_{t-1}^{\prime}\right)\right] \\
= & \beta\left(\bar{u}_{t+1}\left(j^{*}, \Theta\left(x^{\prime}, \theta_{t-1}^{\prime}\right)\right)-\bar{u}_{t+1}\left(j^{*}, \Theta\left(x, \theta_{t-1}\right)\right)\right) \\
& -\beta \ln \left(\frac{p_{t+1}\left(j^{*}, \Theta\left(x^{\prime} \mid \theta_{t-1}^{\prime}\right)\right)}{p_{t+1}\left(j^{*}, \Theta\left(x \mid \theta_{t-1}\right)\right)}\right)+\Delta \xi_{t}^{V} .
\end{aligned}
$$

To fully remove the conditional value functions, we once again must remove the difference in log sums $I_{t}\left(\theta_{t-1}\right)-I_{t}\left(\theta_{t-1}^{\prime}\right)$.

We follow the same procedure as previously, subtracting equation (8) from equation (10):

$$
\begin{aligned}
& \ln \left(\frac{p_{t}\left(j \mid \theta_{t-1}\right)}{p_{t}\left(j^{\prime} \mid \theta_{t-1}^{\prime}\right)}\right)-\ln \left(\frac{p_{t}\left(j^{*} \mid \theta_{t-1}\right)}{p_{t}\left(j^{*} \mid \theta_{t-1}^{\prime}\right)}\right)+\beta \ln \left(\frac{p_{t+1}\left(j^{*}, \Theta\left(x \mid \theta_{t-1}\right)\right)}{p_{t+1}\left(j^{*}, \Theta\left(x^{\prime} \mid \theta_{t-1}^{\prime}\right)\right)}\right) \\
= & {\left[\bar{u}_{t}\left(x, \theta_{t-1}\right)-\bar{u}_{t}\left(x^{\prime}, \theta_{t-1}^{\prime}\right)\right]-\left[\bar{u}_{t}\left(j^{*}, \theta_{t-1}\right)-\bar{u}_{t}\left(j^{*}, \theta_{t-1}^{\prime}\right)\right] } \\
& +\beta\left(\bar{u}_{t+1}\left(j^{*}, \Theta\left(x, \theta_{t-1}\right)\right)-\bar{u}_{t+1}\left(j^{*}, \Theta\left(x, \theta_{t-1}\right)\right)\right)+\Delta \xi_{t}^{V} .
\end{aligned}
$$

Equations (9) and (11) provide a linear regression framework which we can use to fully identify and estimate the parameters of the model.

\subsection{Empirical Framework}

We now discuss how to empirically operationalize the preceding considerations.

\subsubsection{Constructing Conditional Choice Probabilities}

We first need to construct empirical estimates of the conditional choice probabilities, $p_{t}\left(x \mid \theta_{t-1}\right)$. In a given year $t$, we focus on those households who were part of the 1994 treatment and control groups described in the previous section and who have not moved away from their 1994 residence. 
Given the latter restriction, we do not need to keep track of $\tau_{h}$ and we therefore suppress the dependence of $\theta_{t-1}$ on this state variable in what follows.

With a large enough dataset, we could simply compute empirical frequencies for all conditional choice probabilities. However, since there are many states, not all CCPs in our data are measured precisely. We therefore use kernel smoothing on the empirical frequencies to improve the prediction error. We smooth over distance, neighborhood tenure, and age. We use a Gaussian kernel. Distance is measured between the midpoints of zipcodes. Neighborhood tenure equals the number of years the renter has lived in that zipcode. Young renters are those under the age of 40, while mature/old renters are those 40 and older. We use $k$-fold cross validation to set the optimal bandwidths with $k=5$. The young to mature transition probabilities $\kappa_{t}$ are estimated each year from the Infutor data.

\subsubsection{Identifying the Parameters of the Model}

We set $\beta=.85 .^{12}$ We estimate the various parameters of the model by estimating equation (9) and (11) for appropriately chosen values of $\left(\theta_{t-1}, \theta_{t-1}^{\prime}\right)$ and $\left(x, x^{\prime}\right)$. Intuitively, by examining the differential behavior of individuals in certain states of the world and following certain types of deviations, we can isolate the impact of the different parameters of the model. We begin by constructing a regression equation for $\gamma_{M}, \lambda_{1}$, and $\lambda_{2}$. These are the (mature) rent utility parameter and the parameters of the transfer function. Normally, we would be confronted with a significant endogeneity problem in estimating these parameters since market rents $R_{t}(j, 0)$ in neighborhood $j$ are likely correlated with the amenity value $\omega_{j t}$ unobservable to the econometrician.

We overcome this essential endogeneity problem by exploiting the quasi-experimental nature of the 1994 San Francisco rent control ballot measure. This law change quasi-randomly assigned renters within a given neighborhood $j$ to rent control status. As mentioned, we focus exclusively on this population for our regressions.

Now let $\theta_{t-1}=\left(j, \tau_{n}, 1, M\right)$ and $\theta_{t-1}^{\prime}=\left(j, \tau_{n}, 0, M\right)$ for some $j \in \mathcal{J}$ not equal to $j$. We furthermore set $x=x^{\prime}=\mathcal{S}$ and let $j^{*}$ be any element of $\mathcal{J}$. In words, we consider two mature households who both lived in neighborhood $j$ in 1994 and have not moved as of year $t$. The two households are of equal tenure $\tau_{n}$. One was assigned to rent control status in 1994 and the other was not. We examine the relative probabilities of these individuals staying in neighborhood $j$ in year $t$, using neighborhood $j^{*}$ as the renewal choice in the manner described in the previous

\footnotetext{
${ }^{12}$ This choice is consistent with the evidence provided in De Groote and Verboven (2016), who estimate a household discount factor of .87 .
} 
section. Under these assumptions, equation (11) gives the regression:

$$
\begin{aligned}
Y_{j, j^{*}}^{t}= & \gamma_{M}\left[\exp R_{t}(j, 1)-\exp R_{t}(j, 0)\right] \\
& +\lambda_{1}\left[\left(\beta \ln R_{t+1}(j, 0)-\ln R_{t}(j, 0)\right)-\left(\beta \ln R_{t+1}(j, 1)-\ln R_{t}(j, 1)\right)\right] \\
& +\lambda_{2}\left[\beta\left(t+\tau_{n}+1\right)-\left(t+\tau_{n}\right)\right] \\
& +\Delta \xi_{t}^{V}+\chi_{j, j^{*}}^{t} \\
Y_{j, j^{*}}^{t}= & \ln \left(\frac{p_{t}\left(\mathcal{S} \mid j, 1, \tau_{n}\right)}{p_{t}\left(\mathcal{S} \mid j, 0, \tau_{n}\right)}\right)-\ln \left(\frac{p_{t}\left(j^{*} \mid j, 1, \tau_{n}\right)}{p_{t}\left(j^{*} \mid j, 0, \tau_{n}\right)}\right)+\beta \ln \left(\frac{p_{t+1}\left(j^{*} \mid j, 1, \tau_{n}\right)}{p_{t+1}\left(j^{*} \mid j, 0, \tau_{n}\right)}\right)
\end{aligned}
$$

Intuitively, this regression compares the probability of staying in the neighborhood for one more year and then moving to $j^{*}$ versus moving to $j^{*}$ this year. This difference in probabilities is then differenced between treatment and control, which differences out all the utility impacts of living in $j$ vs $j^{*}$ other than those which are impacted by rent control.

Note that we have included an additional error term $\chi_{j, j^{*}}^{t}$, reflecting measurement error in our constructed conditional choice probabilities. The key for identification is that the unobserved amenity value $\omega_{j t}$ differences out. Since $\omega_{j t}$ does not enter the estimating equation, these methods are robust to the possibility that tenants living in different zipcodes have unobservably heterogeneous preferences for the value of each zipcode's unobserved amenities. Specifically, suppose tenants were of different "types" in their valuation of neighborhood amenities and these types were perfectly sorted across zipcodes. Then, by comparing treatment and control tenants in the same zipcode, we always compare tenants of the same unobservable type, and difference out their type-specific valuation of neighborhood amenities.

We furthermore know that:

$$
E_{t}\left[\left(\exp R_{t}(j, 1)-\exp R_{t}(j, 0)\right)\left(\xi_{t}^{V}\left(x^{\prime}, \theta_{t-1}^{\prime}\right)-\xi_{t}^{V}\left(x, \theta_{t-1}\right)\right)\right]=0
$$

due to treatment and control groups not having differentially biased expectations. That is, the difference in expectational errors between treatment and control is uncorrelated with any time $t$ information. In general, however, we do not have:

$E_{t}\left[\left(\beta \ln R_{t+1}(j, 0)-\ln R_{t}(j, 0)\right)-\left(\beta \ln R_{t+1}(j, 1)-\ln R_{t}(j, 1)\right)\left(\xi_{t}^{V}\left(x^{\prime}, \theta_{t-1}^{\prime}\right)-\xi_{t}^{V}\left(x, \theta_{t-1}\right)\right)\right]=0$

The time $t+1$ rent difference may be correlated with the expectational error. This is intuitive. For instance, neighborhood $j$ may be better at date $t+1$ than was expected since market rents are lower than anticipated. We, therefore, instrument for the time $t+1$ rent difference $\ln R_{t+1}(j, 1)-$ $\ln R_{t}(j, 1)$ with $Z_{t}$, equal to the one-period lagged value $\ln R_{t}(j, 1)-\ln R_{t-1}(j, 1)$. Since $Z_{t}$ is in the time $t$ information set, we have:

$$
E_{t}\left[Z_{t}\left(\xi_{t}^{V}\left(x^{\prime}, \theta_{t-1}^{\prime}\right)-\xi_{t}^{V}\left(x, \theta_{t-1}\right)\right)\right]=0
$$


Thus, our exclusion restrictions are satisfied and the parameters are identified.

To estimate moving costs, we consider two households of equal tenure $\tau_{n}$ living in non-rent controlled housing in neighborhood $j$. Suppose that one household immediately moves to another house in the same zipcode and one household stays in the same home. Formally, $\theta_{t-1}=\theta_{t-1}^{\prime}=$ $\left(j, \tau_{n}, 0, M\right), x=\mathcal{S}$, and $x^{\prime}=j$. As was discussed in Section 5.2.1, this constitutes an immediate renewal since rents do not change and neighborhood tenure does not change. Since one is only changing the house they live in due to the logit error and the moving costs, we can identify the fixed cost of moving. If people move houses a lot within a zipcode, moving costs must be low. If they do it rarely, moving costs must be high. Equation (9) gives the regression:

$$
\begin{aligned}
Y_{j}^{t} & =-\varphi_{0}, M+\chi_{j}^{t} \\
Y_{j}^{t} & =\ln \left(\frac{p_{t}\left(\mathcal{S} \mid j, 0, \tau_{n}\right)}{p_{t}\left(j \mid j, 0, \tau_{n}\right)}\right)
\end{aligned}
$$

which identifies the fixed moving cost parameter $\varphi_{0}, M$. Note that there is only one log difference instead of two since the households begin in the same state.

We also need the variable moving cost parameter, $\varphi_{d, M}$. Consider two mature households of equal tenure $\tau_{n}$, both living in non-rent controlled housing, one living in neighborhood $j$ and the other in neighborhood $j^{\prime}$. Suppose they immediately move to either neighborhood $j^{*}$ or $j^{* *}$. Both of these are choices constitute immediate renewals. Therefore, Equation (9) gives the specification:

$$
\begin{aligned}
Y_{j, j^{\prime}, j^{*}, j^{* *}}^{t}= & \varphi_{d}, M\left(d_{j, j^{*}}-d_{j^{\prime}, j^{*}}\right)-\varphi_{d}, M\left(d_{j, j^{* *}}-d_{j^{\prime}, j^{* *}}\right) \\
& +\varphi_{\tau}, M \tau_{n}\left(d_{j, j^{*}}-d_{j^{\prime}, j^{*}}\right)-\varphi_{\tau}, \tau_{n}\left(d_{j, j^{* *}}-d_{j^{\prime}, j^{* *}}\right)+\chi_{j, j^{\prime}, j^{*}, j^{* *}}^{t} \\
Y_{j, j^{\prime}, j^{*}, j^{* *}}^{t}= & \ln \left(\frac{p_{t}\left(j^{*} \mid j, 0, \tau_{n}\right)}{p_{t}\left(j^{*} \mid j^{\prime}, 0, \tau_{n}\right)}\right)-\ln \left(\frac{p_{t}\left(j^{* *} \mid j, 0, \tau_{n}\right)}{p_{t}\left(j^{* *} \mid j^{\prime}, 0, \tau_{n}\right)}\right) .
\end{aligned}
$$

Intuitively, this compares the relative probabilities of moving to $j^{*}$ vs $j^{* *}$ depending on whether one starts in $j$ or $j^{\prime}$. If $j$ is very close to $j^{*}$, but far from $j^{* *}$, then the difference in moving costs between the moves in large. However, if $j^{\prime}$ is equidistant between the two, the moving costs between the two locations are the same. The relationship between these differences in distances and differences in migration probabilities identifies the marginal cost of moving with respect to distance. As we vary $\tau_{n}$, we further identify the impact of initial tenure on this marginal cost.

To identify the impact of tenure on utility $\alpha_{M}$, consider two mature households living in non-rent controlled housing in neighborhood $j$, with different levels of initial tenure, $\tau_{n}$ and $\tau_{n}^{\prime}$. Suppose both households move to $j^{*}$ after one year. We thus have $\theta_{t-1}=\left(j, \tau_{n}, 0, M\right)$ and $\theta_{t-1}^{\prime}=\left(j, \tau_{n}^{\prime}, 0, M\right)$ for some $j \in \mathcal{J}$ and $x=x^{\prime}=\mathcal{S}$. Then equation (11) becomes:

$$
\begin{aligned}
& Y_{j, j^{*}}^{t}=\alpha_{M}\left(\tau_{n}-\tau_{n}^{\prime}\right)+(\beta-1) \varphi_{\tau, M}\left(\tau_{n}-\tau_{n}^{\prime}\right) d_{j, j^{*}}+\Delta \xi_{t}^{V}+\chi_{j, j^{*}}^{t} \\
& Y_{j, j^{*}}^{t}=\ln \left(\frac{p_{t}\left(\mathcal{S} \mid j, 0, \tau_{n}\right)}{p_{t}\left(\mathcal{S} \mid j, 0, \tau_{n}^{\prime}\right)}\right)-\ln \left(\frac{p_{t}\left(j^{*} \mid j, 0, \tau_{n}\right)}{p_{t}\left(j^{*} \mid j, 0, \tau_{n}^{\prime}\right)}\right)+\beta \ln \left(\frac{p_{t+1}\left(j^{*} \mid j, 0, \tau_{n}\right)}{p_{t+1}\left(j^{*} \mid j, 0, \tau_{n}^{\prime}\right)}\right)
\end{aligned}
$$


Since both households live in non-rent controlled housing in the same neighborhood, they pay the same rents and receive the same unobserved amenity value. Indeed, the only payoff-relevant difference between the two populations is the number of years they have lived in the neighborhood. Thus, appropriately examining the relative probabilities of staying in the neighborhood is informative of the importance of tenure on utility or, in other words, of the magnitude of $\alpha_{M}$. Intuitively, as one builds up more neighborhood capital, the benefits of staying in the neighborhood an additional year. Thus, the relative probability of staying one more year versus moving away should grow if neighborhood capital is accruing.

Note that one can use the treatment group as well as the control group to estimate the neighborhood tenure parameters and the variable moving cost parameters. The regression equations for the moving cost parameters are exactly the same when using the treatment group. However, since individuals with different levels of tenure receive different transfer payments, the equation identifying the utility impact of tenure needs to be modified to take this into account. The equations for young households are very similar to the ones described above, but the probability of transitioning to a mature household must be taken into account. The regression equations for the young are detailed in Appendix B. The full model is then estimated via GMM.

Finally, it remains to estimate the permanent component of amenities $\omega_{j} \cdot{ }^{13}$ We do so after estimating the full GMM system detailed above. We once again consider two mature households of equal tenure $\tau_{n}$, living in neighborhoods $j$ and $j^{\prime}$ respectively and suppose that both households move to some neighborhood $j^{*}$ after one year. We thus have, $\theta_{t-1}=\left(j, \tau_{n}, 0, M\right)$, $\theta_{t-1}^{\prime}=\left(j^{\prime}, \tau_{n}, 0, M\right)$, and $x=x^{\prime}=\mathcal{S}$. These choices yield the equation:

$$
\begin{aligned}
Y_{j, j^{\prime}, j^{*}}^{t}= & \omega_{j}-\omega_{j^{\prime}}+\tilde{\omega}_{j t}-\tilde{\omega}_{j^{\prime} t}+\Delta \xi_{t}^{V}+\chi_{j, j^{\prime}, j^{*}}^{t} \\
Y_{j, j^{\prime}, j^{*}}^{t}= & \ln \left(\frac{p_{t}\left(\mathcal{S} \mid j, 0, \tau_{n}\right)}{p_{t}\left(\mathcal{S} \mid j^{\prime}, 0, \tau_{n}\right)}\right)-\ln \left(\frac{p_{t}\left(j^{*} \mid j, 0, \tau_{n}\right)}{p_{t}\left(j^{*} \mid j^{\prime}, 0, \tau_{n}\right)}\right)+\beta \ln \left(\frac{p_{t+1}\left(j^{*} \mid j, 0, \tau_{n}\right)}{p_{t+1}\left(j^{*} \mid j^{\prime}, 0, \tau_{n}\right)}\right) \\
& -(\beta-1) \varphi_{d}, M\left(d_{j, j^{*}}-d_{j^{\prime}, j^{*}}\right)-(\beta-1) \varphi_{\tau}, M \tau_{n}\left(d_{j, j^{*}}-d_{j^{\prime}, j^{*}}\right) \\
& +\gamma_{M}\left[\exp R_{t}(j, 0)-\exp R_{t}\left(j^{\prime}, 0\right)\right] .
\end{aligned}
$$

Identification comes from the fact that, averaging over time, we average out the per-period neighborhood amenity shocks and expectational error shocks. Moreover, note that we do not have an endogeneity problem since we have already estimated $\gamma_{M}$ and can therefore move the utility impact of the rent difference to the left hand side of the equation. We also account for the differential moving costs related to distance on the left hand side of the equation. Finally, note that we can only identify fixed amenity value differences between neighborhoods. We therefore choose a normalization, letting zipcode 94110, representing the Mission District and Bernal Heights, be our baseline zipcode. We set its amenity value fixed effect to zero.

\footnotetext{
${ }^{13}$ We cannot identify amenities of the outside options, i.e. the rest of the Bay Area and the rest of the country, as no one in our 1994 cohorts started off living in those locations.
} 


\subsection{Model Estimates}

Table 3 shows the parameter estimates of the model. Panel A reports the parameters measured in rent equivalent dollar units, with the exception of the transfer payments, which are measured assuming a constant marginal utility of a dollar,. ${ }^{14}$ Panel $\mathrm{B}$ reports the estimates in units of migration elasticities. We will focus on the estimates in Panel A. Normalizing the coefficient on exponential rents to 1, we identify the standard deviation of tenants' idiosyncratic shocks to their location preferences. We find that young renters have annual location taste shocks with a standard deviation equivalent to $\$ 7,411$. Mature renters face location shocks with a $12.7 \%$ lower standard deviation. These estimates are consistent with our previously discussed hypothesis that young renters' migration decisions are more driven by idiosyncratic shocks than mature households.

Turning to the magnitudes of the tenant buyouts, we find young renters receive $\$ 1.631$ more dollars from their landlords for each additional $\$ 1$ below market their rent is. Mature renters face similar impact of $\$ 1.404$. We also find buyout offers are larger as tenants live in their zipcodes longer. For each additional year a young (mature) tenant lives in their zipcode, they receive $\$ 164$ (\$141) additional dollars in the buyout offer from their landlord. Finally, we find mature tenants receive larger buyout offers overall by $\$ 70,702$. This may reflect that landlords expect mature tenants to remain in their apartments for the very long term. Along the same lines, to the extent that these transfers reflect evictions, landlords would be more incentivized to evict mature renters. To get a better sense of the magnitudes of these buyout payments, Figure E.9 plots the average buyout to young tenants offered in each year in the data, across all tenants and neighborhoods. By 2010, the average offer to tenants who still remain at their 1994 address is just over $\$ 30,000$. Figure E.10 plots the heterogeneity across zipcodes in mean buyout offers, highlighting that some zipcodes experience much larger rent increases than others over this time period. In the most expensive zipcode, the average buyout in 2010 is just about $\$ 40,000$, while in the cheapest zipcode the mean buyout offer is around $\$ 25,000$. These numbers seem very much in line with popular press anecdotes about tenant buyouts in San Francisco.

Moving along to our estimates of moving costs, we find the fixed cost of moving is equivalent, in rent-equivalent dollars, to $\$ 42,626$ for young renters and $\$ 38,988$ for old renters. These estimates seem quite reasonable and actually quite below what is typically found in the literature. A main driver of the magnitude of this estimate are the short-run migration elasticities with respect to a one-year temporary change. It is often quite hard to find a high quality instrument for rents that does not effect other omitted variables such as amenities. Likely, many instruments for rent also impact the supply and quality of amenities, leading to rent elasticities being biased towards 0. Our rent control policy experiment only affects rents and cannot affect amenities in our regressions, as

\footnotetext{
${ }^{14}$ These are measured at the mean rent paid by rent-controlled households, $\$ 2350$. We fix the marginal utility of a dollar for the tenant buyout parameters to account for the fact that the buyout need not be spent all in that period. Since the buyout amounts could easily be more than a year's rent, it does not make sense to allow the MU of a dollar to go to zero as the model assumes if rent were zero.
} 
we are comparing migration decisions between market rent and rent controlled households in the same neighborhood consuming the same amenities.

In addition to the fixed costs of moving, we find that the moving costs increase with the distance of the move. A $1 \%$ increase in move distance is equivalent to $\$ 114$ for the young and $\$ 101$ for the old. Finally, we also consider whether these variable moving costs change as households live in their zipcodes longer. One might think that the longer a household has lived in the area the more familiar they are with further and further away neighborhoods, lowering those marginal moving costs. Indeed, we find this is the case, with each additional year a tenant has lived in their zipcode lowering the moving cost by $\$ 415$ for the young and $\$ 357$ for the old.

Lastly, we turn to our neighborhood capital estimates. Proponents of rent control often argue that long-term residents are the ones in the most need of rent control as migrating away from their community forces them to lose many of the connections and investments they have been in the neighborhoods over time. We do find very statistically significant effects of neighborhood capital accumulation, though the economic magnitude is small. Young (mature) households increasingly

value living in their zipcode by $\$ 266$ (\$292) in dollar rent equivalent terms. However, these effects can add up to a sizable effect over a lifetime.

\section{Welfare Effects of Rent Control}

\subsection{Welfare Decomposition: 1994-2012}

We begin our investigation of the welfare effects of rent control by decomposing the impacts of the 1994 ballot initiative on its beneficiaries, relative to the control group. We discuss here mature households. The expressions for young households are exactly analogous.

In any given year $t$ between the years of 1994 and 2012, the average utility difference between the treatment group and the control group is given by:

$$
\Delta U_{t}^{M}=\sum_{\theta_{t-1}} \sum_{x}\left(\bar{u}_{t}\left(x, \theta_{t-1}\right)+E_{t}\left[\varepsilon_{i x t} \mid x, \theta_{t-1}\right]\right)\left(p_{t}^{T}\left(x, \theta_{t-1}\right)-p_{t}^{C}\left(x, \theta_{t-1}\right)\right)
$$

where recall $\bar{u}_{t}\left(x, \theta_{t-1}\right)=u\left(x, \omega_{t}, 0, \theta_{t-1}\right)$ and the utility function is defined in equation (3). The expressions $p_{t}^{T}\left(x, \theta_{t-1}\right)$ and $p_{t}^{C}\left(x, \theta_{t-1}\right)$ denote the fraction of the treatment and control groups respectively that are in state $\theta_{t-1}$ and choose action $x$ at time $t$. The conditional expectation $E_{t}\left[\varepsilon_{i t} \mid x, \theta_{t-1}\right]$ denotes the average logit error conditional on choosing $x$ from state $\theta_{t-1}$. Of course, equation (12) simply says that the average utility difference at time $t$ is the weighted average utility received by the treatment group minus the weighted average utility received by the control group.

We can decompose this average utility difference by substituting in for the utility function from 
equation (3). We find that:

$$
\begin{aligned}
\Delta U_{t}^{M}= & \Delta U_{t}^{M, \text { Rent }}+\Delta U_{t}^{M, \text { Payoff }}+\Delta U_{t}^{M, N C} \\
& +\Delta U_{t}^{M, M C}+\Delta U_{t}^{M, \text { Miles }}+\Delta U_{t}^{M, \text { Amenity }}+\Delta U_{t}^{M, \text { Logit }} .
\end{aligned}
$$

That is, the average utility difference between the treatment group and the control arises from differences in average rent paid $\Delta U_{t}^{M, \operatorname{Re} n t}$, in transfers received from landlords $\Delta U_{t}^{M, P a y o f f}$, in accumulated neighborhood capital $\Delta U_{t}^{M, N C}$, in fixed costs $\Delta U_{t}^{M, M C}$, in variable moving costs $\Delta U_{t}^{M, \text { Miles }}$, in neighborhood amenity values $\Delta U_{t}^{M, \text { Amenity }}$, and in idiosyncratic valuations $\Delta U_{t}^{M, \text { Logit }}$. Using our structural estimates for each component of the utility function, each of these components can readily calculated through a standard differences-in-differences regression. The details are provided in Appendix C. ${ }^{15}$ To gain an understanding of the magnitudes of each of these component effects, we convert our estimated utility differences into rent equivalent dollar amounts. That is, we determine what change in rent would to the same (incremental) utility difference as the effect under consideration.

\subsubsection{Results}

The results of this decomposition are reported in Table 4. We find that the beneficiaries of the 1994 rent control law received large welfare benefits between the 1995-2012 period. Older households received a total rent-equivalent dollar benefit of $\$ 119,837$, reflecting an annual benefit of $\$ 6,658$. These benefits were front loaded, with households earning a cumulative benefit of $\$ 74,622$ and average annual benefit of $\$ 8,291$ during the 1995 -2003 period Cumulative benefits equaled $\$ 45,216$ during the 2004-2012 period, reflecting an annual average of $\$ 5,024$.

In terms of decomposition, most of the benefits from the rent control law came from protection against rent increases and transfers. ${ }^{16}$ Respectively, protection against rent increases constituted $44.2 \%$ of the total benefit and transfers constituted $30.1 \%$ of the total. Lower moving costs, both fixed and variable, were $13.5 \%$ of the total. Increased neighborhood capital constituted only small fraction of the total benefit at $1.2 \%$. The welfare benefits from increased amenity values were negligible. Interestingly, we find increased utility from the utility value of one's idiosyncratic preference equal to $11.3 \%$ of the welfare gain. This likely due to the fact that we found some low neighborhood capital households were more likely to move due to rent control, allowing them to

\footnotetext{
${ }^{15}$ As shown in the appendix, calculating these expressions can actually be done with just a simple difference between treatment and control. We use the pre-post difference-in-difference to be consistent with our previous estimations.

${ }^{16}$ The model assumes that all observed moves are rational choices. The transfers we estimate are those which rationalize the observed empirical frequencies. It is possible that some of the moves we see in the data are forced evictions, rather than the result of negotiations between landlords and tenants over monetary compensation. To the extent that this is the case, our welfare benefits from transfer payments over overstated. However, even in the extreme case where the welfare benefits from transfers are zero, the benefits from protection against rent increases would still be large.
} 
overcome moving costs and live in a location that best suits their idiosyncratic preference.

The benefits of the rent control expansion were smaller for younger households, although still large. That they are smaller is consistent with our estimate that younger households receive larger idiosyncratic shocks, which leads to more frequent moving and thus smaller benefits from rent control protections. Younger households are also estimated to receive smaller transfers. Cumulative welfare benefits for these households totaled $\$ 41,121$, reflecting an annual average of $\$ 2,285$. Similar to mature households, the benefits were front loaded. Younger households received cumulative benefits of $\$ 32,960$ during the 1995-2003 period and cumulative benefits of $\$ 8,162$ during the 2004-2012 period. Annual averages were \$3,662 and \$907 respectively.

Also similar to mature households, most of the benefits came from protection against rent increases and transfers, constituting $79.6 \%$ and $45.4 \%$ respectively over the total period. The fraction due to moving costs is much smaller for younger households, at only $6.8 \%$. Note this reinforces the idea that, due to a higher variance if idiosyncratic shocks, younger households optimally choose to move more often. The fraction due to neighborhood capital is once again small, constituting just $2.9 \%$ for the average. Welfare benefits due to increased amenity values now reflect a small, but non-negligible, fraction of the total benefit at 2.6\%. Finally, the young face a substantial welfare loss due to living in places that are worse matches to their idiosyncratic preference under rent control, equal to $-37.2 \%$. This reflects that to stay in one's apartment to benefit from below market rents, one must give up living in the best apartment and location that suits one's preferences. Our estimates shows that idiosyncratic preference variance is higher for the young, making giving up the match value a larger sacrifice.

We aggregate these numbers over the entire population of renters impacted by the rent control law. The aggregate welfare benefits are very large. Older households received a cumulative (undiscounted) benefit of $\$ 2.5$ billion over the entire period, while younger households received a cumulative benefit of $\$ 1.3$ billion dollars. Across the entire population, the aggregate benefit was $\$ 3.9$ billion dollars, reflecting an annual average of $\$ 214$ million dollars. To put this in present discount value using a discount rate of 0.95 , this equates to a $\$ 2.9$ billion dollar welfare gain to treated tenants. Note also that these welfare numbers are only for the 1994 population impacted by the rent control expansion. It does not take into account the welfare benefits for renters who moved into the impacted properties in later years, which presumably were also quite large.

\subsection{General Equilibrium Welfare Impact of Reduced Supply}

We finally turn to evaluating the GE welfare impact of the landlord supply response. Since small multifamily housing constituted $44 \%$ of 1994 non rent-controlled housing stock, our reduced form results indicate that rental supply in San Francisco decreased by $6 \%$ as a result of the rent control expansion. Given this reduction in supply, we would therefore expect that average San Francisco rents are higher than they otherwise would have been. Using our structural framework, 
we quantify how large this long-run implied rent increase is and quantify the welfare impacts of the rent increase. Here, we show how to derive the implied rent increase in a world populated only with mature renters. Our numbers, however, are based on the full model in which there are both young renters and mature renters. The derivation of the implied rent increase in the full model is provided in Appendix D.

To derive the rent increase, we assume that the world is initially in steady-state. Supposing that the world is populated by only old renters, steady-state requires that the flow of renters into each neighborhood must equal the flow of renters out of that neighborhood, where we again index neighborhoods by $j .{ }^{17}$ Recall that our set of possible locations are all the zipcodes in San Francisco, the larger Bay Area, and the rest of the United States. The steady-state condition takes the form:

$$
N_{j}(1-p(j \mid j))=\sum_{j^{\prime} \neq j} N_{j^{\prime}} p\left(j \mid j^{\prime}\right),
$$

where $N_{j}$ is the steady-state population living in neighborhood $j$ and $p\left(j \mid j^{\prime}\right)$ is the steady-state probability of moving from state $j^{\prime}$ to state $j .{ }^{18}$ Normalizing the size of the population to one, we require that:

$$
\sum_{j} N_{j}=1
$$

Equations (14) and (15) provide a linear system of equations which solves for the steady-state number of people $N_{j}$ living in each location $j$.

As discussed above, our reduced form results indicate that the 1994 rent control expansion led to a San Francisco-wide reduction in supply of $6 \%$. We assume that this proportional decrease in supply was the same across all San Francisco zipcodes. That is, we suppose:

$$
\frac{d \ln N_{j}}{d \Phi}=-.06
$$

for all zipcodes $j$ in San Francisco. Here, $\Phi$ is simply a convenient notation indicating the impact of the supply shock. We further assume that supply is perfectly elastic in the Bay Area and the rest of the United States, so that there is no long-run change in rents in these areas. In particular:

$$
\frac{d \ln R_{j}}{d \Phi}=0
$$

for $j$ not in San Francisco. Our unknowns are the proportional rent increases $d \ln R_{j} / d \Phi$ for all $j$ in San Francisco and the proportional population changes $d \ln N_{j} / d \Phi$ in the areas $j$ outside of San Francisco, i.e. the Bay Area and the rest of the United States.

\footnotetext{
${ }^{17}$ Since the model estimates show that the utility value of neighborhood capital is economically small, we assume it to be zero for these calculations. This collapses the state-space dramatically and only requires us to track tenants ages (young/mature) and neighborhoods.

${ }^{18}$ Note that $p(j \mid j)$ reflects both the probability of staying at the current address and moving to another address within the same zipcode.
} 
As rents change in response to the supply shock, so too will the equilibrium choice probabilities. Intuitively, all else equal, higher rents make an area less desirable and decrease the probability than an individual will choose to move there. Formally, recall that equilibrium choice probabilities are given by:

$$
p(x \mid j)=\frac{\exp (v(x, j))}{\sum_{x^{\prime}} \exp \left(v\left(x^{\prime}, j\right)\right)},
$$

where $x$ denotes the location of choice. Taking the derivative of this equation with respect to a rent change in location $k$, we find that:

$$
\frac{\partial p(x \mid j)}{\partial \ln R_{k}}=p(x \mid j)\left(\frac{\partial v(x, j)}{\partial \ln R_{k}}-\sum_{x^{\prime}} p\left(x^{\prime} \mid j\right) \frac{\partial v\left(x^{\prime}, j\right)}{\partial \ln R_{k}}\right) .
$$

Taking a total derivative of the equilibrium choice probability yields:

$$
\frac{d p(x \mid j)}{d \Phi}=\sum_{k} \frac{\partial p(x \mid j)}{\partial \ln R_{k}} \frac{d \ln R_{k}}{d \Phi} .
$$

We now can see that the change in equilibrium choice probabilities depends in turn on how the equilibrium value functions change as a function of rent increases.

In steady-state, the value of choosing location $x$ conditional on being in location $j$ is given by:

$$
v(x, j)=\bar{u}(x, j)+\beta \ln \left(\sum_{x^{\prime}} \exp \left(v\left(x^{\prime}, j(x)\right)\right)\right)+\beta \Gamma,
$$

where we have applied equation (5) to replace the expected continuation value. The derivative of this conditional value function with respect to an increase in rents at location $j$ is given by:

$$
\frac{\partial v(x, j)}{\partial \ln R_{k}}=\gamma_{M} \exp \left(R_{x}\right) R_{x} 1[x=k]+\beta \sum_{x^{\prime}} p\left(x^{\prime} \mid x\right) \frac{\partial v\left(x^{\prime}, x\right)}{\partial \ln R_{k}}
$$

There is a direct impact of the rent increase on the agent only if the she chooses to move to location $k$ today. Otherwise, the effect is an indirect one, arising from the possibility that the agent will move to location $k$ and thus face the higher rents at some point in the future. Note also that the gradient of the conditional value function with respect to the rent increase is independent of the current location $j$. Equation (18) provides a linear system of equation which can be numerically solved to determine $\partial v(x, j) / \partial \ln R_{k}$ for all possible $x$ and $k$. These value function gradients can then be plugged into equation (16) to numerically determine the response of equilibrium choice probabilities to rent increases $\partial p(x \mid j) / \partial \ln R_{k}$.

To finish the calculation, we take a total derivative of equation (14) with respect to $\Phi$, since, naturally, the steady-state condition must continue to hold at the new long-run equilibrium. Per- 
forming this calculation yields:

$$
\frac{d \ln N_{j}}{d \Phi} N_{j}-\sum_{j^{\prime}} \frac{d \ln N_{j^{\prime}}}{d \Phi} N_{j^{\prime}} p\left(j \mid j^{\prime}\right)=\sum_{j^{\prime}} N_{j^{\prime}} \frac{d p\left(j \mid j^{\prime}\right)}{d \Phi} .
$$

We then use equation (17) to rewrite the change in conditional choice probabilities as a linear function of the rent changes, which yields:

$$
\frac{d \ln N_{j}}{d \Phi} N_{j}-\sum_{j^{\prime}} \frac{d \ln N_{j^{\prime}}}{d \Phi} N_{j^{\prime}} p\left(j \mid j^{\prime}\right)=\sum_{k} \sum_{j^{\prime}} N_{j^{\prime}} \frac{\partial p(j \mid j)}{\partial \ln R_{k}} \frac{d \ln R_{k}}{d \Phi}
$$

We know that $d \ln N_{j} / d \Phi=-.06$ for all zipcodes $j$ in San Francisco and that $d \ln N_{k} / d \Phi=0$ for $k$ equal to either the Bay Area or the rest of the United States. Our final equation is:

$$
\sum_{j \notin S F} \frac{d \ln N_{j}}{d \Phi}=.06 N_{S F}
$$

where $N_{S F}$ is the fraction of the total population which resides in San Francisco in the initial pre-law steady-state. Recall that we have normalized the total population size to one. This equation simply states that the total increase in population outside of San Francisco must equal the total population decrease in San Francisco. Equations (19) and (20) provide a linear system of equations which can be numerically solved to determine the proportional rent increases $d \ln R_{j} / d \Phi$ for zipcodes in San Francisco and the proportional population changes $d \ln N_{j} / d \Phi$ for the Bay Area and the rest of the United States.

Finally, we can decompose the distribution of welfare effects by measuring the changes in the value function of each state, multiplied by the number of tenants in that state at the time of the supply reduction. Summing up this across all states gives the aggregate welfare effects.

\subsubsection{Results}

We find that $6 \%$ decrease in housing supply led to $5.1 \%$ increase in rental prices. We can calculate the change in households' value functions. We next look at the distribution of changes in value functions across households living in SF versus outside. We find that $42 \%$ of the welfare losses due to this rent increase fall on those not living in SF in 1993. These future residents bear the burden of rent control, while the incumbent residents are those who are able to reap rent control's direct rewards. The change in the value function is challenging to put in dollar terms, since an upfront dollar value in units or rent would lead to dramatic increases in the marginal utility of a rental payment. Thus, we opt for an accounting metric to summarize the present discounted value of the

$5.1 \%$ rent increase. Using a typical account discount rate of 0.95 , we find this rent increases has a present discounted value of $\$ 2.9$ billion. To compare this to the direct tenant benefits of rent control, we must also discount those per period payoffs by the same accounting discount rate. The 
tenant benefits from 1995-2012 would be valued at $\$ 2.9$ billion. This is (surprisingly) the same estimate we get for the GE losses due to the city-wide rent increase. These GE welfare losses only account for the increased rents due to the decreased supply of housing. We also found that rent control incentivized landlords to invest in their properties by renovating and building new housing, as well as converting to owner occupancy. These effects likely attached higher income tenants to San Francisco and further raised rents. It appears that the GE losses from the landlords' response to rent control essentially completely undoes the gains accrued to the households that were lucky enough to receive rent control in 1994.

\section{Conclusion}

In this paper, we study the welfare impacts of rent control on its tenant beneficiaries as well as the welfare impacts of landlords' responses. To answer this question, we exploit a unique rent control expansion in San Francisco in 1994 that suddenly provided rent control protections for small multifamily housing built prior to 1980. By combining new panel micro data on individual migration decisions with detailed assessor data on individual SF parcels we get quasi-experimental variation in the assignment of rent control at both the individual tenant level and at the parcel level.

We find that, on average, in the medium to long term the beneficiaries of rent control are between 10 and $20 \%$ more likely to remain at their 1994 address relative to the control group. These effects are significantly stronger among older households and among households that have already spent a number of years at their current address. On the other hand, individuals in areas with quickly rising rents and with few years at their 1994 address are less likely to remain at their current address, consistent with the idea that landlords try to remove tenants when the reward is high, through either eviction or negotiated payments.

We find that landlords actively respond to the imposition of rent control by converting their properties to condos and TICs or by redeveloping the building in such as a way as to exempt it from the regulations. In sum, we find that impacted landlords reduced the supply the available rental housing by $15 \%$. Consistent with this evidence, we find that there was a $20 \%$ decline in the number of renters living in impacted buildings, relative to 1990-1994 levels, and a 30\% decline in the number of renters living in units protected by rent control.

We develop a dynamic, structural model of neighborhood choice to translate our reduced form impacts into welfare impacts. A key contribution of the paper is to show how quasi-experimental evidence can be leveraged to estimate a dynamic discrete choice model. We find that rent control offered large benefits to impacted tenants during the 1995-2012 period, averaging between $\$ 2300$ and $\$ 6600$ per person each year, with aggregate benefits totaling over $\$ 214$ million annually. Over the entire period, tenants received a discounted value of around $\$ 2.9$ billion. We find that most of 
these benefits came from protection against rent increases and transfer payments from landlords. However, we find losses to all renters of $\$ 2.9$ billion due to rent control's effect on decreasing the rental housing and raising market rents. Further, $42 \%$ of these losses are born by future residents of San Francisco, making them worse off, while incumbent residents benefit on net.

These results highlight that forcing landlords to provided insurance against rent increases leads to large losses to tenants. If society desires to provide social insurance against rent increases, it would less distortionary to offer this subsidy in the form of a government subsidy or tax credit. This would remove landlords' incentives to decrease the housing supply and could provide household with the insurance they desire. A point of future research would be to design an optimal social insurance program to insure renters against large rent increases.

\section{References}

Arcidiacono, Peter and Paul B. Ellickson, "Practical Methods for Estimation of Dynamic Discrete Choice Models," Annual Review of Economics, 2011, 3 (1), 363-394.

_ and Robert A. Miller, "Conditional Choice Probability Estimation of Dynamic Discrete Choice Models With Unobserved Heterogeneity," Econometrica, November 2011, 79 (6), 1823-1867.

Autor, David H, Christopher J Palmer, and Parag A Pathak, "Housing Market Spillovers: Evidence from the End of Rent Control in Cambridge, Massachusetts," Journal of Political Economy, 2014, 122 (3), 661-717.

Bayer, Patrick, Robert McMillan, Alvin Murphy, and Christopher Timmins, "A Dynamic Model of Demand for Houses and Neighborhoods," Econometrica, May 2016, 84 (3), 893-942.

Bishop, Kelly C. and Alvin D. Murphy, "Estimating the Willingness to Pay to Avoid Violent Crime: A Dynamic Approach," American Economic Review, May 2011, 101 (3), 625-629.

Davis, Morris A., Jess Gregory, Daniel A. Hartley, and Kegon Teng Kok Tan, "Neighborhood Choices, Neighborhood Effects and Housing Vouchers," 2017.

Downs, Anthony, "Residential Rent Controls," Washington, DC: Urban Land Institute, 1988.

Early, Dirk W., "Rent Control, Rental Housing Supply, and the Distribution of Tenant Benefits," Journal of Urban Economics, September 2000, 48 (2), 185-204.

Glaeser, Edward L and Erzo FP Luttmer, "The Misallocation of Housing under Rent Control," The American Economic Review, 2003, 93 (4), 1027-1046.

Groote, Olivier De and Frank Verboven, "Subsidies and Myopia in Technology Adoption: Evidence from Solar Photovoltaic Systems," SSRN Scholarly Paper ID 2827556, Social Science Research Network, Rochester, NY August 2016.

Gyourko, Joseph and Peter Linneman, "Equity and Efficiency Aspects of Rent Control: An Empirical Study of New York City," Journal of urban Economics, 1989, 26 (1), 54-74.

_ and _, "Rent Controls and Rental Housing Quality: A Note on the Effects of New York City's Old Controls," Journal of Urban Economics, May 1990, 27 (3), 398-409.

Hotz, V. Joseph and Robert A. Miller, "Conditional Choice Probabilities and the Estimation of Dynamic Models," The Review of Economic Studies, 1993, 60 (3), 497-529.

Kasarda, John D. and Morris Janowitz, "Community Attachment in Mass Society," American Sociological Review, 1974, 39 (3), 328-339. 
Kennan, John and James R. Walker, "The Effect of Expected Income on Individual Migration Decisions," Econometrica, January 2011, 79 (1), 211-251.

Moon, Choon-Geol and Janet G. Stotsky, "The Effect of Rent Control on Housing Quality Change: A Longitudinal Analysis," Journal of Political Economy, December 1993, 101 (6), 1114-1148.

Murphy, Alvin, "A Dynamic Model of Housing Supply," SSRN Scholarly Paper ID 2200459, Social Science Research Network, Rochester, NY February 2017.

Olsen, Edgar O, "An Econometric Analysis of Rent Control," Journal of Political Economy, 1972, 80 (6), 1081-1100.

Scott, Paul T., "Dynamic Discrete Choice Estimation of Agricultural Land Use," Toulouse School of Economics Working Paper, 2013, 526.

Sims, David P, "Out of Control: What Can We Learn from the End of Massachusetts Rent Control?," Journal of Urban Economics, 2007, 61 (1), 129-151.

_ , "Rent Control Rationing and Community Composition: Evidence from Massachusetts," The BE Journal of Economic Analysis 85 Policy, 2011, 11 (1). 
Table 1: Sample Characteristics of Multi-Family Properties (2-4 Units) and their Tenants

A. Tenants Living in Multi-Family Residence (2-4 Units)

\begin{tabular}{|c|c|c|c|c|}
\hline & \multicolumn{2}{|c|}{$1990-1993$} & \multicolumn{2}{|c|}{ 1994-2016 } \\
\hline & Treat & Control & Treat & Control \\
\hline $\begin{array}{l}\text { A1. Demographics } \\
\text { Age in } 1993\end{array}$ & $\begin{array}{c}37.708 \\
(10.438)\end{array}$ & $\begin{array}{c}37.120 \\
(10.639)\end{array}$ & $\begin{array}{c}37.708 \\
(10.438)\end{array}$ & $\begin{array}{c}37.120 \\
(10.639)\end{array}$ \\
\hline $\begin{array}{l}\text { A2. Residency } \\
\text { In SF }\end{array}$ & $\begin{array}{c}0.954 \\
(0.210)\end{array}$ & $\begin{array}{c}0.954 \\
(0.210)\end{array}$ & $\begin{array}{c}0.569 \\
(0.495)\end{array}$ & $\begin{array}{c}0.538 \\
(0.499)\end{array}$ \\
\hline Same Zipcode & $\begin{array}{l}0.895 \\
(0.307)\end{array}$ & $\begin{array}{c}0.890 \\
(0.313)\end{array}$ & $\begin{array}{l}0.337 \\
(0.473)\end{array}$ & $\begin{array}{l}0.308 \\
(0.462)\end{array}$ \\
\hline Same Address & $\begin{array}{c}0.870 \\
(0.336)\end{array}$ & $\begin{array}{l}0.867 \\
(0.340)\end{array}$ & $\begin{array}{c}0.261 \\
(0.439)\end{array}$ & $\begin{array}{c}0.240 \\
(0.427)\end{array}$ \\
\hline Years at Address & $\begin{array}{l}6.015 \\
(3.958)\end{array}$ & $\begin{array}{l}5.825 \\
(3.927)\end{array}$ & $\begin{array}{c}6.590 \\
(5.898)\end{array}$ & $\begin{array}{l}6.267 \\
(5.530)\end{array}$ \\
\hline No. Persons & 44502 & 1861 & 44502 & 1861 \\
\hline \multicolumn{5}{|c|}{ B. Multi-Family Properties (2-4 Units) } \\
\hline $\begin{array}{l}\text { B1. Residency } \\
\text { Vacant }\end{array}$ & $\begin{array}{c}0.123 \\
(0.328)\end{array}$ & $\begin{array}{c}0.107 \\
(0.309)\end{array}$ & $\begin{array}{c}0.099 \\
(0.299)\end{array}$ & $\begin{array}{c}0.098 \\
(0.297)\end{array}$ \\
\hline \multicolumn{5}{|l|}{ B2. Population } \\
\hline Population/Avg Pop 90-94 & $\begin{array}{c}0.898 \\
(0.436)\end{array}$ & $\begin{array}{c}0.905 \\
(0.426)\end{array}$ & $\begin{array}{c}2.282 \\
(4.029)\end{array}$ & $\begin{array}{l}2.252 \\
(2.998)\end{array}$ \\
\hline Renters/Avg Pop 90-94 & $\begin{array}{c}0.741 \\
(0.484)\end{array}$ & $\begin{array}{c}0.737 \\
(0.482)\end{array}$ & $\begin{array}{l}1.680 \\
(3.555)\end{array}$ & $\begin{array}{l}1.700 \\
(2.517)\end{array}$ \\
\hline $\begin{array}{l}\text { Renters in Rent-Controlled } \\
\text { Buildings/Avg Pop 90-94 }\end{array}$ & $\begin{array}{c}0.741 \\
(0.484)\end{array}$ & $\begin{array}{l}0.737 \\
(0.482)\end{array}$ & $\begin{array}{c}1.404 \\
(1.927)\end{array}$ & $\begin{array}{l}1.570 \\
(2.053)\end{array}$ \\
\hline $\begin{array}{l}\text { Renters in Redeveloped } \\
\text { Buildings /Avg Pop 90-94 }\end{array}$ & $\begin{array}{c}0 \\
(0)\end{array}$ & $\begin{array}{c}0 \\
(0)\end{array}$ & $\begin{array}{l}0.129 \\
(0.740)\end{array}$ & $\begin{array}{c}0.060 \\
(0.541)\end{array}$ \\
\hline Owners/Avg Pop 90-94 & $\begin{array}{c}0.157 \\
(0.329)\end{array}$ & $\begin{array}{c}0.168 \\
(0.335)\end{array}$ & $\begin{array}{c}0.602 \\
(1.581)\end{array}$ & $\begin{array}{c}0.552 \\
(1.348)\end{array}$ \\
\hline \multicolumn{5}{|l|}{ B3. Permits } \\
\hline Cumulative Add/Alter/Repair per Unit & $\begin{array}{c}0.072 \\
(0.231)\end{array}$ & $\begin{array}{c}0.088 \\
(0.287)\end{array}$ & $\begin{array}{c}0.290 \\
(0.511)\end{array}$ & $\begin{array}{c}0.254 \\
(0.536)\end{array}$ \\
\hline Ever Received Add/Alter/Repair & $\begin{array}{c}0.127 \\
(0.333)\end{array}$ & $\begin{array}{c}0.137 \\
(0.344)\end{array}$ & $\begin{array}{c}0.375 \\
(0.484)\end{array}$ & $\begin{array}{c}0.315 \\
(0.464)\end{array}$ \\
\hline No. Parcels & 25925 & 892 & 25925 & 892 \\
\hline
\end{tabular}

Notes: Panel A reports the mean and standard deviation (in parentheses) of demographic characteristics and residency outcomes during 1990 - 2016 of our tenant sample. The sample consists of all tenants between 20 and 65 years old living in San Francisco as of December 31, 1993 and in multi-family residences with 2-4 units that were built during 1900 - 1990. Panel B reports the mean and standard deviation (in parentheses) of outcomes variables related to residency, population changes and permit issuance during $1990-2016$ of our property sample. The sample consists of all parcels that are multi-family residence with 2-4 units in San Francisco that were built during $1900-1990$. 
Table 2: Treatment Effect for Tenants of Multi-Family Residence (2-4 Units)

\begin{tabular}{lccc}
\hline & $(1)$ & $(2)$ & $(3)$ \\
& In SF & Same Zip & Same Address \\
\hline Treat× Period & & & \\
1994-1999 & 0.0200 & 0.0226 & 0.0218 \\
& $(0.0081)$ & $(0.0087)$ & $(0.0083)$ \\
$2000-2004$ & 0.0451 & 0.0355 & 0.0354 \\
& $(0.0115)$ & $(0.0104)$ & $(0.0088)$ \\
Post 2005 & 0.0366 & 0.0302 & 0.0147 \\
& $(0.0109)$ & $(0.0084)$ & $(0.0063)$ \\
\hline Control Mean 1994-1999 & 0.7641 & 0.5971 & 0.5410 \\
Control Mean 2000-2004 & 0.5138 & 0.2672 & 0.1827 \\
Control Mean Post 2005 & 0.4346 & 0.1801 & 0.1135 \\
Adjusted $R^{2}$ & 0.600 & 0.630 & 0.655 \\
Observations & 1251747 & 1251747 & 1251747 \\
\hline
\end{tabular}

Notes: Sample consists of all tenants between 20 and 65 years old living in San Francisco as of December 31, 1993 and in multi-family residences with 2-4 units that were built during $1900-1990$. Table reports the mean of dependent variables for the control group during 1990 - 1994, 2000 - 2004 and post-2005. Standard errors are clustered at the person level. 
Table 3: Model Estimates

A. Parameter Estimates in 2010 Dollars

\begin{tabular}{|c|c|c|c|c|c|c|c|}
\hline \multicolumn{2}{|c|}{ St Dev of Logit Shocks } & \multicolumn{2}{|c|}{ Tenant Buyouts } & \multicolumn{2}{|c|}{ Moving Costs } & \multicolumn{2}{|c|}{ Neighborhood Capital } \\
\hline Young Renters & $\begin{array}{l}7441.178 \\
(1278.596)\end{array}$ & $\begin{array}{l}\text { In Below Market Rent } \\
\text { (Young Renters) }\end{array}$ & $\begin{array}{c}1.631 \\
(0.092)\end{array}$ & $\begin{array}{l}\text { Fixed Cost } \\
\text { (Young Renters) }\end{array}$ & $\begin{array}{c}42626.11 \\
(4776.017)\end{array}$ & Young Renters & $\begin{array}{l}265.795 \\
(52.9889)\end{array}$ \\
\hline & & Years in Zipcode & 164.222 & MC per ln Mile & 11426.11 & & \\
\hline & & (Old Renters) & $(90.99)$ & (Old Renters) & $(1437.622)$ & & \\
\hline & & Old Renter-Direct effect & 70702.05 & $\Delta \mathrm{MC}$ wrt Yrs in Zip & -415.607 & & \\
\hline & & & $(12339.43)$ & (Young Renters) & $(74.24046)$ & & \\
\hline & & & & $\Delta \mathrm{MC}$ wrt Yrs in Zip & -357.6618 & & \\
\hline & & & & (Old Renters) & $(57.12502)$ & & \\
\hline
\end{tabular}

B. Demand Semi-Elasticities to Remain in Home with respect to 1 year Temporary Changes

\begin{tabular}{|c|c|c|c|c|c|c|c|}
\hline \multicolumn{2}{|c|}{ ln Rent } & \multicolumn{2}{|c|}{ Tenant Buyouts } & \multicolumn{2}{|c|}{ Moving Costs } & \multicolumn{2}{|c|}{ Neighborhood Capital } \\
\hline Young Renters & $\begin{array}{l}-0.210 \\
(0.040)\end{array}$ & $\begin{array}{l}\text { In Below Market Rent } \\
\text { (Young Renters) }\end{array}$ & $\begin{array}{l}-0.327 \\
(0.068)\end{array}$ & $\begin{array}{l}\text { Fixed Cost } \\
\text { (Young Renters) }\end{array}$ & $\begin{array}{c}0.580 \\
(0.003)\end{array}$ & Young Renters & $\begin{array}{l}0.0019 \\
(0.00007)\end{array}$ \\
\hline Old Renters & $\begin{array}{l}-0.244 \\
(0.041)\end{array}$ & $\begin{array}{l}\text { In Below Market Rent } \\
\text { (Old Renters) } \\
\text { Years in Zipcode } \\
\text { (Young Renters) } \\
\text { Years in Zipcode } \\
\text { (Old Renters) } \\
\text { Old Renter-Direct effect }\end{array}$ & $\begin{array}{c}-0.327 \\
(0.068) \\
-0.0012 \\
(0.0008) \\
-0.0012 \\
(0.0008) \\
-0.583 \\
(0.0082)\end{array}$ & $\begin{array}{l}\text { Fixed Cost } \\
\text { (Old Renters) } \\
\text { MC per Mile } \\
\text { (Young Renters) } \\
\text { MC per Mile } \\
\text { (Old Renters) } \\
\Delta \text { MC wrt Yrs in Zip } \\
\text { (Young Renters) } \\
\Delta \text { MC wrt Yrs in Zip } \\
\text { (Old Renters) }\end{array}$ & $\begin{array}{c}0.580 \\
(0.003) \\
0.095 \\
(0.005) \\
0.096 \\
(0.005) \\
-0.003 \\
(-0.0002) \\
-0.003 \\
(-0.0002)\end{array}$ & Old Renters & $\begin{array}{l}0.0024 \\
(0.00008)\end{array}$ \\
\hline
\end{tabular}

Notes: Table reports the parameter estimates of the model. Panel A reports the parameters measured in rent equivalent dollar units, with the exception of the transfer payments, which are measured in actual dollars. Panel B reports the estimates in units of migration elasticities. Standard errors are clustered at zipcode level. 
Table 4: Welfare Effects of 1994 Rent-Controlled Cohort in 2010 Dollars

\begin{tabular}{|c|c|c|c|c|c|c|c|c|c|}
\hline & \multicolumn{3}{|c|}{$1995-2003$} & \multicolumn{3}{|c|}{$2004-2012$} & \multicolumn{3}{|c|}{$1995-2012$} \\
\hline & Cumulative & Per Year & Share & Cumulative & Per Year & Share & Cumulative & Per Year & Share \\
\hline Rent & 30,285 & 3,365 & $40.6 \%$ & 22,644 & 2,516 & $50.1 \%$ & 52,929 & 2,940 & $44.2 \%$ \\
\hline Payoff & 25,560 & 2,840 & $34.3 \%$ & 10,511 & 1,168 & $23.2 \%$ & 36,071 & 2,004 & $30.1 \%$ \\
\hline Neighborhood Capital & 812 & 90 & $1.1 \%$ & 583 & 65 & $1.3 \%$ & 1,395 & 77 & $1.2 \%$ \\
\hline Fixed Moving Cost & 8,125 & 903 & $10.9 \%$ & 1,352 & 150 & $3.0 \%$ & 9,477 & 526 & $7.9 \%$ \\
\hline Distance of Moves & 3,857 & 429 & $5.2 \%$ & 2,827 & 314 & $6.3 \%$ & 6,684 & 371 & $5.6 \%$ \\
\hline Amenity & -42 & -5 & $-0.1 \%$ & -276 & -31 & $-0.6 \%$ & -318 & -18 & $-0.3 \%$ \\
\hline Logit Shock & 6,026 & 670 & $8.1 \%$ & 7,575 & 842 & $16.8 \%$ & 13,600 & 756 & $11.3 \%$ \\
\hline Total per Person & 74,622 & 8,291 & & 45,216 & 5,024 & & 119,837 & 6,658 & \\
\hline \multicolumn{10}{|c|}{ B. Young Residents (Age 20-39) } \\
\hline & \multicolumn{3}{|c|}{$1995-2003$} & \multicolumn{3}{|c|}{$2004-2012$} & \multicolumn{3}{|c|}{$1995-2012$} \\
\hline & Cumulative & Per Year & Share & Cumulative & Per Year & Share & Cumulative & Per Year & Share \\
\hline Rent & 20,782 & 2,309 & $63.1 \%$ & 11,940 & 1,327 & $146.3 \%$ & 32,722 & 1,818 & $79.6 \%$ \\
\hline Payoff & 12,537 & 1,393 & $38.0 \%$ & 6,113 & 679 & $74.9 \%$ & 18,650 & 1,036 & $45.4 \%$ \\
\hline Neighborhood Capital & 431 & 48 & $1.3 \%$ & 750 & 83 & $9.2 \%$ & 1,181 & 66 & $2.9 \%$ \\
\hline Fixed Moving Cost & 3,741 & 416 & $11.3 \%$ & $-1,643$ & -183 & $-20.1 \%$ & 2,098 & 117 & $5.1 \%$ \\
\hline Distance of Moves & 1,655 & 184 & $5.0 \%$ & -949 & -105 & $-11.6 \%$ & 706 & 39 & $1.7 \%$ \\
\hline Amenity & 243 & 27 & $0.7 \%$ & 829 & 92 & $10.2 \%$ & 1,073 & 60 & $2.6 \%$ \\
\hline Logit Shock & $-6,428$ & -714 & $-19.5 \%$ & $-8,879$ & -987 & $-108.8 \%$ & $-15,308$ & -850 & $-37.2 \%$ \\
\hline Total per Person & 32,960 & 3,662 & & 8,162 & 907 & & 41,121 & 2,285 & \\
\hline \multicolumn{10}{|c|}{ C. SF Aggregate (Millions) } \\
\hline & \multicolumn{3}{|c|}{$1995-2003$} & \multicolumn{3}{|c|}{ 2004-2012 } & \multicolumn{3}{|c|}{$1995-2012$} \\
\hline & Cumulative & Per Year & Share & Cumulative & Per Year & Share & Cumulative & Per Year & Share \\
\hline Old & 1567 & 174 & $59.4 \%$ & 949 & 105 & $78.1 \%$ & 2516 & 140 & $65.3 \%$ \\
\hline Young & 1072 & 119 & $40.6 \%$ & 266 & 30 & $21.9 \%$ & 1338 & 74 & $34.7 \%$ \\
\hline All & 2639 & 293 & & 1215 & 135 & & 3854 & 214 & \\
\hline Present Discounted Value & 2246 & & & 611 & & & 2857 & & \\
\hline
\end{tabular}

Notes: Table decomposes the welfare impacts of the 1994 rent control law change on the treatment group into different channels, relative to the control group. Using the model, we find a difference-in-difference treatment effect in average rent paid, transfers received from landlords, accumulated neighborhood capital, fixed moving costs, variable moving costs, and neighborhood amenity values. With the marginal utility of each of those characteristics, we convert treatment effects into dollar units. For details on estimating the treatment effect due to idiosyncratic match values, refer to equation (24). Cumulative sums represent undiscounted sums. Shares represent what share of welfare impacts is attributed to each characteristics of the utility function. SF aggregate numbers represent the welfare impact by aggregating over the 1994 households of renters impacted by the rent control expansion, which are calculated from the $19905 \%$ Census. Present discounted values of the aggregate benefits are calculated using a discount factor of 0.95 . 
Figure 1: Treatment Effect for Tenants in Multi-Family Residence (2-4 Units)

(a) Staying at Same Address

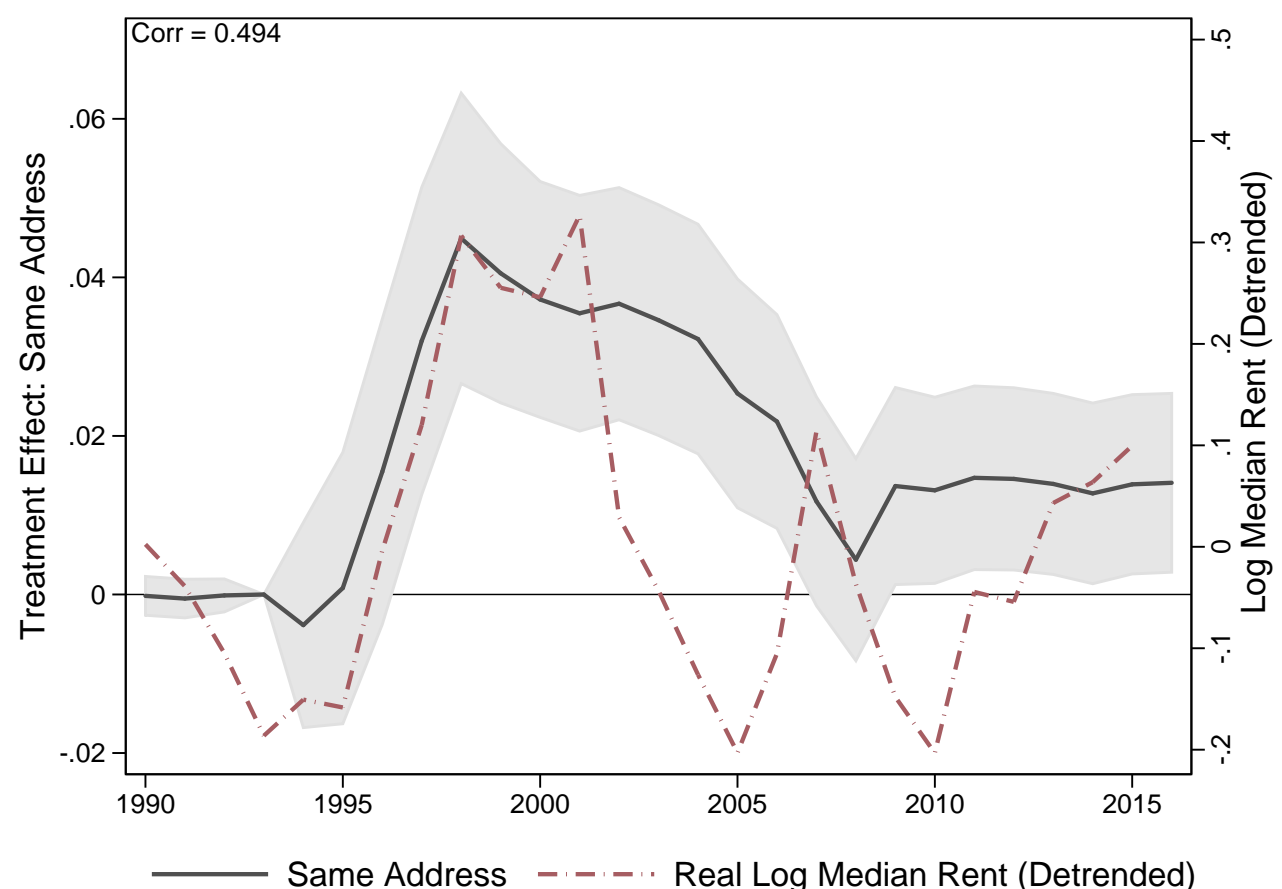

(b) Staying in San Francisco

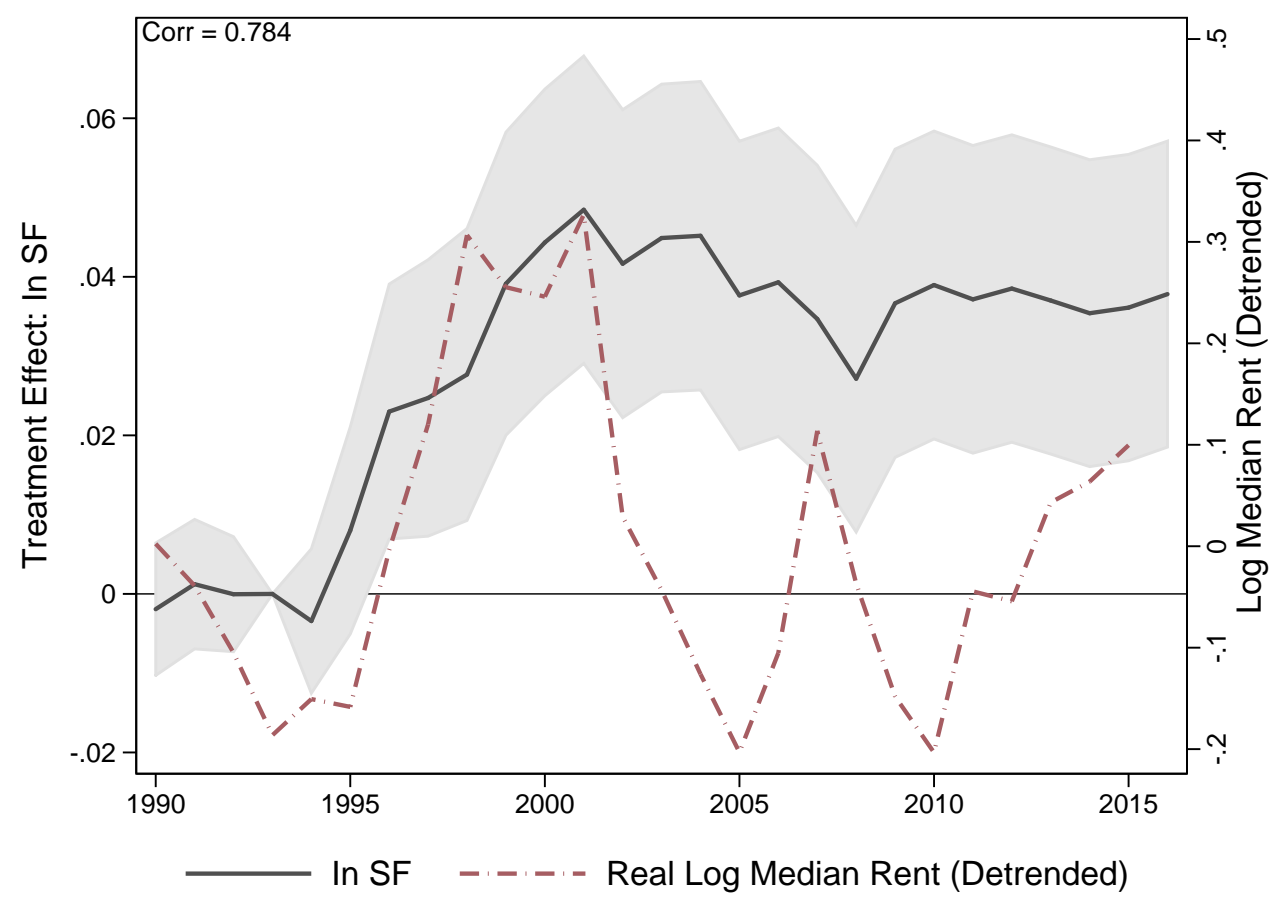

Notes: Sample consists of all tenants between 20 and 65 years old living in San Francisco as of December 31, 1993 and in multi-family residences with 2-4 units that were built during $1900-1990$. Standard errors are clustered at the person level. 
Figure 2: Heterogeneity by Age and Tenure in Treatment Effect for Tenants of Multi-Family Residence (2-4 Units) with High Rent Appreciation

(a) Young and High Turnover

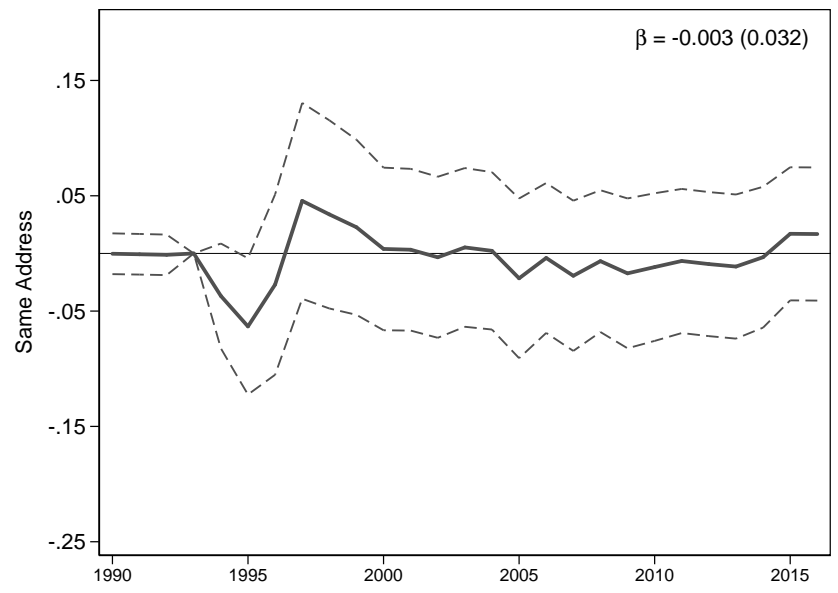

(c) Old and High Turnover

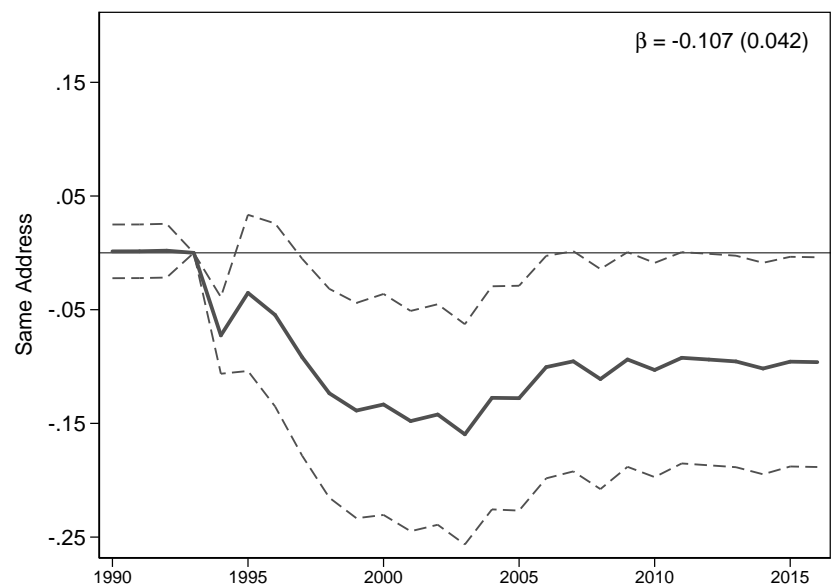

(b) Young and Low Turnover

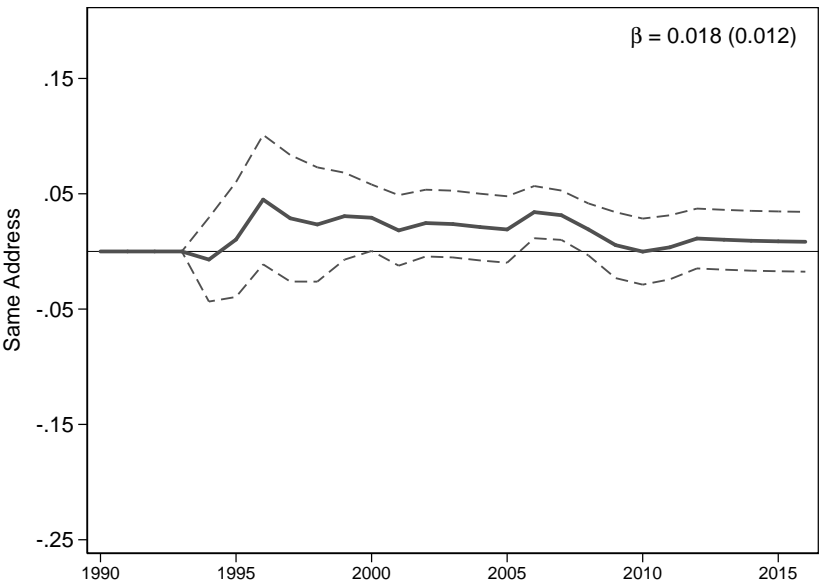

(d) Old and Low Turnover

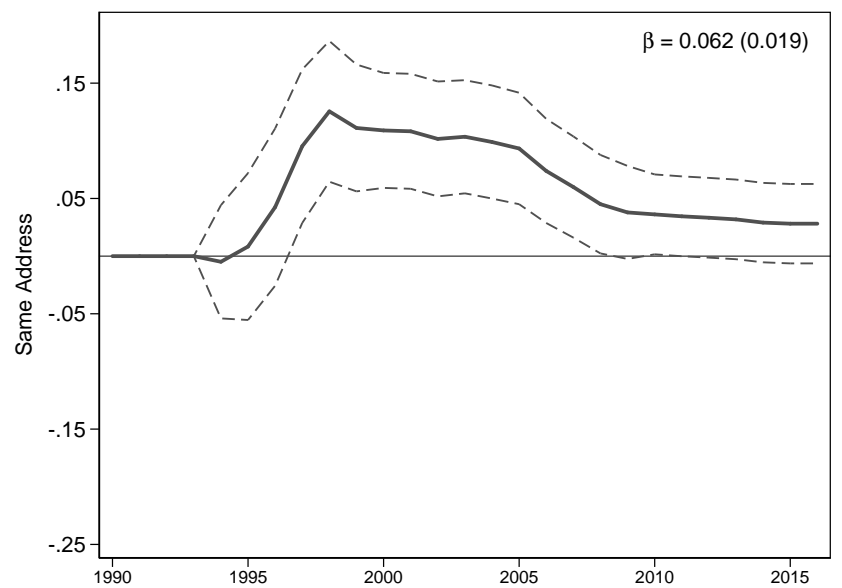

Notes: Sample consists of all tenants between 20 and 65 years old living in San Francisco as of December 31, 1993 and in multi-family residences with 2-4 units that were built during $1900-1990$. We first divide individuals into two groups by whether their 1993 census tract experienced above or below median rent appreciation during 1990-2000, and restrict our sample to individuals living in census tracts that experienced high rent appreciation. We further sort the sample by age group. The young group refers to residents who were aged 20-39 in 1993 and the old group are residents who were aged 40-65 in 1993. Finally, we cut the data by number of years the individual has been living at their 1993 address. We define a "low turnover" group of individuals who had been living at their 1993 address for greater than or equal to four years and a "high turnover" group of individuals who had been living at their address for less than four years. The treatment effects along with $90 \%$ CI are plotted. Standard errors are clustered at the person level. The average treatment effects in the post-1994 period and their standard errors are reported in the upper-right corner. 
Figure 3: Heterogeneity by Age and Tenure in Treatment Effect for Tenants of Multi-Family Residence (2-4 Units) with Low Rent Appreciation

(a) Young and High Turnover

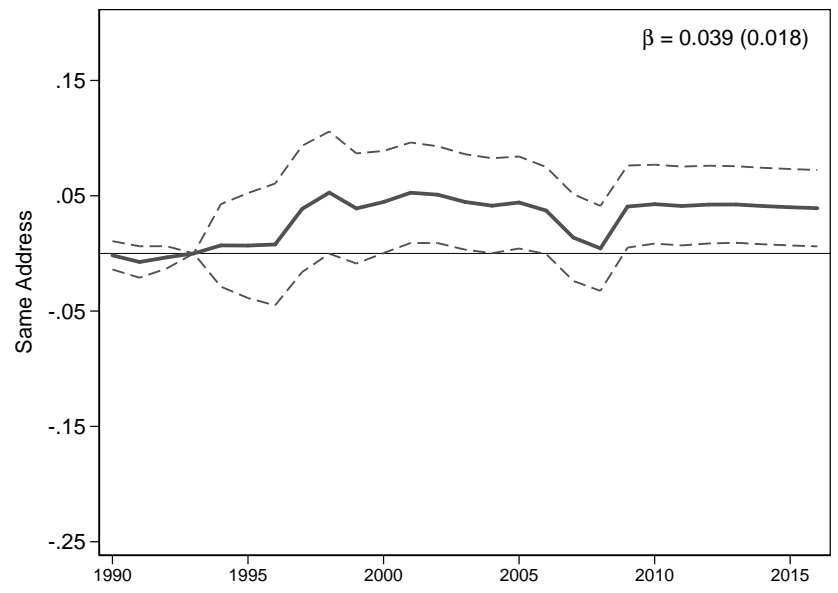

(c) Old and High Turnover

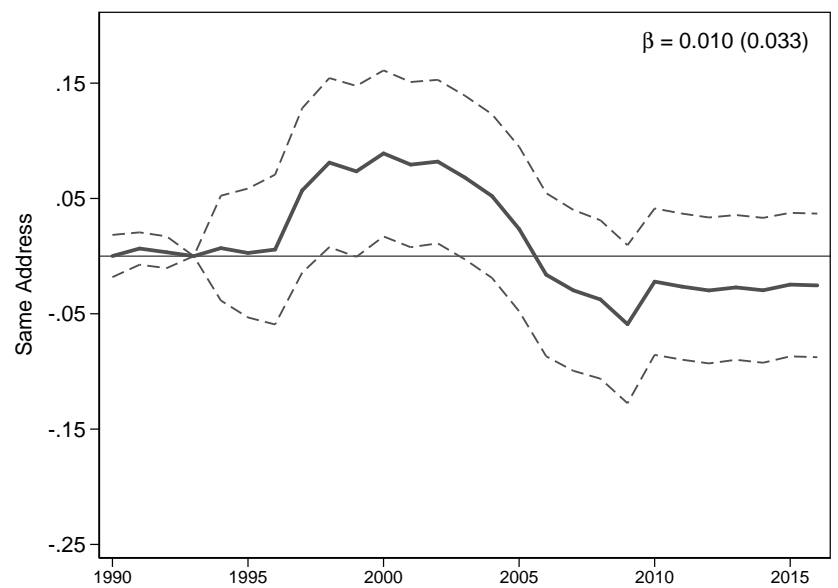

(b) Young and Low Turnover

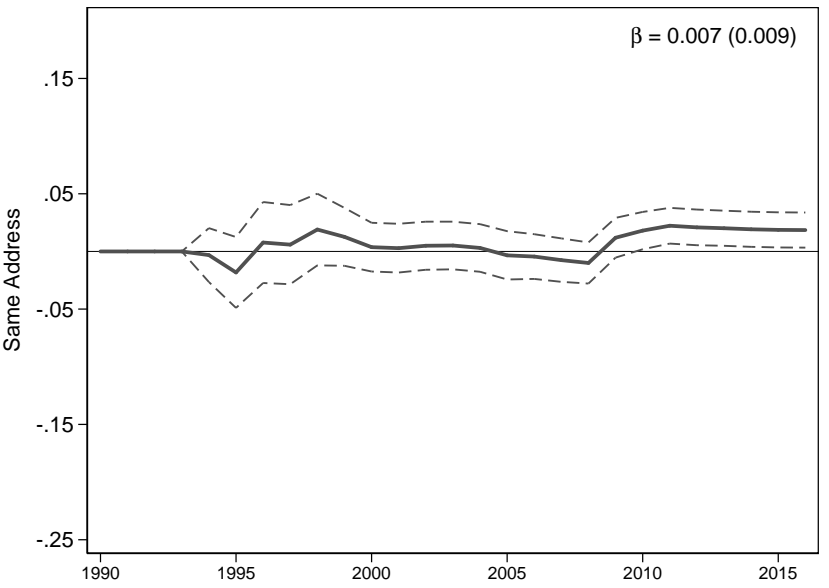

(d) Old and Low Turnover

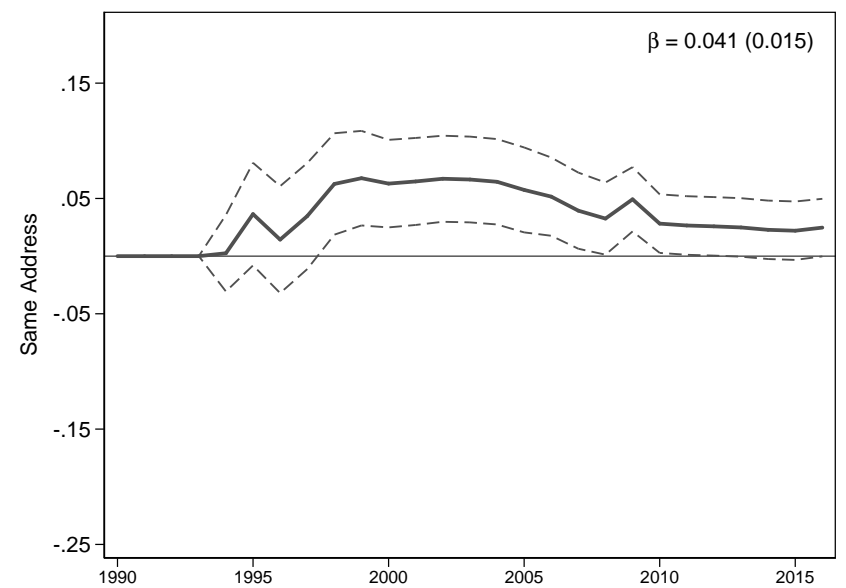

Notes: Sample consists of all tenants between 20 and 65 years old living in San Francisco as of December 31, 1993 and in multi-family residences with 2-4 units that were built during 1900-1990. We first divide individuals into two groups by whether their 1993 census tract experienced above or below median rent appreciation during 1990-2000, and restrict our sample to individuals living in census tracts that experienced low rent appreciation. We further sort the sample by age group. The young group refers to residents who were aged 20-39 in 1993 and the old group are residents who were aged 40-65 in 1993. Finally, we cut the data by number of years the individual has been living at their 1993 address. We define a "low turnover" group of individuals who had been living at their 1993 address for greater than or equal to four years and a "high turnover" group of individuals who had been living at their address for less than four years. The treatment effects along with $90 \%$ CI are plotted. Standard errors are clustered at the person level. The average treatment effects in the post-1994 period and their standard errors are reported in the upper-right corner. 
Figure 4: Treatment Effect on Neighborhood Quality for Tenants of Multi-Family Residence (2-4 Units)

(a) True Treatment Effect
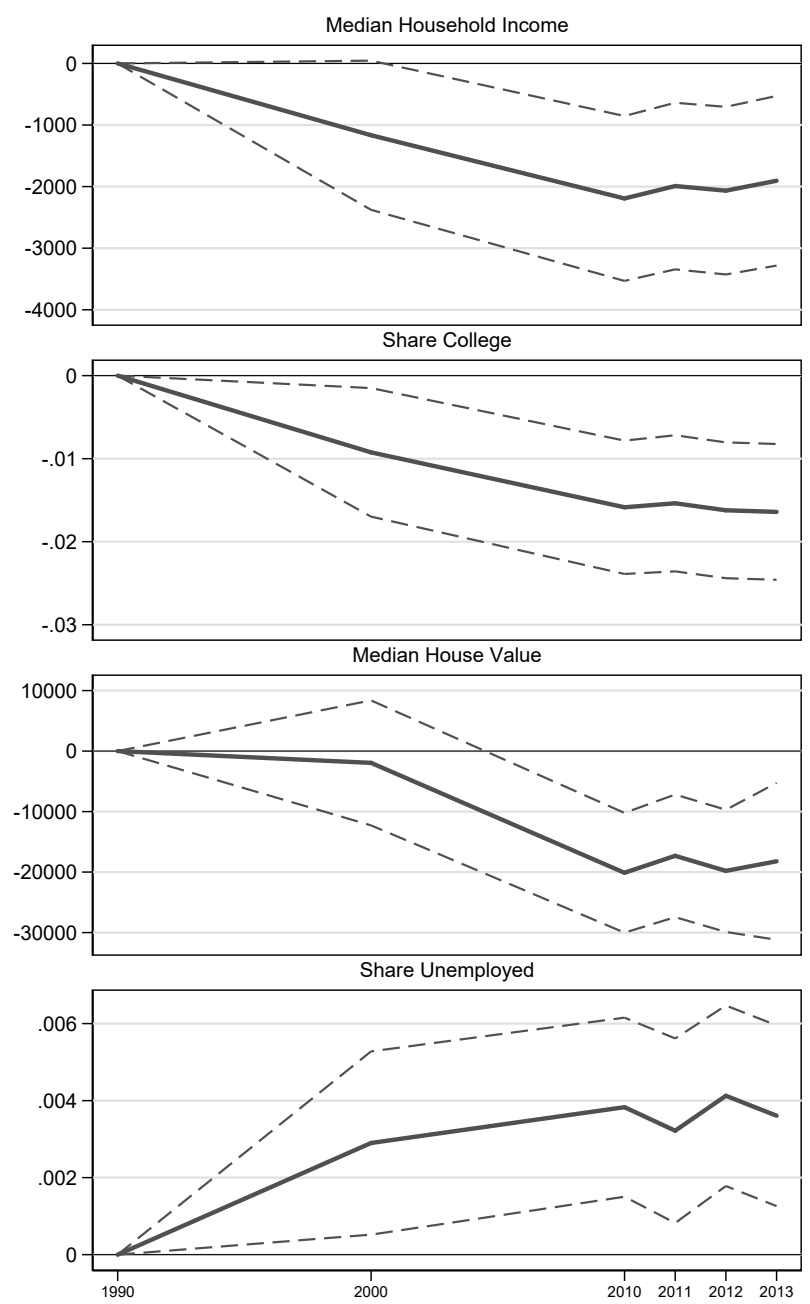

(b) Placebo Treatment Effect
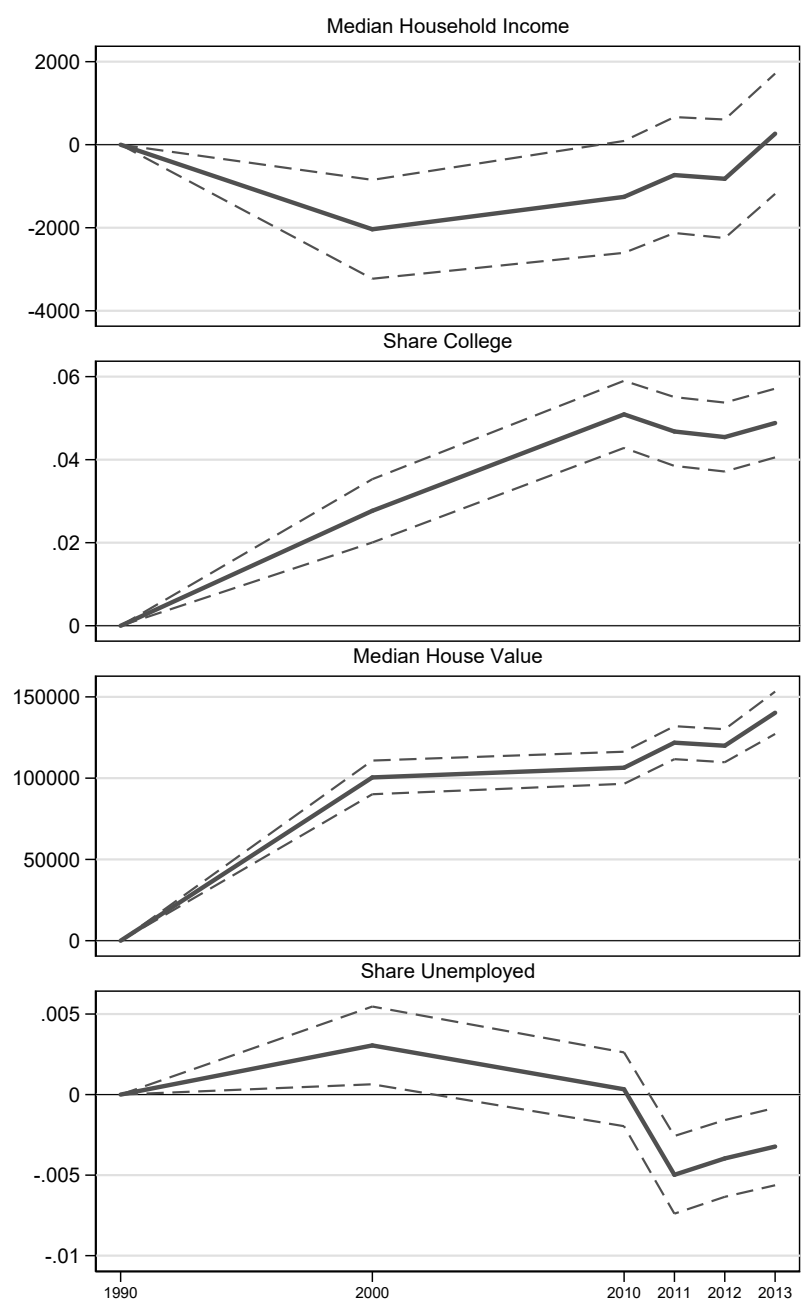

Notes: Sample consists of all tenants between 20 and 65 years old living in San Francisco as of December 31, 1993 and in multi-family residences with 2-4 units that were built during $1900-1990$. Median household income, share of residents with college education and above, median house value, and share of unemployed are measured in the census tract that an individual is living in a given year. Panel (a) plots the true treatment effects for various proxies of neighborhood quality. Panel (b) plots the placebo treatment effects where we assume those treated by rent control remain at their 1993 addresses, but allow the control group to migrate as seen in the data. The treatment effects along with $90 \%$ CI are plotted. Standard errors are clustered at the person level. 
Figure 5: Treatment Effect for Multi-Family Residence (2-4 Units)

(a) Population/Average Population 1990-1994

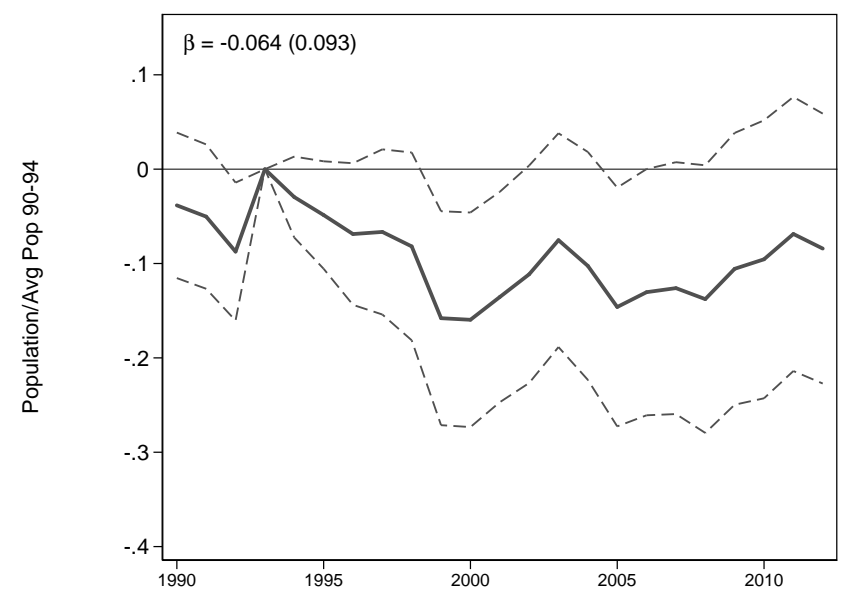

(c) Owners/Average Population 1990-1994

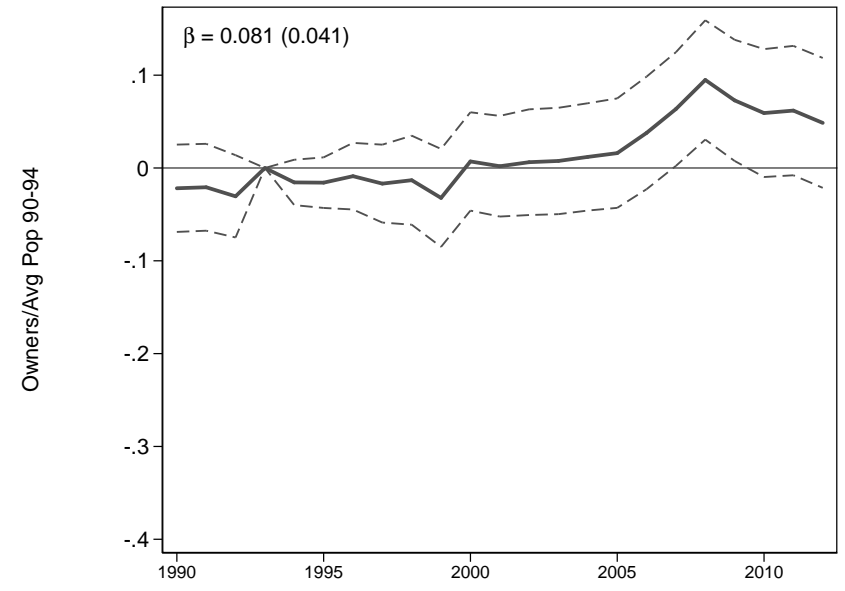

(b) Renters/Average Population 1990-1994

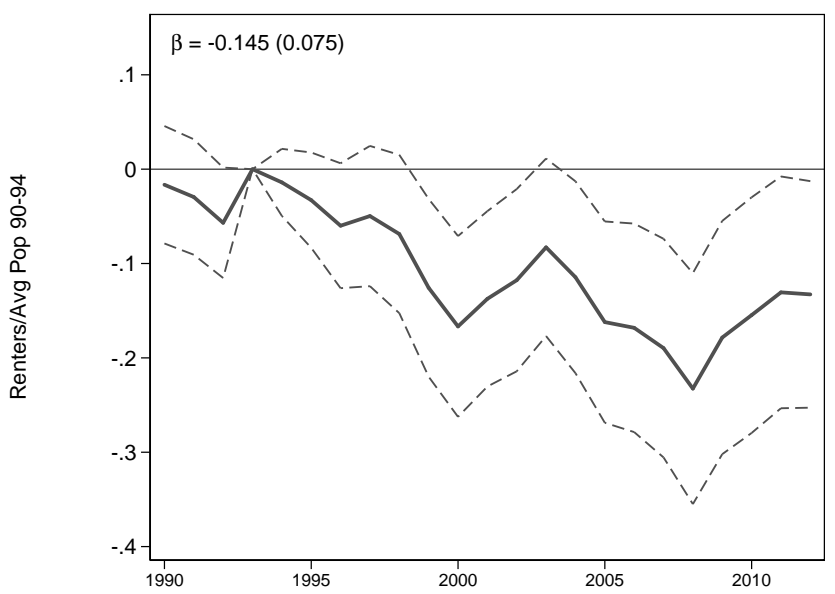

(d) Vacancy

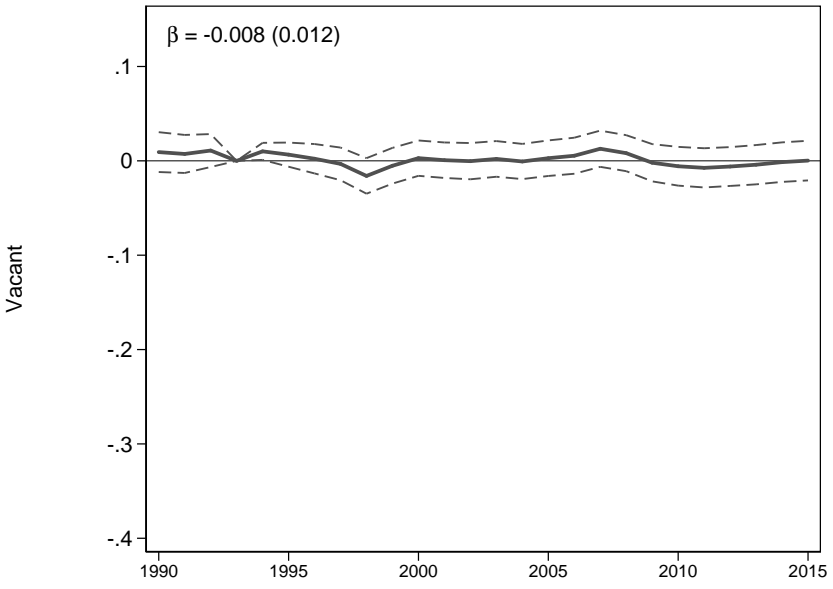

Notes: Sample consists of all multi-family residences with 2-4 units in San Francisco that were built during $1900-$ 1990. The treatment effects along with $90 \%$ CI are plotted. Standard errors are clustered at the parcel level. The average treatment effects in the post-2006 period and their standard errors are reported in the upper-left corner. 
Figure 6: Treatment Effect for Multi-Family Residence (2-4 Units)

(a) Renters in Rent-Controlled Buildings/Average

Population 1990-1994

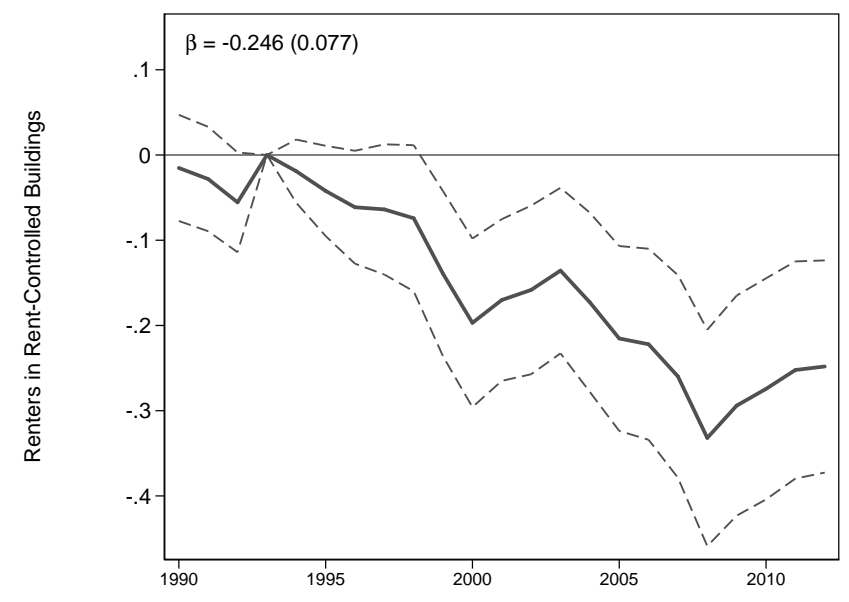

(c) Conversion

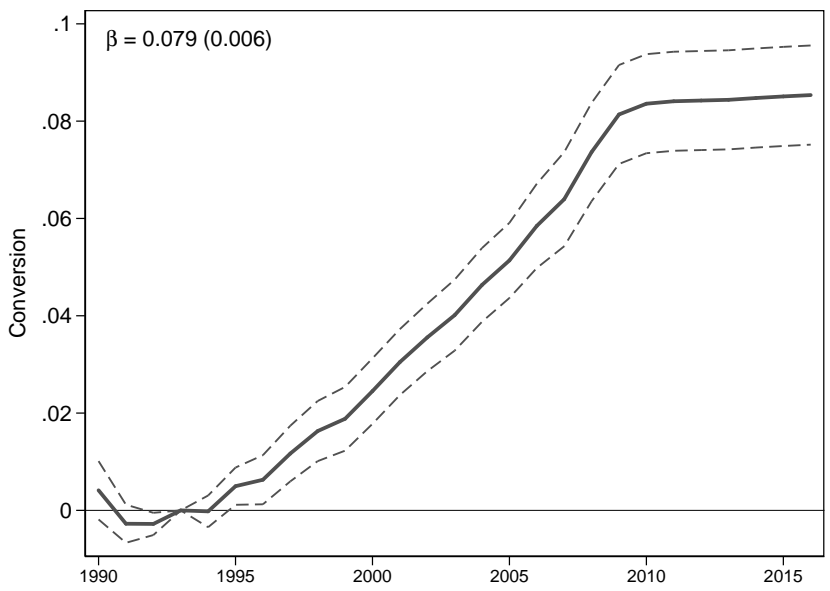

(b) Renters in Redeveloped Buildings/Average Population 1990-1994

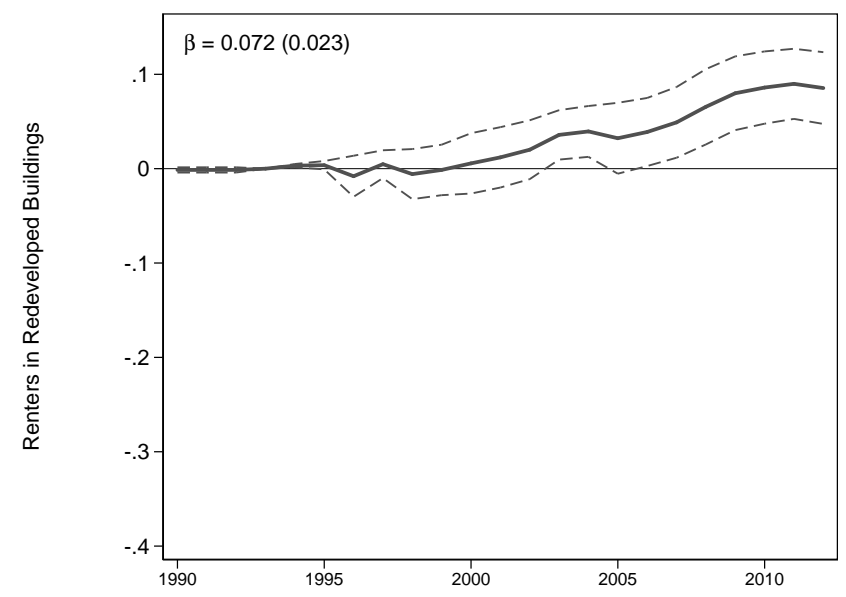

(d) Cumulative Add/Alter/Repair per Unit

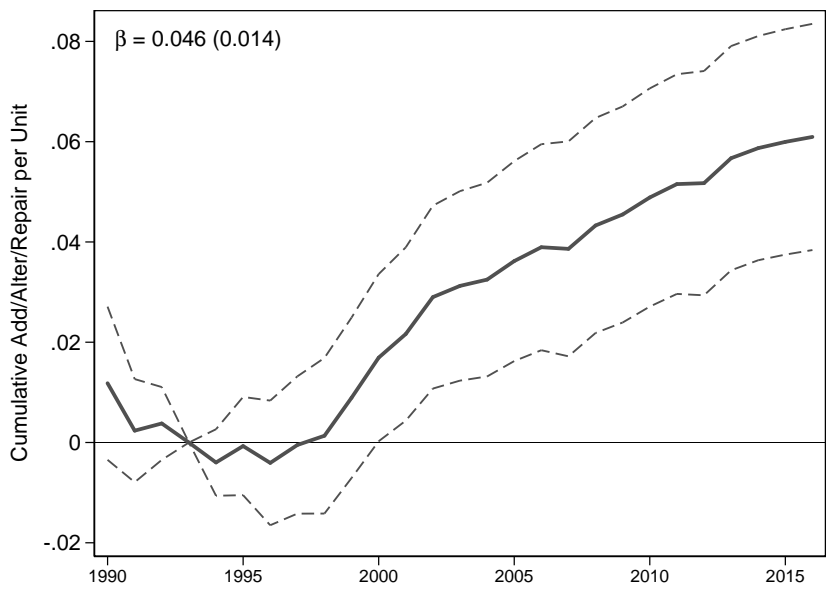

Notes: Sample consists of all multi-family residences with 2-4 units in San Francisco that were built during $1900-$ 1990. The treatment effects along with $90 \%$ CI are plotted. Standard errors are clustered at the parcel level. The average treatment effects in the post-2006 period and their standard errors are reported in the upper-left corner. 
Appendix for Online Publication

\section{A Data Appendix}

To examine the representativeness of the Infutor data, we link all individuals reported as living in San Francisco in 1990 to their census tract, to create census tract population counts as measured in Infutor. We make similar census tract population counts for the year 2000 and compare these San Francisco census tract population counts to those reported in the 1990 and 2000 census population counts for adults 18 years old and above. A regression of the Infutor populations on census population are shown in Figures E.3 and E.4 ${ }^{19}$ Figure E.3 shows that for each additional person recorded in the 1990 Census, Infutor contains an additional 0.45 people, suggesting we have a $45 \%$ sample of the population. While we do not observe the universe of San Francisco residents in 1990, the data appear quite representative, as the census tract population in the 1990 Census can explain $70 \%$ of the census tract variation in population measured from Infutor. Our data is even better in the year 2000. Figure E.4 shows that we appear to have 1.2 people in Infutor for each person observed in the 2000 US census. We likely over count the number of people in each tract in Infutor since we are not conditioning on year of death in the Infutor data, leading to over counting of alive people. However, the Infutor data still track population well, as the census tract population in the 2000 Census can explain $90 \%$ of the census tract variation in population measured from Infutor.

We merge these data with public records information provided by DataQuick about the particular property located at a given address. These data provide us with a variety of property characteristics, such as the use-code (single-family, multi-family, commercial, etc.), the year the building was built, and the number of units in the structure. For each property, the data also details its transaction history since 1988, including transaction prices, as well as the buyer and seller names. Again, we assess the quality of the matching procedure by comparing the distribution of the year buildings were built across census tracts among addresses listed as occupied in Infutor versus the 1990 and 2000 censuses. If a building is constructed post 1993 and we observe a person living there in 1993, we include it into the treatment group for rent control. Figures E.5 and E.6 show the age distribution of the occupied stock by census tract. In both of the years 1990 and 2000, our R-squareds are high and we often cannot reject a slope of one. ${ }^{20}$ This highlights the extremely high quality of the linked Infutor-DataQuick data, as the addresses are clean enough to merge the outside data source DataQuick and still manage to recover the same distribution of building ages as reported in both 1990 and 2000 Censuses.

To measure whether Infutor residents were owners or renters of their properties, we compare the last names of the property owners list in DataQuick to the last names of the residents listed in Infutor. Since property can be owned in trusts, under a business name, or by a partner or spouse with a different last name, we expect to under-classify residents as owners. Figures E.7 and E.8 plot the Infutor measure of

\footnotetext{
${ }^{19}$ We only can do data validation relative to the US Censuses for census tracts in San Francisco because we only have address histories for people that lived in San Francisco at some point in their life.

${ }^{20}$ Since year built comes from the Census long form, these data are based only on a $20 \%$ sample of the true distribution of building ages in each tract, creating measurement error that is likely worse in the census than in the merged Infutor-DataQuick data.
} 
ownership rates by census tract in 1990 and 2000, respectively, against measures constructed using the 1990 and 2000 censuses. In 1990 (2000), a one percentage point increase in the owner-occupied rate leads to a $0.43(0.56)$ percentage point increase in the ownership rate measured in Infutor. Despite the under counting, our cross-sectional variation across census tract matches the 1990 and 2000 censuses extremely well, with R-squareds over $90 \%$ in both decades. This further highlights the quality of the Infutor data.

To perform the merge, we first match each address from the Infutor data to the master San Francisco address file provided by the San Francisco City Assessor's office. These data link addresses to parcels and provides the complete public tax records address of the parcel. ${ }^{21}$ We next match our data to DataQuick using the public tax records address according to street number and street name.

Next we match each address to its official parcel number from the San Francisco Assessor's office. Using the parcel ID number from the Secured Roll data, we also merge with any building permits that have been associated with that property since 1980. These data come from the San Francisco Planning Office. This allows us to track large investments into renovations and changes in building use type over time based on the quantity and type of permit issued to each building over time.

The parcel number also allows us to link to the parcel history file from the Assessor's office. This allows us to observe changes in the parcel structure over time. In particular, this allows us to determine whether parcels were split off over time, a common occurrence when a multi-family apartment building (one parcel) splits into separate parcels for each apartment during a condo conversion.

\section{A.1 Rent Imputation}

To measure annual market rents for each zipcode in San Francisco in each year, we will combine data from three sources: Annual advertised rents from the San Francisco Chronicle and Craigslist collected by Fischer (https://github.com/ericfischer/housing-inventory/). Since we do not have the microdata, this gives us an aggregate San Francisco-wide annual time series of rents. This is likely the more accurate measure of market rate rents, among all of over data sources. Our second data source is median rents in each zipcode as reported in the Census and American Community Survey. These data are only available in certain years, and will combine rent controlled rents with market rate rents. An issue we will discuss more below. Finally, our last data source is all housing market transactions in San Francisco from 1988 to 2012, which come from DataQuick. While these data should produce a very accurate measure of house price indices, they may not perfectly draft the rental market as well.

Our first step is the create an annual house price index for each San Francisco zipcode. We use a hedonic house price index where we regress transaction prices on house type dummies (single family, condo, small multi-family, large multi-family) interacted with log square feet, age and its square, a dummy for whether the property would be subject to rent control if it were rented, number of bedrooms, number of bathrooms, log lot size, and a dummy for no lot size (e.g. for condos). We also include dummies for indicators of distressed sales. Our house price index will be constructed from zipcode-year dummies in

\footnotetext{
${ }^{21}$ In certain cases, multiple addresses correspond to the same parcel number. The SF master address file provides all addresses associated with a particular parcel as well as the parcel ID number. Using the parcel ID number, we can link to the San Francisco Assessor's Secured Roll data, which provides the public tax records address for the parcel.
} 
this above regression. This house price data is our only source of annual level prices at the zip code level. ${ }^{22}$

The second step is to estimate the relationship between census reported median zipcode rents and our house price index. This will tell us how much we expect rents to move in response to house price movements. We estimate the relationship between census median rents and one year lagged house prices, as current rents were likely set during the previous years. Also, in the ACS year of our data, we have 5 -year pooled estimates of median rents. To make our house prices index comparable to the ACS data in those years, we also pool our house price index over the same 5 years. We then run the regression of the census median rents on year dummies, zipcode dummies and our lagged house price index. We find that for a $1 \%$ increase in our house price index, census median rents go up by $0.34 \%$. This regression has an $R^{2}$ of 0.98 , suggesting that our rent predictions are quite accurate. This estimate tells how much local rents would go up, over and beyond the aggregate SF-wide trend when local house prices have gone up, relative to their aggregate $\mathrm{SF}$ wide trend. The reason we want to compare deviations in house prices to deviations in census rents is because we know the SF-wide rent time series in rents from the Fischer data. We only need to use the local house price data to infer differential trends in house prices across zip codes.

The third step is to estimate the relationship between census median rents and the SF-wide market rents. While the previous regression predicts the relationship between median rents and house prices, we want to estimate the relationship between market rents and house prices. Since a large share of San Francisco is subject to rent control, median rents need not perfectly reflect market rents. We now estimate the relationship between census median rents and the Fischer SF-wide asking market rents. We find that a $1 \%$ increase in the SF market rents only leads to an $0.8 \%$ increase in census median rents. Thus, we will inflate the estimated effects between house prices and census rents by $1 / 0.8=1.25$. Combining steps 2 and 3 , we find a $1 \%$ increase in house prices leads to a $0.425 \%$ increases in rents.

Finally, we combine these zip-code specific rent predictions with the Fischer aggregate SF time series. Since these data are the closest to raw data on market rents, we will ensure the average across our zipcode specific rent predictions aggregate across zipcodes to match the SF overall time series. Thus, we assume the zipcode-year rent time series will equal the SF-wide time series plus our estimated effect of house prices on rents (0.425) times the zipcode house price index, annually demeaned by its SF-wide average.

\section{B Estimation for Young Renters}

In this appendix, we first describe how renewals work for young renters and then derive the equations which estimate the structural parameters for young renters. Let $y$ superscripts denote young renters in what follows. So utility functions, conditional choice probabilities, and value functions without a $y$ superscript denote mature renters.

\footnotetext{
${ }^{22}$ We have also tried repeat sales methods and the results are similar, but noisier, so we opt for the hedonic index.
} 


\section{B.1 Renewals for Young Renters}

\section{B.1.1 Immediate Renewals}

The logic of immediate renewals is exactly the same for young renters as it is for mature renters. Suppose we have two young households in states $\theta_{t-1}$ and $\theta_{t-1}^{\prime}$ and these two households take the actions $x$ and $x^{\prime}$ in period $t$. Using equation (4) and differencing we find that:

$$
v_{t}^{y}\left(x, \theta_{t-1}\right)-v_{t}^{y}\left(x^{\prime}, \theta_{t-1}^{\prime}\right)=\ln \left(\frac{p_{t}^{y}\left(x \mid \theta_{t-1}\right)}{p_{t}^{y}\left(x^{\prime} \mid \theta_{t-1}^{\prime}\right)}\right)+I_{t}^{y}\left(\theta_{t-1}\right)-I_{t}^{y}\left(\theta_{t-1}^{\prime}\right)
$$

Substituting in the conditional value functions, we get:

$$
\begin{aligned}
& \bar{u}_{t}^{y}\left(x, \theta_{t-1}\right)-\bar{u}_{t}^{y}\left(x^{\prime}, \theta_{t-1}^{\prime}\right)+\beta\left(1-\kappa_{t}\right)\left\{E_{t}\left[\bar{V}_{t+1}^{y}\left(\Theta\left(x, \theta_{t-1}\right)\right)\right]-E_{t}\left[\bar{V}_{t+1}^{y}\left(\Theta\left(x^{\prime}, \theta_{t-1}^{\prime}\right)\right)\right]\right\} \\
& +\beta \kappa_{t}\left\{E_{t}\left[\bar{V}_{t+1}\left(\Theta\left(x, \theta_{t-1}\right)\right)\right]-E_{t}\left[\bar{V}_{t+1}\left(\Theta\left(x^{\prime}, \theta_{t-1}^{\prime}\right)\right)\right]\right\} \\
= & \ln \left(\frac{p_{t}^{y}\left(x \mid \theta_{t-1}\right)}{p_{t}^{y}\left(x^{\prime} \mid \theta_{t-1}^{\prime}\right)}\right)+I_{t}^{y}\left(\theta_{t-1}\right)-I_{t}^{y}\left(\theta_{t-1}^{\prime}\right) .
\end{aligned}
$$

Now assume $x$ and $x^{\prime}$ are renewal actions in the sense that, conditional on the realization of the $\kappa_{t}$ shock, $\Theta\left(x, \theta_{t-1}\right)=\Theta\left(x^{\prime}, \theta_{t-1}^{\prime}\right)$. This implies:

$$
\bar{u}_{t}^{y}\left(x, \theta_{t-1}\right)-\bar{u}_{t}^{y}\left(x^{\prime}, \theta_{t-1}^{\prime}\right)=\ln \left(\frac{p_{t}^{y}\left(x \mid \theta_{t-1}\right)}{p_{t}^{y}\left(x^{\prime} \mid \theta_{t-1}^{\prime}\right)}\right)+I_{t}^{y}\left(\theta_{t-1}\right)-I_{t}^{y}\left(\theta_{t-1}^{\prime}\right) .
$$

If $\theta_{t-1} \neq \theta_{t-1}^{\prime}$, we need to remove the difference of log sums. Suppose the households move to some neighborhood $j^{*} \in \mathcal{J}$, with $j^{*} \neq x$ and $j^{*} \neq x^{\prime}$. As with mature renters, we find:

$$
\ln \left(\frac{p_{t}^{y}\left(x \mid \theta_{t-1}\right)}{p_{t}^{y}\left(x^{\prime} \mid \theta_{t-1}^{\prime}\right)}\right)-\ln \left(\frac{p_{t}^{y}\left(j^{*} \mid \theta_{t-1}\right)}{p_{t}^{y}\left(j^{*} \mid \theta_{t-1}^{\prime}\right)}\right)=\left[\bar{u}_{t}^{y}\left(x, \theta_{t-1}\right)-\bar{u}_{t}^{y}\left(x^{\prime}, \theta_{t-1}^{\prime}\right)\right]-\left[\bar{u}_{t}^{y}\left(j^{*}, \theta_{t-1}\right)-\bar{u}_{t}^{y}\left(j^{*}, \theta_{t-1}^{\prime}\right)\right],
$$

which removes the log sums.

\section{B.1.2 One Period Ahead Renewals}

The difference between mature and young renters arises when considering one-period ahead renewals. Suppose $x$ and $x^{\prime}$ are not renewals. Substitute the expected difference in continuation values with its realization and expectational errors in equation(21):

$$
\begin{aligned}
& \bar{u}_{t}^{y}\left(x, \theta_{t-1}\right)-\bar{u}_{t}^{y}\left(x^{\prime}, \theta_{t-1}^{\prime}\right)-\ln \left(\frac{p_{t}^{y}\left(j \mid \theta_{t-1}\right)}{p_{t}^{y}\left(j^{\prime} \mid \theta_{t-1}^{\prime}\right)}\right)-\left[I_{t}^{y}\left(\theta_{t-1}\right)-I_{t}^{y}\left(\theta_{t-1}^{\prime}\right)\right] \\
= & \beta\left(1-\kappa_{t}\right)\left(\bar{V}_{t+1}^{y}\left(\Theta\left(x^{\prime}, \theta_{t-1}^{\prime}\right)\right)-\bar{V}_{t+1}^{y}\left(\Theta\left(x, \theta_{t-1}\right)\right)\right)+\left(1-\kappa_{t}\right)\left(\xi_{t}^{V, y}\left(x^{\prime}, \theta_{t-1}^{\prime}\right)-\xi_{t}^{V, y}\left(x, \theta_{t-1}\right)\right) \\
& +\beta \kappa_{t}\left(\bar{V}_{t+1}\left(\Theta\left(x^{\prime}, \theta_{t-1}^{\prime}\right)\right)-\bar{V}_{t+1}\left(\Theta\left(x, \theta_{t-1}\right)\right)\right)+\kappa_{t}\left(\xi_{t}^{V}\left(x^{\prime}, \theta_{t-1}^{\prime}\right)-\xi_{t}^{V}\left(x, \theta_{t-1}\right)\right)
\end{aligned}
$$


where:

$$
\begin{aligned}
\xi_{t}^{V, y}\left(x, \theta_{t-1}\right) & =\beta\left(E_{t}\left[\bar{V}_{t+1}^{y}\left(\Theta\left(x, \theta_{t-1}\right)\right)\right]-\bar{V}_{t+1}^{y}\left(\Theta\left(x, \theta_{t-1}\right)\right)\right) \\
\xi_{t}^{V}\left(x, \theta_{t-1}\right) & =\beta\left(E_{t}\left[\bar{V}_{t+1}\left(\Theta\left(x, \theta_{t-1}\right)\right)\right]-\bar{V}_{t+1}\left(\Theta\left(x, \theta_{t-1}\right)\right)\right)
\end{aligned}
$$

are the expectational errors. We define:

$$
\Delta \xi_{t}^{V, y}=\left(1-\kappa_{t}\right)\left(\xi_{t}^{V, y}\left(x^{\prime}, \theta_{t-1}^{\prime}\right)-\xi_{t}^{V, y}\left(x, \theta_{t-1}\right)\right)+\kappa_{t}\left(\xi_{t}^{V}\left(x^{\prime}, \theta_{t-1}^{\prime}\right)-\xi_{t}^{V}\left(x, \theta_{t-1}\right)\right)
$$

in what follows.

As with older renters, we make use of renewals. Suppose that at time $t+1$, both households move to the same neighborhood, that is $x_{t+1}=x_{t+1}^{\prime}=j^{*} \in \mathcal{J}$. Substituting out the realized ex-ante value functions yields:

$$
\begin{aligned}
& \bar{u}_{t}^{y}\left(x, \theta_{t-1}\right)-\bar{u}_{t}^{y}\left(x^{\prime}, \theta_{t-1}^{\prime}\right)-\ln \left(\frac{p_{t}^{y}\left(j \mid \theta_{t-1}\right)}{p_{t}^{y}\left(j^{\prime} \mid \theta_{t-1}^{\prime}\right)}\right)-\left[I_{t}^{y}\left(\theta_{t-1}\right)-I_{t}^{y}\left(\theta_{t-1}^{\prime}\right)\right] \\
= & \beta\left(1-\kappa_{t}\right)\left(v_{t+1}^{y}\left(j^{*}, \Theta\left(x^{\prime}, \theta_{t-1}^{\prime}\right)\right)-v_{t+1}^{y}\left(j^{*}, \Theta\left(x, \theta_{t-1}\right)\right)\right) \\
& +\beta \kappa_{t}\left(v_{t+1}\left(j^{*}, \Theta\left(x^{\prime}, \theta_{t-1}^{\prime}\right)\right)-v_{t+1}\left(j^{*}, \Theta\left(x, \theta_{t-1}\right)\right)\right) \\
& -\beta\left(1-\kappa_{t}\right) \ln \left(\frac{p_{t+1}^{y}\left(j^{*}, \Theta\left(x^{\prime} \mid \theta_{t-1}^{\prime}\right)\right)}{p_{t+1}^{y}\left(j^{*}, \Theta\left(x \mid \theta_{t-1}\right)\right)}\right) \\
& -\beta \kappa_{t} \ln \left(\frac{p_{t+1}\left(j^{*}, \Theta\left(x^{\prime} \mid \theta_{t-1}^{\prime}\right)\right)}{p_{t+1}\left(j^{*}, \Theta\left(x \mid \theta_{t-1}\right)\right)}\right)+\Delta \xi_{t}^{V, y}
\end{aligned}
$$

Since $j^{*}$ is a renewal action, the time $t+2$ expected value functions difference out and this equation becomes:

$$
\begin{aligned}
& \bar{u}_{t}^{y}\left(x, \theta_{t-1}\right)-\bar{u}_{t}^{y}\left(x^{\prime}, \theta_{t-1}^{\prime}\right)-\ln \left(\frac{p_{t}^{y}\left(j \mid \theta_{t-1}\right)}{p_{t}^{y}\left(j^{\prime} \mid \theta_{t-1}^{\prime}\right)}\right)-\left[I_{t}^{y}\left(\theta_{t-1}\right)-I_{t}^{y}\left(\theta_{t-1}^{\prime}\right)\right] \\
= & \beta\left(1-\kappa_{t}\right)\left(\bar{u}_{t+1}^{y}\left(j^{*}, \Theta\left(x^{\prime}, \theta_{t-1}^{\prime}\right)\right)-\bar{u}_{t+1}^{y}\left(j^{*}, \Theta\left(x, \theta_{t-1}\right)\right)\right) \\
& +\beta \kappa_{t}\left(\bar{u}_{t+1}\left(j^{*}, \Theta\left(x^{\prime}, \theta_{t-1}^{\prime}\right)\right)-\bar{u}_{t+1}\left(j^{*}, \Theta\left(x, \theta_{t-1}\right)\right)\right) \\
& -\beta\left(1-\kappa_{t}\right) \ln \left(\frac{p_{t+1}^{y}\left(j^{*}, \Theta\left(x^{\prime} \mid \theta_{t-1}^{\prime}\right)\right)}{p_{t+1}^{y}\left(j^{*}, \Theta\left(x \mid \theta_{t-1}\right)\right)}\right) \\
& -\beta \kappa_{t} \ln \left(\frac{p_{t+1}\left(j^{*}, \Theta\left(x^{\prime} \mid \theta_{t-1}^{\prime}\right)\right)}{p_{t+1}\left(j^{*}, \Theta\left(x \mid \theta_{t-1}\right)\right)}\right)+\Delta \xi_{t}^{V, y}
\end{aligned}
$$


To remove the difference in log sums, we follow the same procedure as for older renters, which gives:

$$
\begin{aligned}
& \quad \ln \left(\frac{p_{t}^{y}\left(j \mid \theta_{t-1}\right)}{p_{t}^{y}\left(j^{\prime} \mid \theta_{t-1}^{\prime}\right)}\right)-\ln \left(\frac{p_{t}^{y}\left(j^{*} \mid \theta_{t-1}\right)}{p_{t}^{y}\left(j^{*} \mid \theta_{t-1}^{\prime}\right)}\right) \\
& +\beta\left(1-\kappa_{t}\right) \ln \left(\frac{p_{t+1}^{y}\left(j^{*}, \Theta\left(x \mid \theta_{t-1}\right)\right)}{p_{t+1}^{y}\left(j^{*}, \Theta\left(x^{\prime} \mid \theta_{t-1}^{\prime}\right)\right)}\right)+\beta \xi \ln \left(\frac{p_{t+1}\left(j^{*}, \Theta\left(x \mid \theta_{t-1}\right)\right)}{p_{t+1}\left(j^{*}, \Theta\left(x^{\prime} \mid \theta_{t-1}^{\prime}\right)\right)}\right) \\
& =\quad\left[\bar{u}_{t}^{y}\left(x, \theta_{t-1}\right)-\bar{u}_{t}\left(x^{\prime}, \theta_{t-1}^{\prime}\right)\right]-\left[\bar{u}_{t}^{y}\left(j^{*}, \theta_{t-1}\right)-\bar{u}_{t}\left(j^{*}, \theta_{t-1}^{\prime}\right)\right] \\
& +\beta\left(1-\kappa_{t}\right)\left(\bar{u}_{t+1}^{y}\left(j^{*}, \Theta\left(x, \theta_{t-1}\right)\right)-\bar{u}_{t+1}^{y}\left(j^{*}, \Theta\left(x, \theta_{t-1}\right)\right)\right) \\
& +\beta \kappa_{t}\left(\bar{u}_{t+1}\left(j^{*}, \Theta\left(x, \theta_{t-1}\right)\right)-\bar{u}_{t+1}\left(j^{*}, \Theta\left(x, \theta_{t-1}\right)\right)\right) \\
& +\Delta \xi_{t}^{V, y} .
\end{aligned}
$$

We can use this framework to estimate the structural parameters of the young renters.

\section{B.2 Regression Equations for Young Renters}

The equations are direct counterparts of those for older renters, following the exact same logic, but with the required adjustments to account for the possibility of transitioning to an older renter. To estimate the rent utility parameter and the transfer functions, we compare individuals from the treatment and control group living in the same neighborhood with the same tenure. We suppose that they move to neighborhood $j^{*}$ after one year. We get the estimating equation.

$$
\begin{aligned}
Y_{j, j^{*}}^{t}= & \gamma_{Y}\left[\exp R_{t}(j, 1)-\exp R_{t}(j, 0)\right]+ \\
& +\lambda_{1}\left[\left(\beta \ln R_{t+1}(j, 0)-\ln R_{t}(j, 0)\right)-\left(\beta \ln R_{t+1}(j, 1)-\ln R_{t}(j, 1)\right)\right] \\
& +\lambda_{2}\left[\beta\left(t+\tau_{n}+1\right)-\left(t+\tau_{n}\right)\right]+\kappa_{t} \lambda_{Y} \\
& +\Delta \xi_{t}^{V, y}+\chi_{j, j^{*}}^{t} \\
Y_{j, j^{*}}^{t}= & \ln \left(\frac{p_{t}^{y}\left(\mathcal{S} \mid j, 1, \tau_{n}\right)}{p_{t}^{y}\left(\mathcal{S} \mid j, 0, \tau_{n}\right)}\right)-\ln \left(\frac{p_{t}^{y}\left(j^{*} \mid j, 1, \tau_{n}\right)}{p_{t}^{y}\left(j^{*} \mid j, 0, \tau_{n}\right)}\right) \\
& +\beta\left(1-\kappa_{t}\right) \ln \left(\frac{p_{t+1}^{y}\left(j^{*} \mid j, 1, \tau_{n}\right)}{p_{t+1}^{y}\left(j^{*} \mid j, 0, \tau_{n}\right)}\right)+\beta \kappa_{t} \ln \left(\frac{p_{t+1}\left(j^{*} \mid j, 1, \tau_{n}\right)}{p_{t+1}\left(j^{*} \mid j, 0, \tau_{n}\right)}\right)
\end{aligned}
$$

where recall $\chi_{j, j^{*}}^{t}$ denotes measurement error. To estimate fixed moving costs, we consider two individuals in the control group of equal tenure living in the same neighborhood, one of which immediately moves to a new location in the same zipcode. This yields:

$$
\begin{aligned}
Y_{j}^{t} & =-\varphi_{0}, Y \\
Y_{j}^{t} & =\ln \left(\frac{p_{t}^{y}\left(\mathcal{S} \mid j, 0, \tau_{n}\right)}{p_{t}^{y}\left(j \mid j, 0, \tau_{n}\right)}\right)
\end{aligned}
$$

To estimate variable moving costs, we consider two individuals of equal tenure $\tau_{n}$, one of which lives in neighborhood $j$ and the other in neighborhood $j^{\prime}$. We suppose they immediately move to either $j^{*}$ or $j^{* *}$. 
Similar to mature renters, we find the regression:

$$
\begin{aligned}
Y_{j, j^{\prime}, j^{*}, j^{* *}}^{t}= & \varphi_{d}, Y\left(d_{j, j^{*}}-d_{j^{\prime}, j^{*}}\right)-\varphi_{d}, Y\left(d_{j, j^{* *}}-d_{j^{\prime}, j^{* *}}\right) \\
& +\varphi_{\tau}, Y \tau_{n}\left(d_{j, j^{*}}-d_{j^{\prime}, j^{*}}\right)-\varphi_{\tau}, Y \tau_{n}\left(d_{j, j^{* *}}-d_{j^{\prime}, j^{* *}}\right)+\chi_{j, j^{\prime}, j^{*}, j^{* *}}^{t} \\
Y_{j, j^{\prime}, j^{*}, j^{* *}}^{t}= & \ln \left(\frac{p_{t}^{y}\left(j^{*} \mid j, 0, \tau_{n}\right)}{p_{t}^{y}\left(j^{*} \mid j^{\prime}, 0, \tau_{n}\right)}\right)-\ln \left(\frac{p_{t}^{y}\left(j^{* *} \mid j, 0, \tau_{n}\right)}{p_{t}^{y}\left(j^{* *} \mid j^{\prime}, 0, \tau_{n}\right)}\right) .
\end{aligned}
$$

We can use the same equations when considering two individuals from the treatment group. To identify the impact of tenure on utility $\alpha_{Y}$, we consider two individuals from the control group living in the same neighborhood with different levels of initial tenure, $\tau_{n}$ and $\tau_{n}^{\prime}$. Assuming they move to $j^{*}$ after one year, we arrive at the equation:

$$
\begin{aligned}
Y_{j, j^{*}}^{t}= & \alpha_{Y}\left(\tau_{n}-\tau_{n}^{\prime}\right)+(\beta-1)\left(\left(1-\kappa_{t}\right) \varphi_{\tau}, Y+\kappa_{t} \varphi_{\tau}, M\right)\left(\tau_{n}-\tau_{n}^{\prime}\right) d_{j, j^{*}}+\Delta \xi_{t}^{V, y}+\chi_{j, j^{*}}^{t} \\
Y_{j, j^{*}}^{t}= & \ln \left(\frac{p_{t}^{y}\left(\mathcal{S} \mid j, 0, \tau_{n}\right)}{p_{t}^{y}\left(\mathcal{S} \mid j, 0, \tau_{n}^{\prime}\right)}\right)-\ln \left(\frac{p_{t}^{y}\left(j^{*} \mid j, 0, \tau_{n}\right)}{p_{t}^{y}\left(j^{*} \mid j, 0, \tau_{n}^{\prime}\right)}\right) \\
& +\beta\left(1-\kappa_{t}\right) \ln \left(\frac{p_{t+1}^{y}\left(j^{*} \mid j, 0, \tau_{n}\right)}{p_{t+1}^{y}\left(j^{*} \mid j, 0, \tau_{n}^{\prime}\right)}\right)+\beta \kappa_{t} \ln \left(\frac{p_{t+1}\left(j^{*} \mid j, 0, \tau_{n}\right)}{p_{t+1}\left(j^{*} \mid j, 0, \tau_{n}^{\prime}\right)}\right) .
\end{aligned}
$$

For two individuals from the treatment group, we must include the impact of the difference in transfers due to the difference in tenure. These equations, along with all of the mature renter equations, form our full GMM system.

Finally, we estimate fixed amenity values according to the regression equation:

$$
\begin{aligned}
Y_{j, j^{\prime}, j^{*}}^{t}= & \omega_{j}-\omega_{j^{\prime}}+\widetilde{\omega}_{j t}-\widetilde{\omega}_{j^{\prime} t}+\xi_{t}^{V}\left(x^{\prime}, \theta_{t-1}^{\prime}\right)-\xi_{t}^{V}\left(x, \theta_{t-1}\right) \\
Y_{j, j^{\prime}, j^{*}, j^{* *}}^{t}= & \ln \left(\frac{p_{t}^{y}\left(\mathcal{S} \mid j, 0, \tau_{n}\right)}{p_{t}^{y}\left(\mathcal{S} \mid j^{\prime}, 0, \tau_{n}\right)}\right)-\ln \left(\frac{p_{t}^{y}\left(j^{*} \mid j, 0, \tau_{n}\right)}{p_{t}^{y}\left(j^{*} \mid j^{\prime}, 0, \tau_{n}\right)}\right)+ \\
& \beta(1-\xi) \ln \left(\frac{p_{t+1}^{y}\left(j^{*} \mid j, 0, \tau_{n}\right)}{p_{t+1}^{y}\left(j^{*} \mid j^{\prime}, 0, \tau_{n}\right)}\right)+\beta(1-\xi) \ln \left(\frac{p_{t+1}\left(j^{*} \mid j, 0, \tau_{n}\right)}{p_{t+1}\left(j^{*} \mid j^{\prime}, 0, \tau_{n}\right)}\right) \\
& -(\beta-1)\left(1-\kappa_{t}\right) \varphi_{d}, Y\left(d_{j, j^{*}}-d_{j^{\prime}, j^{*}}\right)-(\beta-1)\left(1-\kappa_{t}\right) \varphi_{\tau}, Y \tau_{n}\left(d_{j, j^{*}}-d_{j^{\prime}, j^{*}}\right) \\
& -(\beta-1) \kappa_{t} \varphi_{d, M}\left(d_{j, j^{*}}-d_{j^{\prime}, j^{*}}\right)-(\beta-1) \kappa_{t} \varphi_{\tau, M} \tau_{n}\left(d_{j, j^{*}}-d_{j^{\prime}, j^{*}}\right) \\
& -\gamma_{Y}\left[\exp R_{t}(j, 0)-\exp R_{t}\left(j^{\prime}, 0\right)\right],
\end{aligned}
$$

where the rent parameter and moving cost parameters are known.

\section{Welfare Decomposition}

In this appendix, we describe formally how we do the welfare decomposition of Section 6.1. Recall from equation 22 that:

$$
\begin{aligned}
\Delta U_{t}^{M}= & \Delta U_{t}^{M, \text { Rent }}+\Delta U_{t}^{M, \text { Payoff }}+\Delta U_{t}^{M, N C} \\
& +\Delta U_{t}^{M, M C}+\Delta U_{t}^{M, \text { Miles }}+\Delta U_{t}^{M, \text { Amenity }}+\Delta U_{t}^{M, \text { Logit }}
\end{aligned}
$$


Suppressing the dependence of $j$ and $\tau$ on $x$, we can formally write these terms as:

$$
\begin{aligned}
\Delta U_{t}^{\operatorname{Re} n t} & =\sum_{\theta_{t-1}} \sum_{x} \gamma_{M} \exp \left(R_{t}\left(j, d, \tau_{h}\right)\right)\left(p_{t}^{T}\left(x, \theta_{t-1}\right)-p_{t}^{C}\left(x, \theta_{t-1}\right)\right) \\
\Delta U_{t}^{\text {Payoff }} & =\sum_{\theta_{t-1}} \sum_{x} \Lambda_{t}\left(x, d_{t-1}, M\right)\left(p_{t}^{T}\left(x, \theta_{t-1}\right)-p_{t}^{C}\left(x, \theta_{t-1}\right)\right) \\
\Delta U_{t}^{M, N C} & =\sum_{\theta_{t-1}} \sum_{x} \alpha_{M} \tau_{n}\left(p_{t}^{T}\left(x, \theta_{t-1}\right)-p_{t}^{C}\left(x, \theta_{t-1}\right)\right) \\
\Delta U_{t}^{M, M C} & =\sum_{\theta_{t-1}} \sum_{x} \varphi_{0, M} 1[x \neq \mathcal{S}]\left(p_{t}^{T}\left(x, \theta_{t-1}\right)-p_{t}^{C}\left(x, \theta_{t-1}\right)\right) \\
\Delta U_{t}^{M, \text { Miles }} & =\sum_{\theta_{t-1}} \sum_{x} \varphi_{d, M} d_{j, j_{t-1}} 1[x \neq \mathcal{S}]\left(p_{t}^{T}\left(x, \theta_{t-1}\right)-p_{t}^{C}\left(x, \theta_{t-1}\right)\right) \\
\Delta U_{t}^{M, \text { Amenity }} & =\sum_{\theta_{t-1}} \sum_{x} \omega_{j t}\left(p_{t}^{T}\left(x, \theta_{t-1}\right)-p_{t}^{C}\left(x, \theta_{t-1}\right)\right) .
\end{aligned}
$$

We can measure each of these terms. ${ }^{23}$ We recover estimates of $\gamma_{M}, \Lambda_{M}, \alpha_{M}, \varphi_{0, M}, \varphi_{d, M}$, and $\omega_{j t}$ from our structural model. We can then recover the other needed quantities from standard reduced form differences-in-differences analysis. For example:

$$
\sum_{\theta_{t-1}} \sum_{x} \exp \left(R_{t}\left(j, d, \tau_{h}\right)\right)\left(p_{t}^{T}\left(x, \theta_{t-1}\right)-p_{t}^{C}\left(x, \theta_{t-1}\right)\right)
$$

is simply the average difference in rents paid between treatment and control in year $t$,

$$
\sum_{\theta_{t-1}} \sum_{x} \tau_{n}\left(p_{t}^{T}\left(x, \theta_{t-1}\right)-p_{t}^{C}\left(x, \theta_{t-1}\right)\right)
$$

is the average difference in accumulated neighborhood capital between treatment and control,

$$
\sum_{\theta_{t-1}} \sum_{x} 1[x \neq \mathcal{S}]\left(p_{t}^{T}\left(x, \theta_{t-1}\right)-p_{t}^{C}\left(x, \theta_{t-1}\right)\right)
$$

is the average difference in number of moves between treatment and control, and

$$
\sum_{\theta_{t-1}} \sum_{x} d_{j, j_{t-1}} 1[x \neq \mathcal{S}]\left(p_{t}^{T}\left(x, \theta_{t-1}\right)-p_{t}^{C}\left(x, \theta_{t-1}\right)\right)
$$

is the average difference in distance moved between treatment and control. Each of these can be readily calculated using the reduced form methodology described in Section 4. The average utility difference due to transfers and the average utility difference due to amenities can be similarly calculated by combining our structural estimates with reduced form differences-in-differences analysis.

Deriving an expression for the utility difference due to idiosyncratic valuations $\Delta U_{t}^{M, L o g i t}$ is a bit more

\footnotetext{
${ }^{23}$ Since we measure rents as monthly rents/3000, we multiply by 36,000 to convert to an annual rent number.
} 
complicated. We have that:

$$
\Delta U_{t}^{M, \text { Logit }}=\sum_{\theta_{t-1}} \sum_{x} E_{t}\left[\varepsilon_{i t} \mid x, \theta_{t-1}\right]\left(p_{t}^{T}\left(x, \theta_{t-1}\right)-p_{t}^{C}\left(x, \theta_{t-1}\right)\right) .
$$

We therefore need an expression for the conditional expectation $E_{t}\left[\varepsilon_{i x t} \mid x, \theta_{t-1}\right]$. Using Bayes' rule, we get:

$$
\begin{aligned}
E_{t}\left[\varepsilon_{i x t} \mid x, \theta_{t-1}\right] & =\frac{\int \varepsilon_{i x t}\left(\prod_{x^{\prime} \neq x} e^{\left.-e^{-\left(\varepsilon_{i x t}+v_{t}\left(x, \theta_{t-1}\right)-v_{t}\left(x^{\prime}, \theta_{t-1}\right)\right)}\right) e^{-\varepsilon_{i x t}} e^{-e^{-\varepsilon_{i x t}} d \varepsilon_{i x t}}}\right.}{p_{t}\left(x \mid \theta_{t-1}\right)} \\
& =\frac{\int \varepsilon_{i x t}\left(\prod_{x^{\prime} \neq x} e^{\left.-e^{-\left(\varepsilon_{i x t}+\ln p_{t}\left(x \mid \theta_{t-1}\right)-\ln p_{t}\left(x^{\prime} \mid \theta_{t-1}\right)\right)}\right) e^{-\varepsilon_{i x t}} e^{-e^{-\varepsilon_{i x t}} d \varepsilon_{i x t}}}\right.}{p_{t}\left(x \mid \theta_{t-1}\right)},
\end{aligned}
$$

where in the second equality we used the Hotz and Miller (1993) inversion $v_{t}\left(x, \theta_{t-1}\right)-v_{t}\left(x^{\prime}, \theta_{t-1}\right)=$ $\ln p_{t}\left(x \mid \theta_{t-1}\right)-\ln p_{t}\left(x^{\prime} \mid \theta_{t-1}\right)$. Substituting into equation (23), we derive:

$$
\begin{aligned}
& \Delta U_{t}^{M, \text { Logit }}=\sum_{\theta_{t-1}} \sum_{x}\left\{\int \varepsilon_{i x t}\left(\prod_{x^{\prime} \neq x} e^{-e^{-\left(\varepsilon_{i x t}+\ln p_{t}\left(x \mid \theta_{t-1}\right)-\ln p_{t}\left(x^{\prime} \mid \theta_{t-1}\right)\right)}}\right) e^{-\varepsilon_{i x t}} e^{-e^{-\varepsilon_{i x t}}} d \varepsilon_{i x t}\right\} \times \\
& \left(p_{t}^{T}\left(\theta_{t-1}\right)-p_{t}^{C}\left(\theta_{t-1}\right)\right) \text {. }
\end{aligned}
$$

Since we have empirical estimates of each of the probabilities, we can estimate this utility difference.

We finally convert our estimated utility differences into rent equivalent dollar amounts. Consider an individual in the control group who pays the average San Francisco rent in year $t$, which we denote as $\bar{R}_{t}$. We now proceed iteratively. The dollar rent equivalent $\Delta W_{t}^{\operatorname{Re} n t}$ of the utility difference $\Delta U_{t}^{\operatorname{Re} n t}$ in year $t$ due to rent differences can be calculated as the solution to :

$$
\gamma_{M} \exp \left(\bar{R}_{t}+\Delta W_{t}^{\operatorname{Re} n t}\right)-\gamma_{M} \exp \left(\bar{R}_{t}\right)=\Delta U_{t}^{\operatorname{Re} n t}
$$

which gives:

$$
\Delta W_{t}^{\operatorname{Re} n t}=\ln \left(\frac{\Delta U_{t}^{\operatorname{Re} n t}}{\gamma_{M}}+\exp \left(\bar{R}_{t}\right)\right)-\bar{R}_{t}
$$

The dollar rent equivalent incremental impact of transfers can then be calculated as:

$$
\Delta W_{t}^{\text {Payoff }}=\ln \left(\frac{\Delta U_{t}^{\text {Payoff }}}{\gamma_{M}}+\exp \left(\bar{R}_{t}+\Delta W_{t}^{\operatorname{Re} n t}\right)\right)-\left(\bar{R}_{t}+\Delta W_{t}^{\operatorname{Re} n t}\right) .
$$

Now let $\Delta U_{t}^{M, \iota}$ denote the utility differences, with $\iota \in\{1, \ldots, 7\}$ corresponding to the ordering in equation (22). Iterating on our procedure gives the dollar rent equivalent incremental impacts of each element of the decomposition:

$$
\Delta W_{t}^{\iota}=\ln \left(\frac{\Delta U_{t}^{\text {Payoff }}}{\gamma_{M}}+\exp \left(\bar{R}_{t}+\sum_{\iota^{\prime}<\iota} \Delta W_{t}^{\iota^{\prime}}\right)\right)-\left(\bar{R}_{t}+\sum_{\iota^{\prime}<\iota} \Delta W_{t}^{\iota^{\prime}}\right)
$$




\section{Welfare Impact of Reduced Supply}

In this appendix, we show how to calculate the GE rent increase caused by the reduction in supply in the full model with both young and old renters. We allow young renters to transition to old renters at the rate $\kappa$. We suppose that the birth rate in an area is proportional to the number of young renters living there. Steady-state therefore requires that the birth rate is also equal to $\kappa$. The rate at which old renters die off must be equal to $\phi=\kappa\left(\bar{N}^{y} / \bar{N}\right)$, where $\bar{N}^{y}$ and $\bar{N}$ are the total population of young and old renters, respectively.

Steady-state requires that the flow of young (old) renters into each neighborhood must equal the flow of young (old) renters out of that neighborhood. We thus require for all $j$ :

$$
\begin{aligned}
\phi N_{j}+(1-\phi) N_{j}(1-p(j \mid j)) & =(1-\phi) \sum_{j^{\prime} \neq j} N_{j^{\prime}} p\left(j \mid j^{\prime}\right)+\kappa \sum_{j^{\prime}} N^{y} p\left(j \mid j^{\prime}\right) \\
N_{j}^{y}\left(1-p^{y}(j \mid j)\right) & =\sum_{j^{\prime} \neq j} N_{j^{\prime}}^{y} p^{y}\left(j \mid j^{\prime}\right) .
\end{aligned}
$$

The first equation gives the steady-state condition across neighborhoods for old renters. The left hand side gives the outflows from neighborhood $j$, which arise from death and moving to other neighborhoods. Inflows come from existing old renters and new old renters deciding to locate in neighborhood $j$. The second equation gives the steady-state condition across neighborhoods for young renters, which simply says that young renters deciding to leave the neighborhood must be balanced by young renters moving into the neighborhood from elsewhere. Given our estimates of the 1993 moving probabilities $p(\cdot \mid \cdot)$ and $p^{y}(\cdot \mid \cdot)$, these equations, along with the following adding up constraints:

$$
\begin{aligned}
\sum_{j} N_{j} & =\bar{N} \\
\sum_{j} N_{j}^{y} & =\bar{N}^{y}
\end{aligned}
$$

allow us to solve for the steady-state number of young and old renters $\left(N_{j}, N_{j}^{y}\right)$ in each neighborhood $j$.

We consider the long-run response to a supply reduction in San Francisco of 6\%. This implies that the total population in each zipcode in San Francisco must decline by $6 \%$. We let $d \ln N_{j} / d \Phi$ and $d \ln N_{j}^{y} / d \Phi$ denote the long-run changes in old and young populations, where $\Phi$ is simply a convenient notation indicating the impact of the law. We assume that, in the long-run, rents do not increase in either the Bay Area or the rest of the country as a result of the shock. We determine how much rents have to change by in each zipcode in San Francisco and how much the populations of the Bay Area and the rest of the country change by so as to achieve a new long-run steady state given the supply response. Taking a 
derivative of the steady-state conditions above with respect to $\Phi$, we find that:

$$
\begin{aligned}
\frac{d \ln N_{j}}{d \Phi} N_{j}^{y}-\sum_{j^{\prime}} p\left(j \mid j^{\prime}\right) & {\left.\left[(1-\phi) \frac{d \ln N_{j^{\prime}}}{d \Phi} N_{j^{\prime}}+\kappa \frac{d \ln N_{j^{\prime}}^{y}}{d \Phi} N_{j^{\prime}}^{y}\right]=\sum_{j^{\prime}} \frac{d p\left(j \mid j^{\prime}\right)}{d \Phi}\left[(1-\phi) N_{j^{\prime}}+\kappa N_{j^{\prime}}^{y}\right] 25\right) } \\
\frac{d \ln N_{j}^{y}}{d \Phi} N_{j}^{y}-\sum_{j^{\prime}} \frac{d \ln N_{j^{\prime}}^{y}}{d \Phi} N_{j^{\prime}}^{y} p^{y}\left(j \mid j^{\prime}\right) & =\sum_{j^{\prime}} N_{j^{\prime}}^{y} \frac{d p^{y}\left(j \mid j^{\prime}\right)}{d \Phi}
\end{aligned}
$$

for all $j$.

To make progress, we must express the change in probabilities $d p(x \mid j) / d \Phi$ and $d p^{y}(x \mid j) / d \Phi$ as functions of the change in rents $d R_{j} / d \Phi$, where $x$ is the location choice. In steady state, the conditional probabilities are given by:

$$
\begin{aligned}
p(x \mid j) & =\frac{\exp (v(x, j))}{\sum_{x^{\prime}} \exp \left(v\left(x^{\prime}, j\right)\right)} \\
p^{y}(x \mid j) & =\frac{\exp \left(v^{y}(x, j)\right)}{\sum_{x^{\prime}} \exp \left(v^{y}\left(x^{\prime}, j\right)\right)} .
\end{aligned}
$$

Taking the total derivative, we get:

$$
\begin{aligned}
\frac{d p(x \mid j)}{d \Phi} & =\sum_{k} \frac{\partial p(x \mid j)}{\partial \ln R_{k}} \frac{d \ln R_{k}}{d \Phi} \\
& =\sum_{k} p(x \mid j)\left(\frac{\partial v(x, j)}{\partial \ln R_{k}}-\sum_{x^{\prime}} p\left(x^{\prime} \mid j\right) \frac{\partial v\left(x^{\prime}, j\right)}{\partial \ln R_{k}}\right) \frac{d \ln R_{k}}{d \Phi}
\end{aligned}
$$

The expression for the young is identical, of course substituting young value functions and young probabilities. To finish the calculation, we therefore need to determine $\partial v(x, j) / \partial \ln R_{k}$ and $\partial v^{y}(x, j) / \partial \ln R_{k}$.

For the old renters, note that in steady-state:

$$
v(x, j)=\bar{u}(x, j)+\beta \ln \left(\sum_{x^{\prime}} \exp \left(v\left(x^{\prime}, j(x)\right)\right)\right)+\beta \Gamma
$$

Taking derivatives with respect to log rents, we get:

$$
\frac{\partial v(x, j)}{\partial \ln R_{k}}=\gamma_{M} \exp \left(R_{x}\right) R_{x} 1[x=k]+\beta \sum_{x^{\prime}} p\left(x^{\prime} \mid j(x)\right) \frac{\partial v\left(x^{\prime}, j(x)\right)}{\partial \ln R_{k}} .
$$

This is a system of equations which can be numerically solved for the partial derivatives. Once this system is solved, we can solve for $\partial v^{y}(x, j) / \partial \ln R_{k}$. In steady-state, the value function of the young renters is:

$$
v^{y}(x, j)=\bar{u}^{y}(x, j)+\beta(1-\kappa) \ln \left(\sum_{x^{\prime}} \exp \left(v^{y}\left(x^{\prime}, j(x)\right)\right)\right)+\beta \kappa \ln \left(\sum_{x^{\prime}} \exp \left(v\left(x^{\prime}, j(x)\right)\right)\right)+\beta \Gamma .
$$


Taking derivatives with respect to log rents, we get:

$$
\begin{aligned}
\frac{\partial v^{y}(x, j)}{\partial \ln R_{k}}= & \gamma_{Y} \exp \left(R_{x}\right) R_{x} 1[x=k]+\beta(1-\kappa) \sum_{x^{\prime}} p^{y}\left(x^{\prime} \mid j(x)\right) \frac{\partial v^{y}\left(x^{\prime}, j(x)\right)}{\partial \ln R_{k}} \\
& +\beta \kappa \sum_{x^{\prime}} p\left(x^{\prime} \mid j(x)\right) \frac{\partial v\left(x^{\prime}, j(x)\right)}{\partial \ln R_{k}} .
\end{aligned}
$$

Again this system of equations can be numerically solved to get the value function derivatives.

With $\partial v(x, j) / \partial \ln R_{k}$ and $\partial v^{y}(x, j) / \partial \ln R_{k}$ in place, we plug into equation (28), which gives $\partial p(x \mid j) / \partial \ln R_{k}$ and $\partial p^{y}(x \mid j) / \partial \ln R_{k}$ We then plug into equations (25) and (26), which gives:

$$
\begin{aligned}
\frac{d \ln N_{j}}{d \Phi} N_{j}^{y}-\sum_{j^{\prime}} p\left(j \mid j^{\prime}\right) & {\left[(1-\phi) \frac{d \ln N_{j^{\prime}}}{d \Phi} N_{j^{\prime}}+\kappa \frac{d \ln N_{j^{\prime}}^{y}}{d \Phi} N_{j^{\prime}}^{y}\right]=\sum_{k} \sum_{j^{\prime}} \frac{\partial p\left(j \mid j^{\prime}\right)}{\partial \ln R_{k}}\left[(1-\phi) N_{j^{\prime}}+\kappa N_{j^{\prime}}^{y}\right] \frac{d \ln \left(\begin{array}{l}
R_{k} \\
d \Phi
\end{array}\right.}{\frac{d \ln N_{j}^{y}}{d \Phi} N_{j}^{y}-\sum_{j^{\prime}} \frac{d \ln N_{j^{\prime}}^{y}}{d \Phi} N_{j^{\prime}}^{y} p^{y}\left(j \mid j^{\prime}\right)}=\sum_{k} \sum_{j^{\prime}} N_{j^{\prime}}^{y} \frac{\partial p^{y}\left(j \mid j^{\prime}\right)}{\partial \ln R_{k}} \frac{d \ln R_{k}}{d \Phi} }
\end{aligned}
$$

We then combine these equations with:

$$
\begin{aligned}
\frac{d \ln N_{j}}{d \Phi}+\frac{d \ln N_{j}^{y}}{d \Phi} & =-.06 \text { for all } j \text { in SF } \\
\sum_{j \notin S F}\left[\frac{d \ln N_{j}}{d \Phi}+\frac{d \ln N_{j}^{y}}{d \Phi}\right] & =.06 N_{S F} \\
\frac{d \ln R_{j}}{d \Phi} & =0 \text { for all } j \text { not in SF }
\end{aligned}
$$

The first equation simply says that the total population must decline by $6 \%$ in each zipcode in San Francisco. The second equation says that the areas outside of San Francisco must absorb the population that leaves San Francisco. Note that $N_{S F}$ is the initial 1993 steady-state population in San Francisco. Finally, the third equation states our assumption that rents do not increase outside of San Francisco in response to the shock. Our unknowns are the rent increases $d \ln R_{j} / d \Phi$ for all $j$ in San Francisco and the population changes in the areas $j$ outside of San Francisco, i.e. the Bay Area and the rest of the United States. Equations (29)-(33) provide a system of equations which can be numerically solved to determine these unknowns. 


\section{E Appendix Tables}

Table E.1: Robustness Check of Treatment Effect for Tenants of Multi-Family Residence (2-4 Units)

\section{A. Treatment Group Lives in Buildings Built between 1960 \& 1979}

\begin{tabular}{lccc}
\hline & $(1)$ & $(2)$ & $(3)$ \\
& In SF & Same Zip & Same Address \\
\hline Treat× Period & & & \\
$1994-1999$ & 0.0326 & 0.0331 & 0.0289 \\
& $(0.0105)$ & $(0.0115)$ & $(0.011)$ \\
$2000-2004$ & 0.0642 & 0.0368 & 0.0370 \\
& $(0.0151)$ & $(0.0138)$ & $(0.0118)$ \\
Post 2005 & 0.0531 & 0.0349 & 0.0164 \\
& $(0.0145)$ & $(0.0113)$ & $(0.0084)$ \\
\hline Control Mean 1994-1999 & 0.7641 & 0.5971 & 0.541 \\
Control Mean 2000-2004 & 0.5138 & 0.2672 & 0.1827 \\
Control Mean Post 2005 & 0.4346 & 0.1801 & 0.1135 \\
Adjusted $R^{2}$ & 0.584 & 0.598 & 0.609 \\
Observations & 135594 & 135594 & 135594 \\
\hline
\end{tabular}

\section{B. Census Tract Fixed Effects}

\begin{tabular}{lccc}
\hline & $(1)$ & $(2)$ & $(3)$ \\
& In SF & Same Zip & Same Address \\
\hline Treat $\times$ Period & & & \\
$1994-1999$ & 0.0175 & 0.0153 & 0.0157 \\
& $(0.0084)$ & $(0.0091)$ & $(0.0087)$ \\
$2000-2004$ & 0.0426 & 0.0259 & 0.0284 \\
& $(0.012)$ & $(0.0109)$ & $(0.0092)$ \\
Post 2005 & 0.0364 & 0.0266 & 0.0113 \\
& $(0.0114)$ & $(0.0088)$ & $(0.0066)$ \\
\hline Control Mean 1994-1999 & 0.7641 & 0.5971 & 0.541 \\
Control Mean 2000-2004 & 0.5138 & 0.2672 & 0.1827 \\
Control Mean Post 2005 & 0.4346 & 0.1801 & 0.1135 \\
Adjusted $R^{2}$ & 0.588 & 0.596 & 0.609 \\
Observations & 1243242 & 1243242 & 1243242 \\
\hline
\end{tabular}

Notes: In Panel A, we change our tenant sample to all tenants between 20 and 65 years old living in San Francisco as of December 31, 1993 and in multi-family residences with 2-4 units that were built during $1960-1990$. Hence we have restricted our treatment group to individuals who lived in buildings built between 1960 and 1979. In Panel $\mathrm{B}$, the sample of tenants is the same as in our baseline regressions. Instead of using zipcode by year fixed effects in our baseline regressions, we use census tract by year fixed effects. Table reports the mean of dependent variables for the control group during 1990 - 1994, 2000 - 2004 and post-2005. Standard errors are clustered at the person level. 
Table E.2: Treatment Effect for Multi-Family Residence (2-4 Units)

\begin{tabular}{|c|c|c|c|c|c|c|c|c|c|}
\hline & $\begin{array}{c}(1) \\
\text { Vacant }\end{array}$ & $\begin{array}{c}(2) \\
\text { Population/ } \\
\text { Avg Pop 90-94 }\end{array}$ & $\begin{array}{c}(3) \\
\text { Renters/ } \\
\text { Avg Pop 90-94 }\end{array}$ & $\begin{array}{c}(4) \\
\text { Renters in Rent-Controlled } \\
\text { Buildings/Avg Pop 90-94 }\end{array}$ & $\begin{array}{c}(5) \\
\text { Renters in Redeveloped } \\
\text { Buildings/Avg Pop 90-94 }\end{array}$ & $\begin{array}{c}(6) \\
\text { Owners/ } \\
\text { Avg Pop 90-94 }\end{array}$ & $\begin{array}{c}(7) \\
\text { Conversion }\end{array}$ & $\begin{array}{c}\text { (8) } \\
\text { Cumulative } \\
\text { Add/Alter/Repair per Unit }\end{array}$ & $\begin{array}{c}\text { (9) } \\
\text { Ever Received } \\
\text { Add/Alter/Repai }\end{array}$ \\
\hline \multicolumn{10}{|l|}{ Treat $\times$ Period } \\
\hline 1994-1999 & $\begin{array}{l}-0.0085 \\
(0.0095)\end{array}$ & $\begin{array}{c}-0.0329 \\
(0.0604)\end{array}$ & $\begin{array}{c}-0.0342 \\
(0.0472)\end{array}$ & $\begin{array}{l}-0.0434 \\
(0.0481)\end{array}$ & $\begin{array}{c}0.0005 \\
(0.0084)\end{array}$ & $\begin{array}{c}0.0013 \\
(0.0299)\end{array}$ & $\begin{array}{c}0.0100 \\
(0.0032)\end{array}$ & $\begin{array}{c}-0.0043 \\
(0.0085)\end{array}$ & $\begin{array}{c}0.0140 \\
(0.0081)\end{array}$ \\
\hline $2000-2005$ & -0.0064 & -0.0791 & -0.1059 & -0.1516 & 0.0253 & 0.0269 & 0.0384 & 0.0234 & 0.0413 \\
\hline Post 2006 & $\begin{array}{c}(0.0114) \\
-0.0076 \\
(0.0116)\end{array}$ & $\begin{array}{r}(0.0814) \\
-0.0642 \\
(0.0933)\end{array}$ & $\begin{array}{l}(0.0638) \\
-0.1453 \\
(0.0747)\end{array}$ & $\begin{array}{l}(0.0654) \\
-0.2457 \\
(0.0773)\end{array}$ & $\begin{array}{c}(0.0176) \\
0.0717 \\
(0.0225)\end{array}$ & $\begin{array}{c}(0.0394) \\
0.0811 \\
(0.0409)\end{array}$ & $\begin{array}{c}(0.0045) \\
0.0793 \\
(0.0061)\end{array}$ & $\begin{array}{c}(0.0123) \\
0.0459 \\
(0.0144)\end{array}$ & $\begin{array}{c}(0.0111) \\
0.0552 \\
(0.0130)\end{array}$ \\
\hline Control Mean 1994- 1999 & 0.0800 & 1.8291 & 1.3540 & 1.3395 & 0.0232 & 0.4752 & 0.3360 & 0.1825 & 0.2352 \\
\hline Control Mean 2000 - 2005 & 0.0968 & 2.1917 & 1.6278 & 1.5978 & 0.0502 & 0.5639 & 0.3460 & 0.2473 & 0.3066 \\
\hline Control Mean Post 2006 & 0.1137 & 2.4287 & 1.8338 & 1.7659 & 0.0965 & 0.5949 & 0.3667 & 0.2976 & 0.3624 \\
\hline Adjusted $R^{2}$ & 0.354 & 0.600 & 0.569 & 0.555 & 0.404 & 0.603 & 0.747 & 0.803 & 0.763 \\
\hline Observations & 724037 & 643589 & 643589 & 643589 & 643589 & 643589 & 769181 & 706633 & 724037 \\
\hline
\end{tabular}

Notes: Sample consists of all multi-family residences with 2-4 units in San Francisco that were built during 1900 - 1990. If a building is constructed post 1993 and we observe a tenant living there in 1993, we include it into the treatment group for rent control. Table reports the mean of dependent variables for the control group during 1994-1999, 2000 - 2005 and post-2006. Standard errors are clustered at the parcel level. 
Figure E.1: Geographic Distribution of Treated and Control Buildings in San Francisco

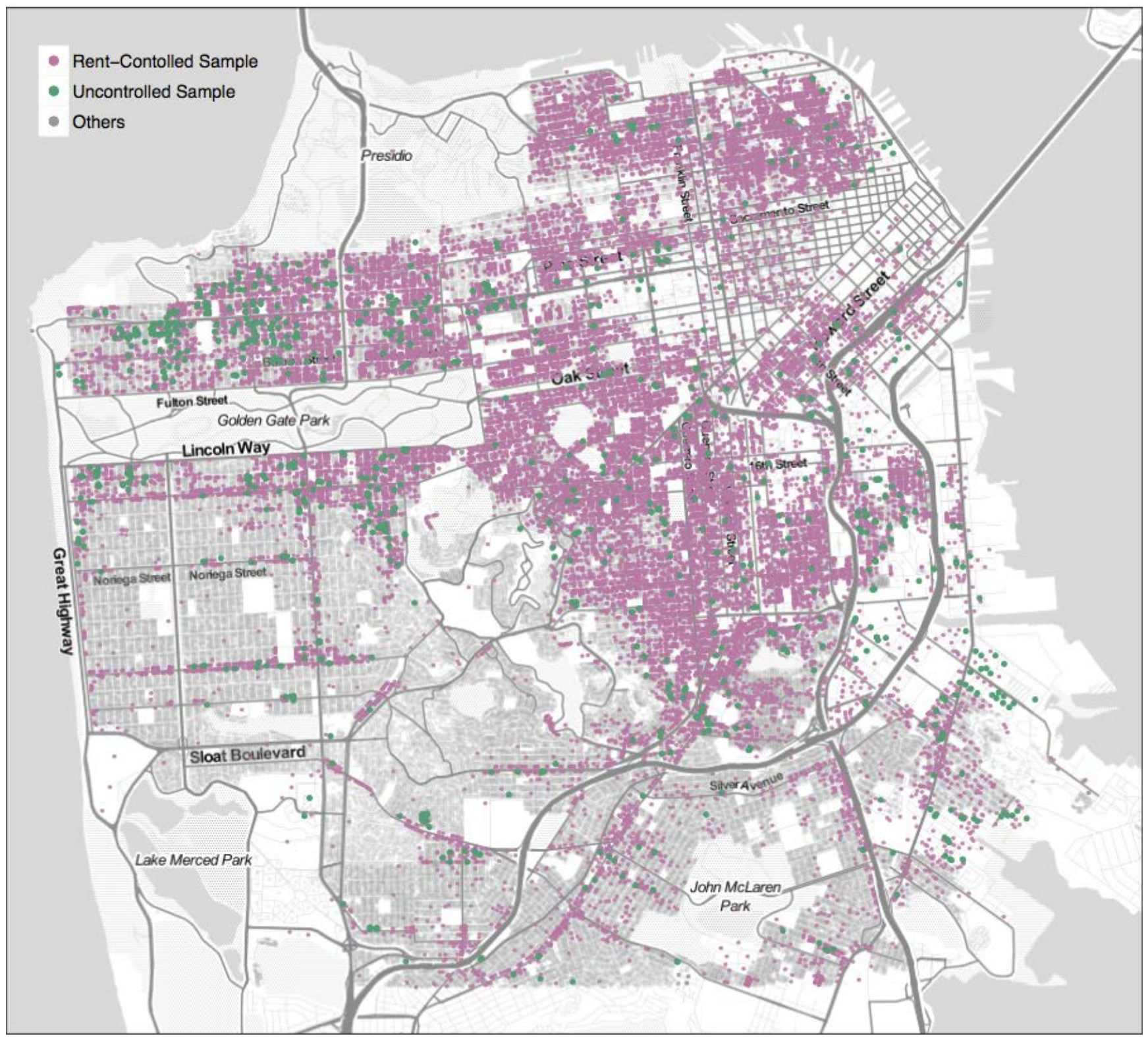

Notes: The purple dots represent parcels in the treatment group, which are parcels corresponding to multi-family residences with 2-4 units in San Francisco that were built between 1900-1979. The green dots represent parcels in the control group, which are parcels corresponding to multi-family residences with 2-4 units in San Francisco that were built between 1980-1990. The gray dots represent other types of housing stocks such as single-family residences and multi-family residences with 5 or more units. 
Figure E.2: Historical Trend of Nominal Median Rent in San Francisco

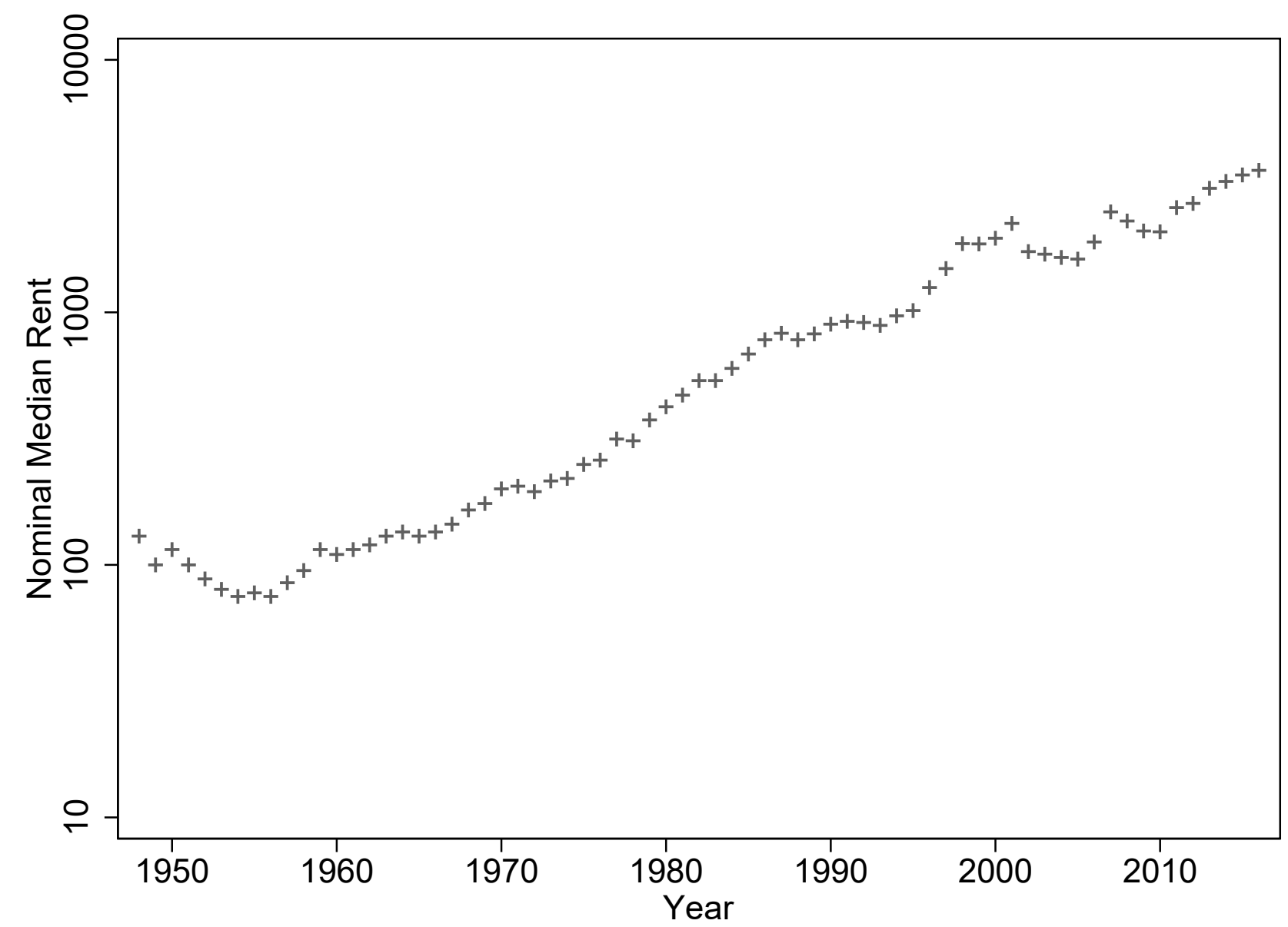

Notes: Figure shows the time series of San Francisco rental rates generated from the dataset on annual San Francisco wide market rents produced by Eric Fisher, who collected historical apartment advertisements dating back to the 1950s. See https://experimental-geography.blogspot.ca/2016/05/employment-construction- and-costof-san.html for further details on the construction. 
Figure E.3: Population Age 18 and above: 1990 Census

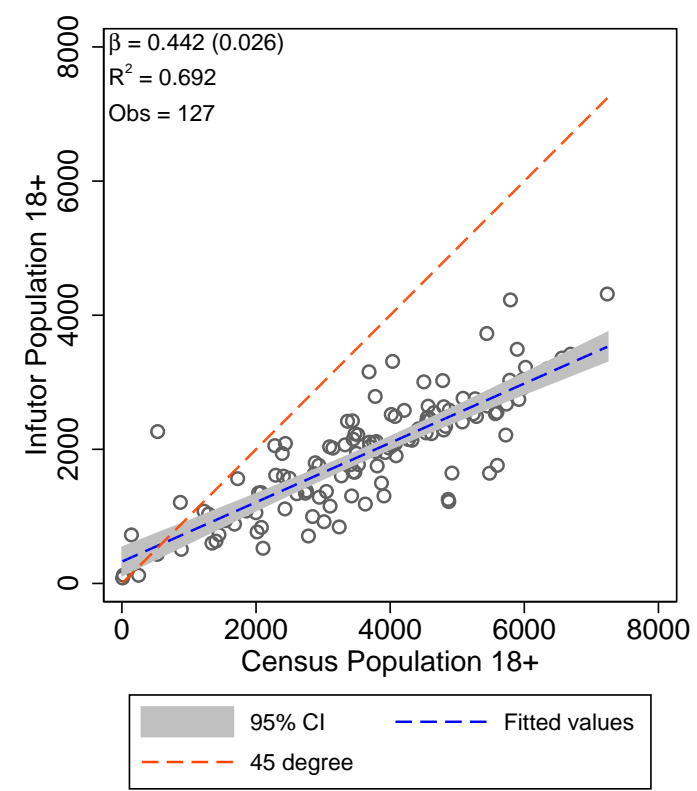

Notes: Plot shows the population of 18 and over in each census tract in 1990 from Infutor data against that from 1990 Census.

Figure E.4: Population Age 18 and above: 2000 Census

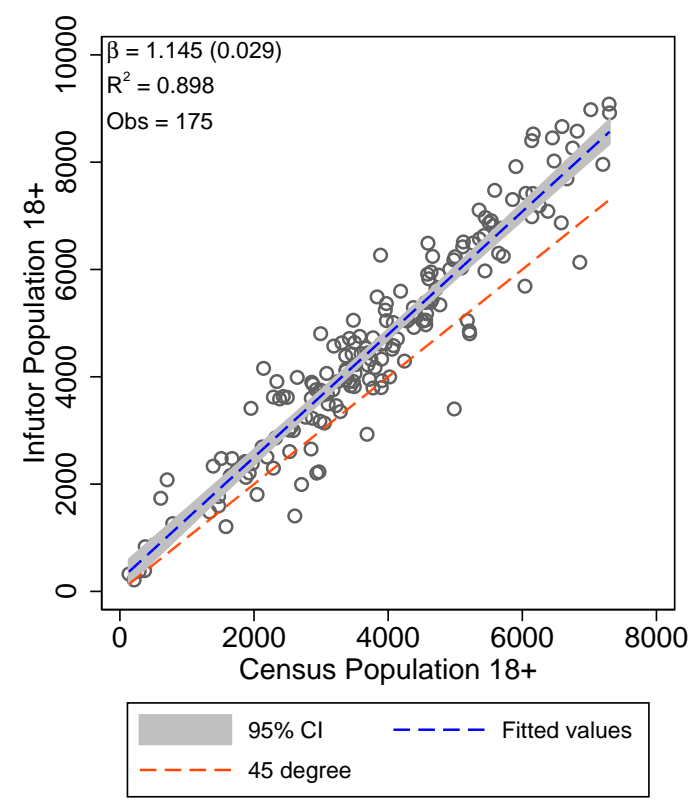

Notes: Plot shows the population of 18 and over in each census tract in 2000 from Infutor data against that from 2000 Census. 
Figure E.5: Age of Occupied Housing: 1990 Census

(a) Built 1970 to 1990: 1990 Census

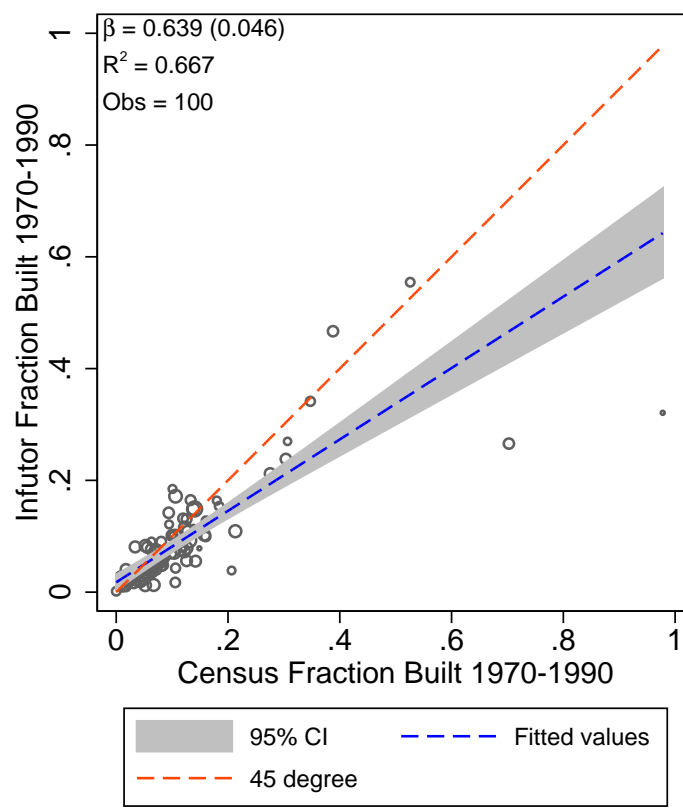

(c) Built 1940 to 1949: 1990 Census

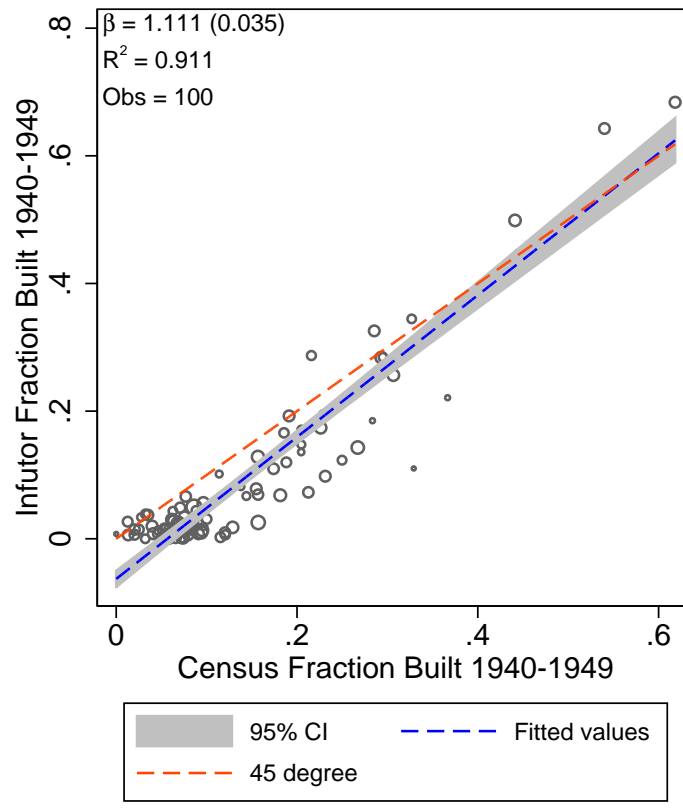

(b) Built 1950 to 1969: 1990 Census

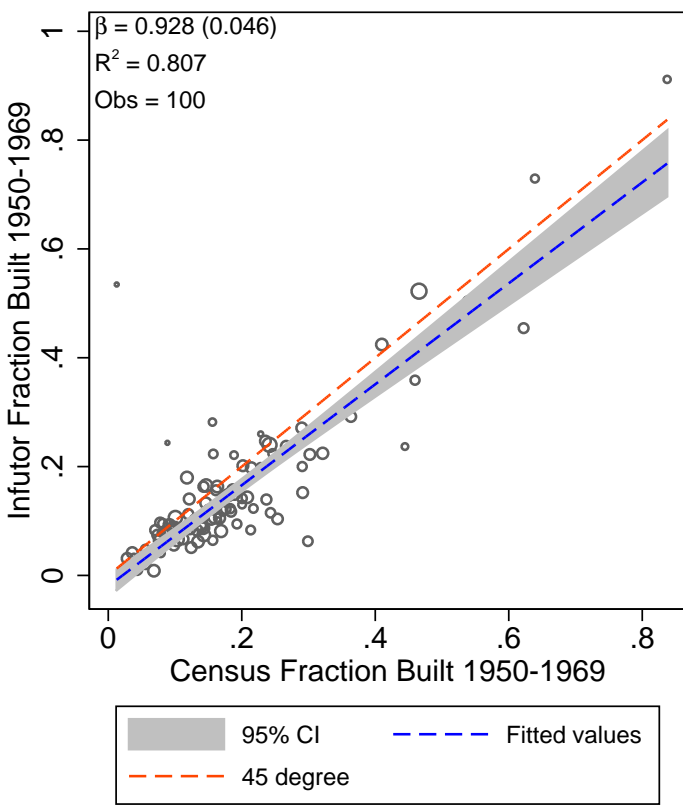

(d) Built 1939 or earlier: 1990 Census

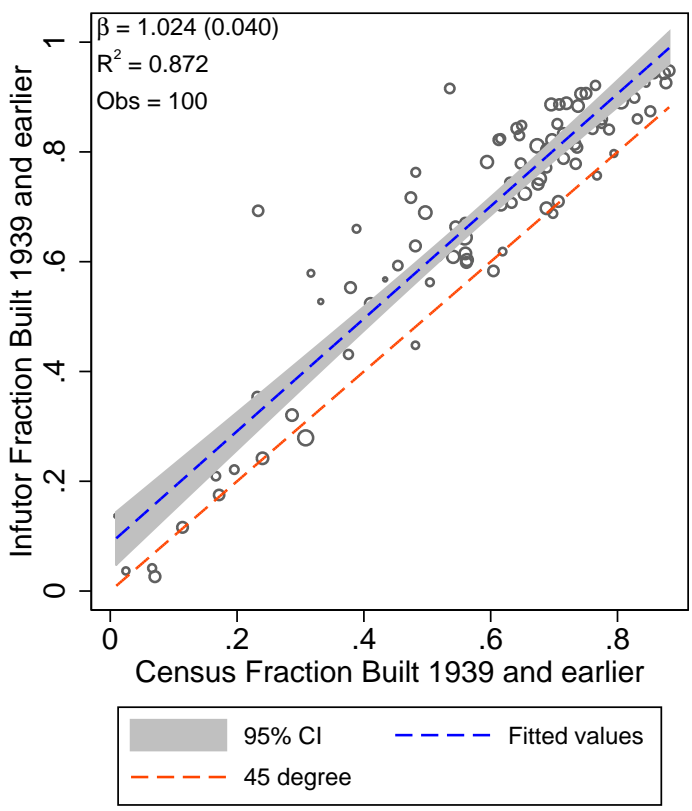

Notes: Plot shows the fraction of buildings built in each time period in each census tract in 1990 from Infutor data against that from 1990 Census. The size of marker is proportional to the number of occupied housing units in each census tract. The fitted line is by weighted least square using the number of occupied housing units as weights. 
Figure E.6: Age of Occupied Housing: 2000 Census

(a) Built 1980 to 2000: 2000 Census

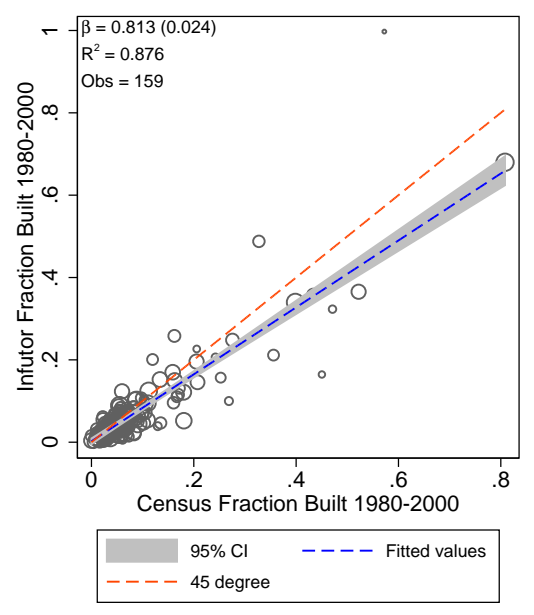

(c) Built 1950 to 1959: 2000 Census

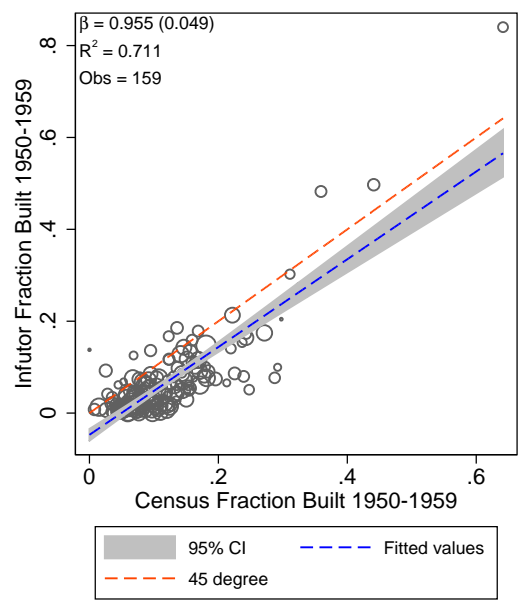

(b) Built 1960 to 1979: 2000 Census

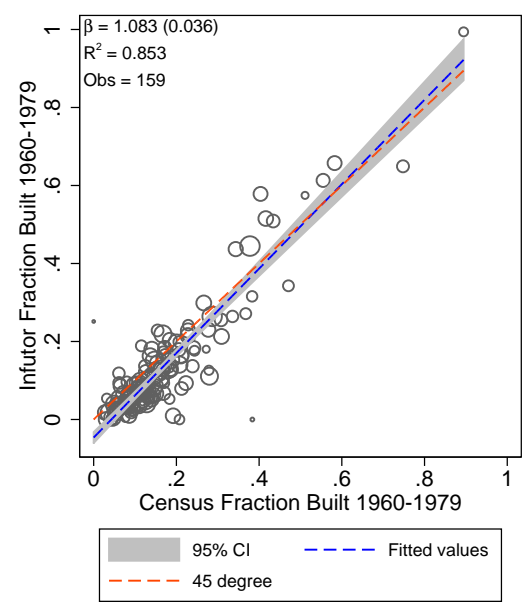

(d) Built 1940 to 1949: 2000 Census

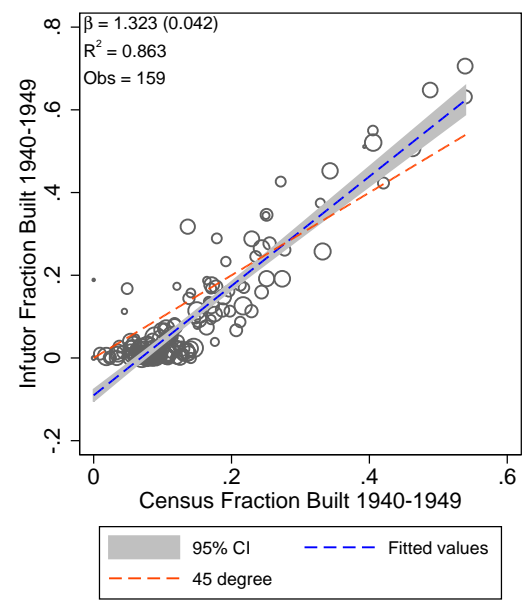

(e) Built 1930 or earlier: 2000 Census

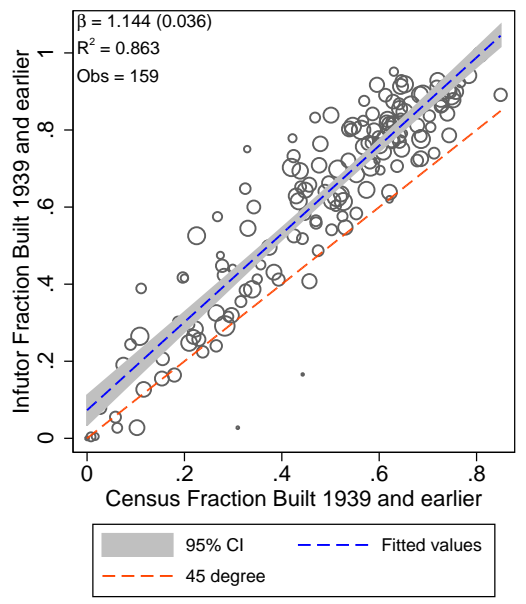

Notes: Plot shows the fraction of buildings built in each time period in each census tract in 2000 from Infutor data against that from 2000 Census. The size of marker is proportional to the number of occupied housing units in each census tract. The fitted line is by weighted least square using the number of occupied housing units as weights. 
Figure E.7: Ownership Rate at Individual Level: 1990 Census

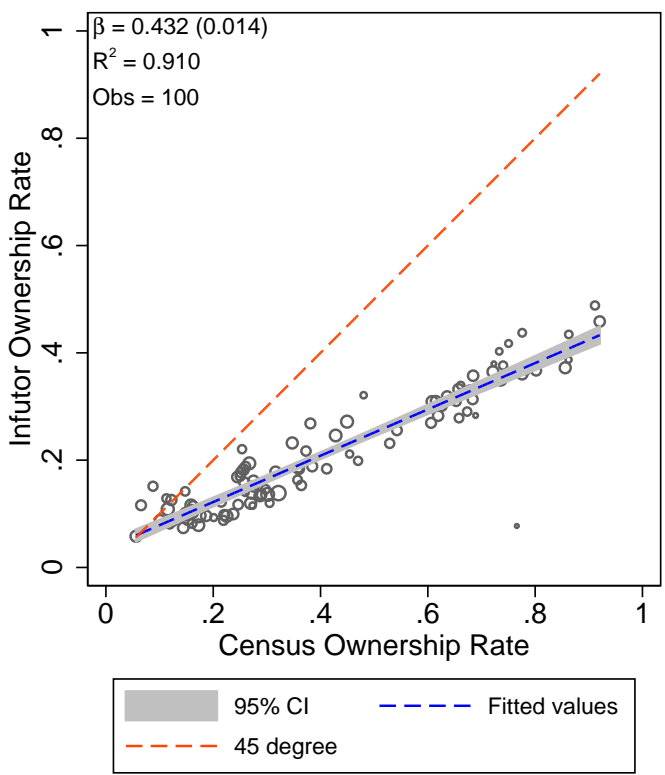

Notes: Plot shows the ownership rate at the individual level in 1990 from Infutor data against the ownership rate of occupied housing units from 1990 Census. The size of marker is proportional to the number of occupied housing units in each census tract. The fitted line is by weighted least square using the number of occupied housing units as weights.

Figure E.8: Ownership Rate at Individual Level: 2000 Census

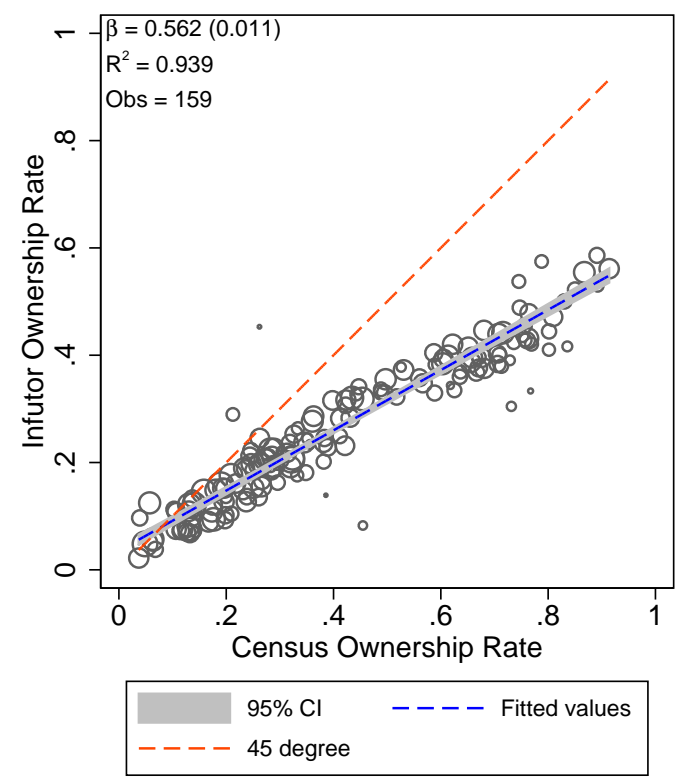

Notes: Plot shows the ownership rate at the individual level in 2000 from Infutor data against the ownership rate of occupied housing units from 2000 Census. The size of marker is proportional to the number of occupied housing units in each census tract. The fitted line is by weighted least square using the number of occupied housing units as weights. 
Figure E.9: Average Annual Tenant Buyouts

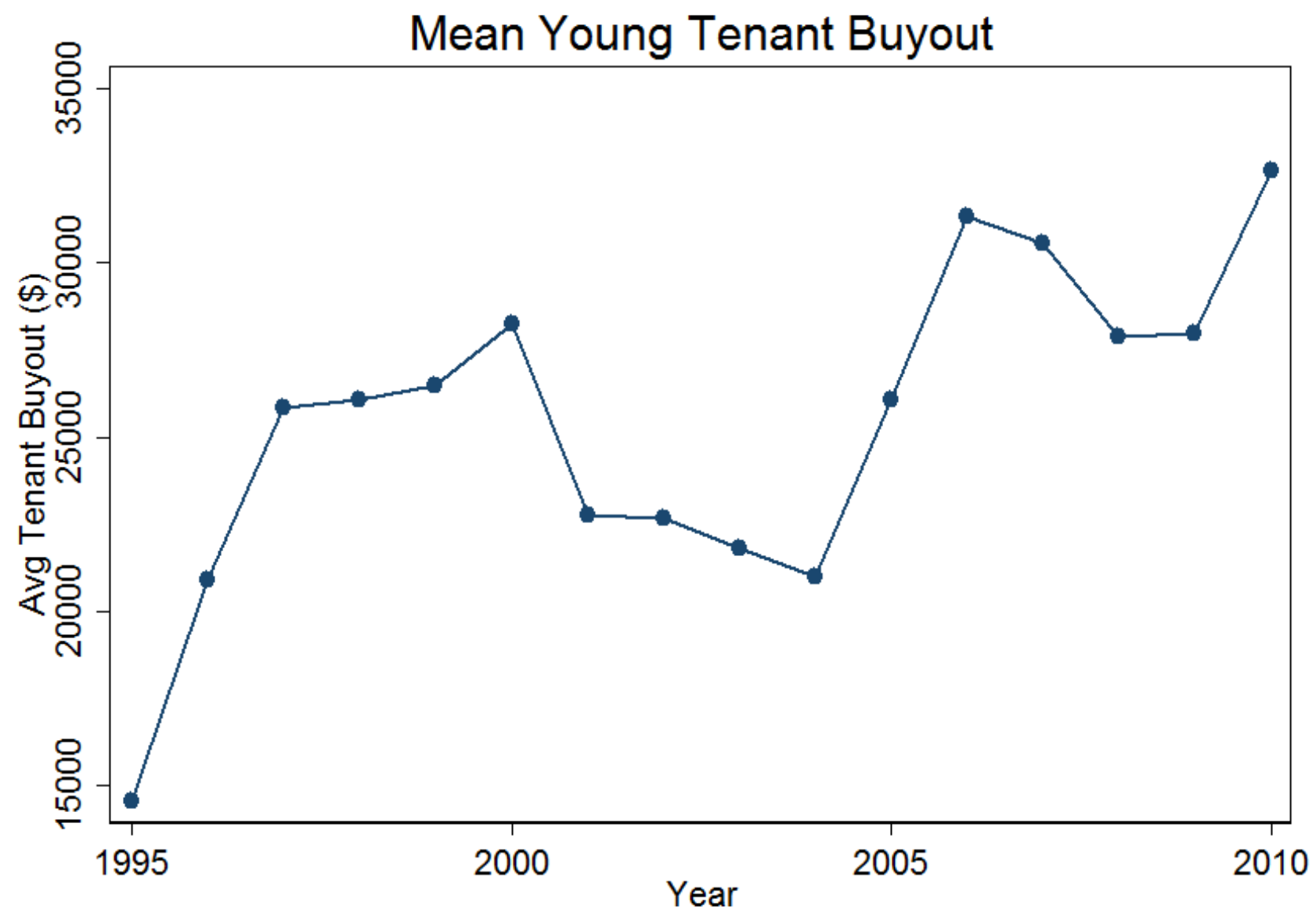

Notes: Figure plots the average buyout to young tenants offered in each year in the data, across all tenants and neighborhoods. 
Figure E.10: Annual Tenant Buyouts by Zipcode

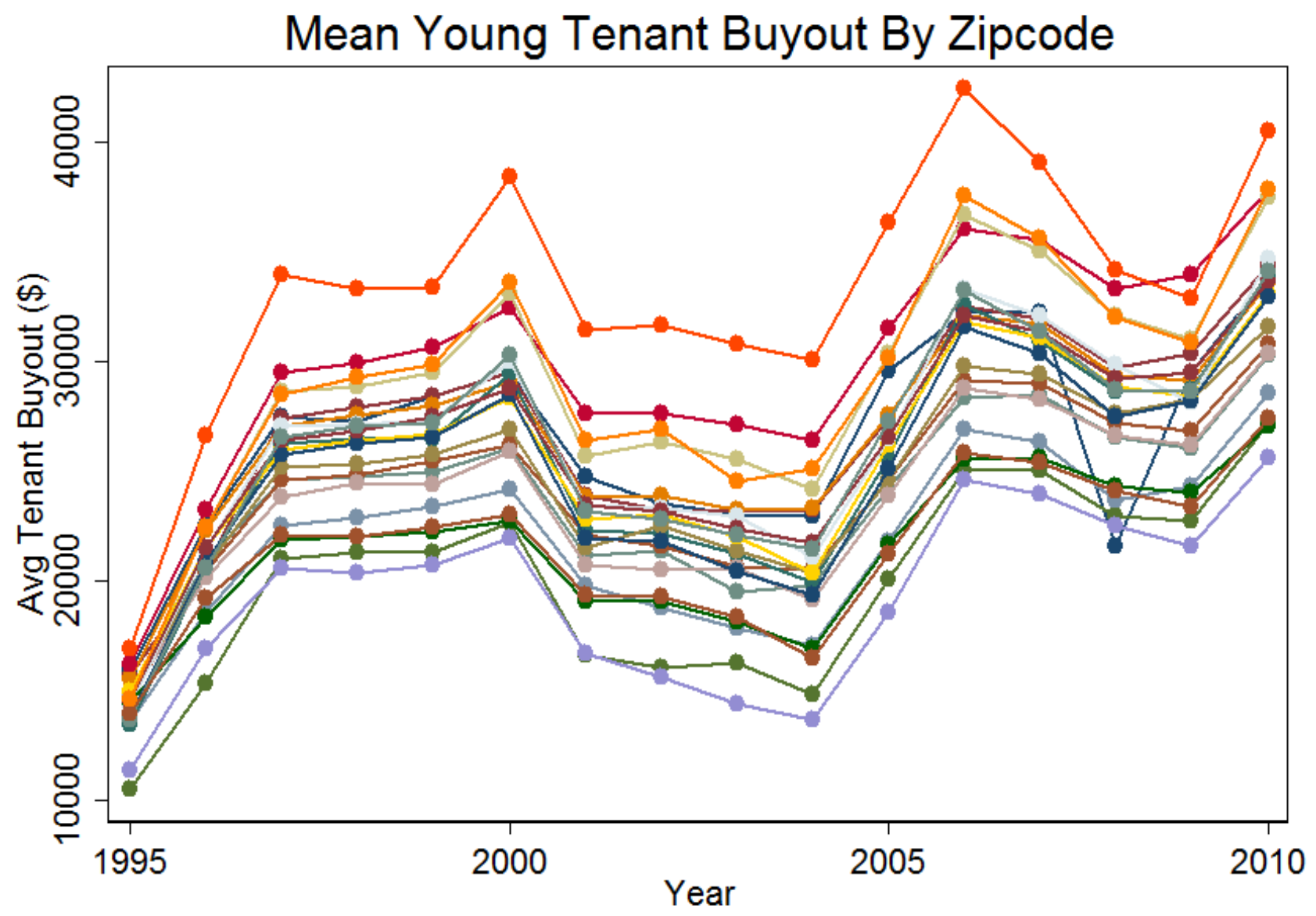

Notes: Figure plots the average buyout offers to young tenants in each year in the data, by zipcode in San Francisco. 